\author{
Federal Reserve Bank of Dallas \\ Globalization and Monetary Policy Institute \\ Working Paper No. 99 \\ https://www.dallasfed.org/ / media/documents/institute/wpapers/2011/0099.pdf
}

\title{
A Cross-Country Quarterly Database of Real House Prices: A Methodological Note*
}

\author{
Adrienne Mack \\ Mutual of Omaha \\ Enrique Martínez-García \\ Federal Reserve Bank of Dallas \\ with Valerie Grossman \\ Federal Reserve Bank of Dallas
}

December 2011

(Revised January 2019)

\begin{abstract}
We build from publicly available national sources a database of (nominal and real) house pricescomplemented with data on personal disposable income (PDI) - for a selection of countries at a quarterly frequency, starting in the first quarter of 1975. We select a house price index for each country that is consistent with the U.S. FHFA quarterly nationwide house price index for existing single-family houses (formerly called OFHEO house price index), and extend the country series back to 1975 with available historical data/proxies whenever necessary. Each house price index is seasonally-adjusted and then rebased to $2005=100$. The house price indexes are expressed in nominal terms, and also in real terms using the personal consumption expenditure (PCE) deflator of the corresponding country with the same base year of $2005=100$. PDIs are always quoted in per capita terms using working age population of the corresponding country and similarly expressed in nominal and real terms (the latter with the PCE deflator). We aggregate all countries in the database, weighted by their IMF purchasing power parity-adjusted GDP shares in 2005, to compute an average (nominal and real) house price series and an average (nominal and real) per capita PDI series.

JEL codes: C80, C82, R30, R31

* (Contacting Authors) Valerie Grossman, Federal Reserve Bank of Dallas. 2200 N. Pearl Street, Dallas, TX 75201. 214-922-5262. Valerie.Grossman@dal.frb.org. Enrique Martínez-García, Federal Reserve Bank of Dallas. 2200 N. Pearl Street, Dallas, TX 75201. 214-922-5262. enrique.martinez-garcia@dal.frb.org. https://sites.google.com/view/emgeconomics/. This research was initiated while Adrienne Mack (Mutual of Omaha) was working at the Federal Reserve Bank of Dallas. Since the update of May 2015, Valerie Grossman has been responsible for maintaining and developing the database and became the main contacting author for this paper too. We acknowledge Christophe André for providing helpful feedback on the OECD's own international house price dataset and the assistance of many national statistical offices and/or central banks in collecting the house price data (especially the relevant historical series). This draft is still work-in-progress as we continue to extend and enhance the database itself. The views in this paper are those of the authors and do not necessarily reflect the views of the Federal Reserve Bank of Dallas or the Federal Reserve System.
\end{abstract}




\section{Table of Contents}

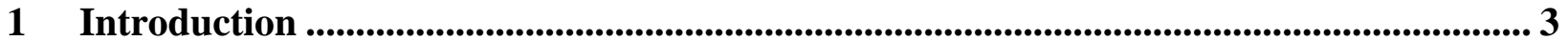

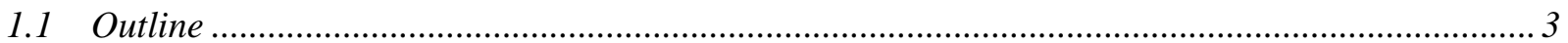

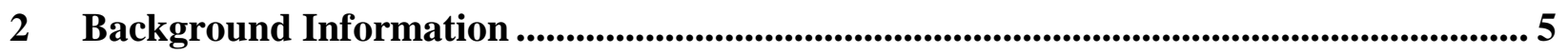

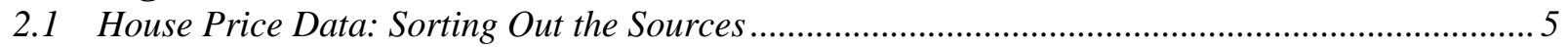

2.1.1 Selection of Comparable House Price Series....................................................................... 7

2.1.2 Other Resources Available on House Prices .................................................................... 8

2.1.3 More in Depth: Different Approaches to Construct a House Price Index ........................... 10

2.2 Personal Disposable Income Data: Measuring Households' Income in the National Accounts .. 11

2.2.1 Differences in the Adoption of the United Nations' System of National Accounts (UNSNA)11

2.2.2 From Gross Domestic Product to National Income........................................................... 13

2.2.3 From National Income to Personal Disposable Income .................................................... 15

2.2.4 More in Depth: The Circular Flow and Personal Disposable Income ................................ 19

3 Methodological Approach....................................................................................................... 20

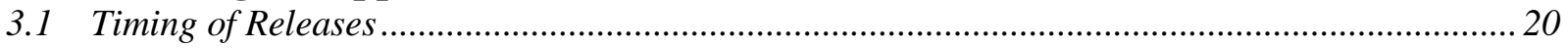

3.2 Approach to Construct the Country Data: Step-by-Step ............................................................. 21

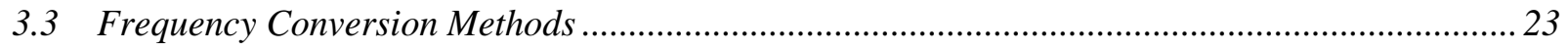

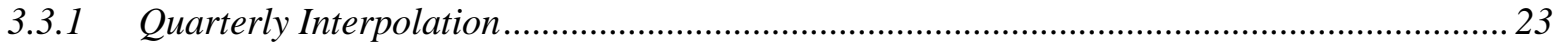

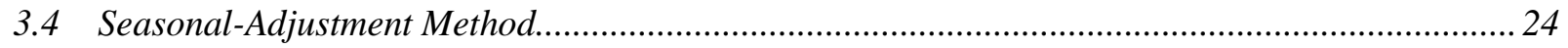

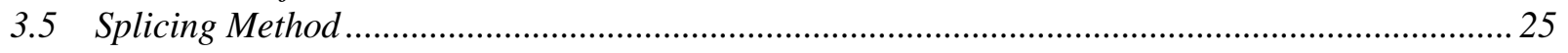

3.6 Approach to Aggregate the Country Data ................................................................................. 26

3.7 More in Depth: An Overview of the Basic Structural Time Series (BSTS) Model........................ 27

3.7.1 All-Encompassing BSTS Model Specification................................................................27

3.7.2 BSTS Model Estimation, Backcasting/Nowcasting and Forecasting ...................................30

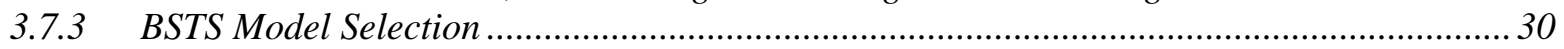

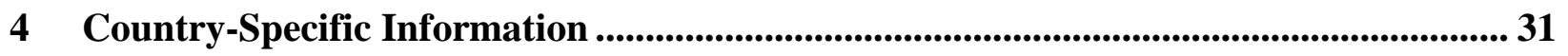

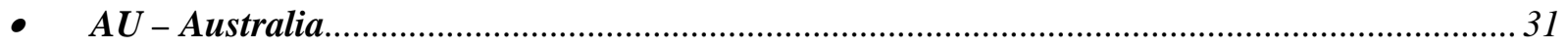

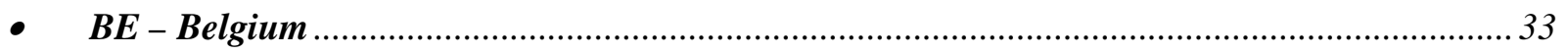

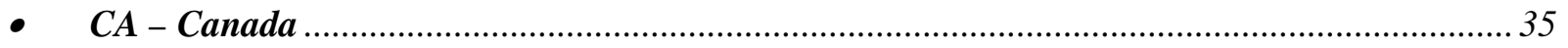

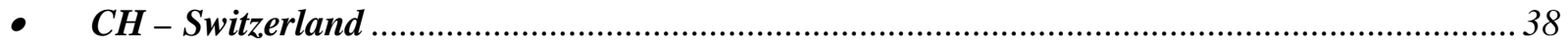

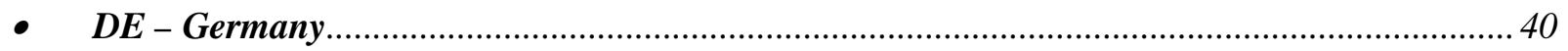

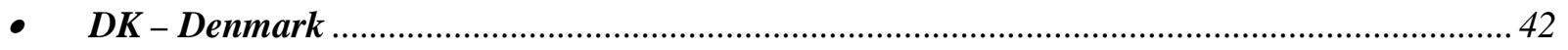

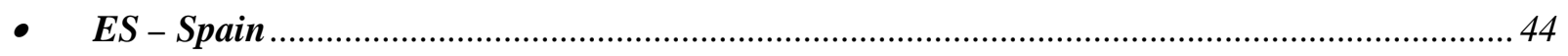

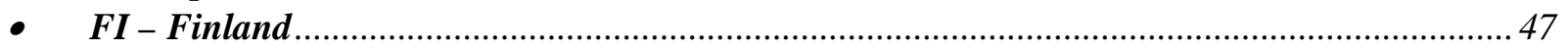

- $\quad F R$ - France

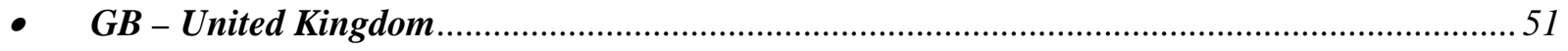

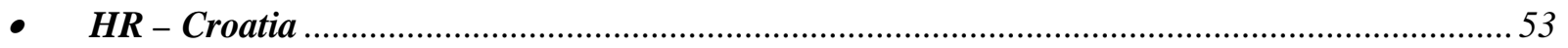

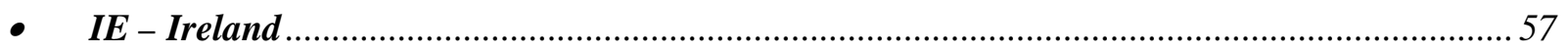

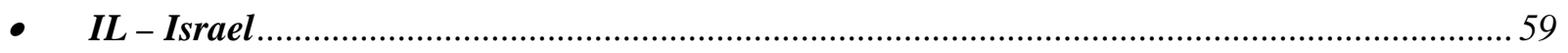

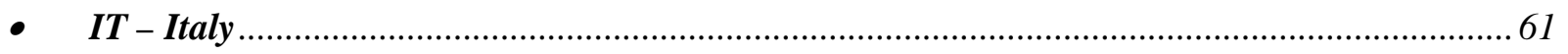

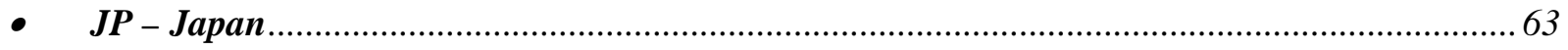

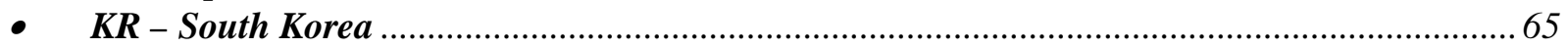

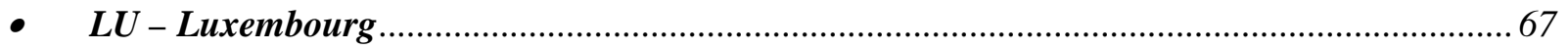

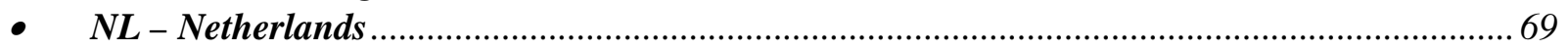

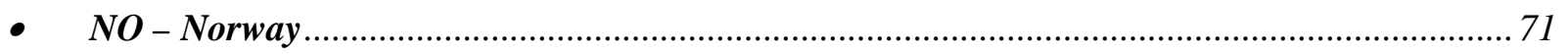

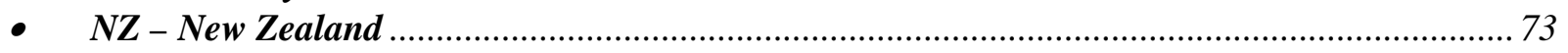

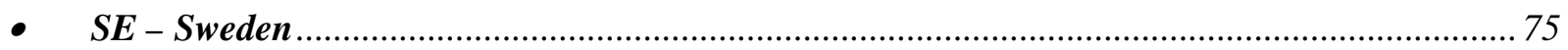

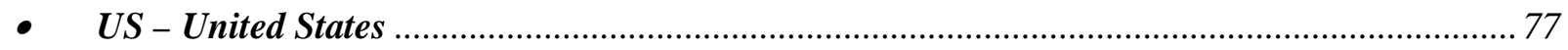




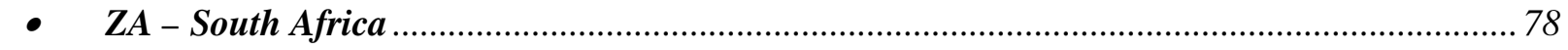

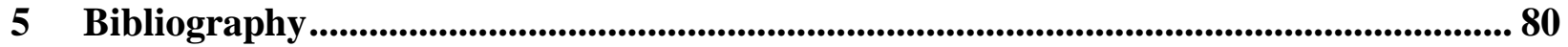

Appendix A. Summary of the National Sources of House Price Data .................................. 83

Appendix B. Table Summaries of House Price Data as Reported from National Sources.. 86

\section{List of Tables}

Table 1. U.S. Income and Expenditure Account Tables from NIPA....................................... 18

Table 2. Personal Disposable Income by Its Components from NIPA.................................... 18

Table 3. Yearly Timeline of Release Dates ............................................................................ 20

Table A.1 Summary of the National Sources of House Price Data .......................................... 83

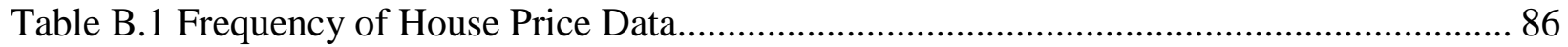

Table B.2 Reported Units of House Price Data .................................................................. 88

Table B.3 Geographic Coverage of House Price Data ....................................................... 90

Table B.4 Property Type Included in House Price Data........................................................... 92

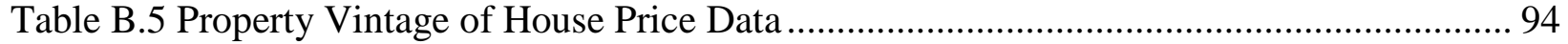

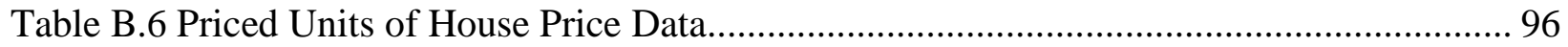

Table B.7 Index Methodology of House Price Data.............................................................. 98

\section{List of Figures}

Figure 1. Composition of U.S. Annual GDP (Current \$, 1975-2012) ...................................... 15

Figure 2. A Circular Flow Representation of the Sources of Personal Disposable Income ......... 19

Figure 3. Methodological Decision Tree for the Construction of Time Series Data................... 22 
"Not everything that can be counted counts, and not everything that counts can be counted."

Albert Einstein (attributed)

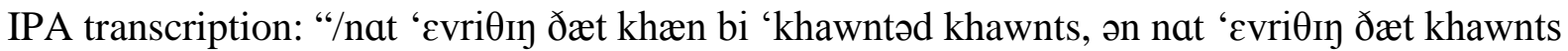

khæn bi 'khawntəd/"

'ælbərt 'ajnstajn ( ə'tribjətəd)

\section{Introduction}

Econometric research on panel data suggests that studies based solely on a given time series could be biased by not incorporating the information content of the cross-section. Not only can panel data provide additional information, it also gives greater sample variation that can be exploited to obtain more precise parameter estimates-see, e.g., Baltagi (2008) on this point. While this is well-known in theory, the use of panel data has many limitations. The heterogeneity and noise of international data sources has always complicated and even restrained the scope of panel data analysis (and the use of related econometric techniques) in empirical work on housing.

Those same data limitations have skewed the evidence available to guide the theoretical work on the macroeconomic effects of housing and the determinants of house prices-especially on openeconomy models. The stylized facts that theory seeks to understand are still largely derived from a reduced country sample — primarily the U.S. as illustrated, e.g., by Davis and Heathcote (2005) and Davis (2010)). Our efforts to develop a consistent panel of international house prices and other housing indicators, therefore, seeks to mitigate the concerns about the comparability of the data and to facilitate the empirical and theoretical research in this area.

As indicated, lack of comparability complicates the research on international house prices. The main contribution of our work is, therefore, sorting out the existing data by country, selecting the most similar series and documenting the differences across countries to clarify the extent to which international sources can be made comparable for empirical analysis purposes. As a result, we construct a panel dataset of house price indexes starting in the first quarter of 1975, which is released regularly to the public at quarterly frequency. We also maintain all vintages of the country series for researchers interested in the effect of data revisions, and complement the database with the corresponding indexes on personal disposable income (PDI) per capita. PDIs per capita can be used to control for changes in the affordability of housing, so as not to treat house price movements in isolation.

\subsection{Outline}

The rest of the paper proceeds as follows. Section 2 discusses the standard methods used to construct a representative house price index, and explains the selection criteria used to obtain comparable reference indexes for house prices. It also outlines the national income and product accounts and the relevant definitions of income used to construct the corresponding indexes of PDI per capita. Section 3 briefly describes our own methodology to extend the reference series, and seasonally-adjust the data. It discusses the aggregation method that we use on the house price and PDI index series as well. Section 3 also explains how the database is maintained and

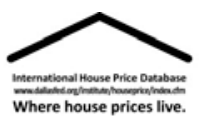


the quarterly updating process that we follow, after a sufficient number of countries in our sample have reported the necessary data. Section 4 provides a detailed discussion of the national data sources and describes the implementation of our methodology to construct a house price index series expressed in nominal and real terms for each country. It also notes the sources of PDI data, working-age population data, and the Personal Consumption Expenditure (PCE) deflator for every country.

The appendix contains a brief description of the data sources as well as a series of tables summarizing the key characteristics of the data by country and by the characteristics of the dwellings. Future drafts of this note will contain notice of any refinements or modifications of the methodology described here as well as detailed references to any new series that might be added to the database. 


\section{Background Information}

\subsection{House Price Data: Sorting Out the Sources}

Even when data for a given country can be identified through national sources, problems with the time series length or geographic coverage are often present. One must also be aware of conceptual and methodological differences in the construction of the house price indexes, in the data aggregation, in the treatment of seasonality, and in the release of the data. These differences across sources in part reflect the segmentation and heterogeneity that characterizes the housing market, but more generally arise from the different motivations that drive the economic agents collecting the primary data that we combine in the database.

The data available from national sources comes from several sources:

A. Private banks, insurers and financial institutions - mortgage or insurance data is often not publicly available and the sample depends on the geographical footprint of these institutions;

B. Real estate agencies — real estate quotes may differ from actual transaction prices and that could bias the construction of the price index, while their sample depends on the geographical footprint of these institutions;

C. Land register/tax offices - tax avoidance motives may bias the results, and could vary over time, over locations and depending on the characteristics of the dwellings;

D. Official institutions not directly participating in the housing or mortgage/insurance markets (Central Banks, National Statistical Offices, international organizations);

E. Others not directly involved in the housing or mortgage/insurance markets (newspapers, universities).

We select data from national public sources-primarily from central banks, statistical offices or other non-government organizations not directly involved in the housing market transactions-to minimize the impact of the potential bias from the collection of data by market participants. We also use data from private organizations (e.g., newspapers, real estate agencies) and even from international organizations (e.g., BIS) in some cases. It is worth pointing out that we rely on publicly available, primary sources in constructing this dataset in order to facilitate both the replication of the country series as well as the wider dissemination of the panel itself. In some instances, we use historical data to extend the series back to the first quarter of 1975. A few of the historical series were obtained upon request from national sources (as indicated in the country descriptions below) or through secondary sources documented in the literature. To the best of our knowledge, the historical series that we use can also be independently recovered by the interested scholars-without further restrictions.

Housing is a heterogeneous good. Quality can vary due to a dwelling's location and its characteristics (e.g., size, property type, new versus existing, date of construction, etc.). The quality of the property differs across locations and over time due to owner modifications as well - a house purchased ten years ago and sold today may be quite different as a result of renovations undertaken and maintenance (or lack thereof). The dwelling characteristics and quality proxies that can be used to control for those differences depend on what is feasible to 
obtain by the source of the primary data and what is necessary for its own purposes. The approach used to control for quality and dwelling characteristics could introduce some crosscountry heterogeneity in the house price indexes as well. The use of few or no explanatory variables may result in an omitted variable bias whereby prices may fluctuate partly because of changes in the composition of houses being transacted. Both problems may well be present to some extent in our dataset, as standardizing the approach and the controls across countries is beyond the scope of our work.

As housing stock data is generally unavailable, house price indexes are constructed with a sample of the stock of houses actually sold over the sample period. Transactions in the housing market occur infrequently and tend to be unequally distributed across locations. Hence, the sample size and representativeness of the data can be a concern-more so depending on the methodology applied to construct the house price indexes. Several house price index construction methods have been widely utilized attempting to control for sample size as well as for the quality and characteristics of the dwellings (see Section 2.1.3 below for further details): the repeat sales method, the stratification or mix adjustment method, the sale price-appraisal ratio (SPAR) method, and the hedonic regression method. Not all sources collect enough explanatory variables to implement all these methods, so the choice of methodology in each country is partly determined by those data limitations. Lack of enough disaggregated data also prevents us from reconstructing the country house price indexes under a common methodology to correct for the biases and inconsistencies that heterogeneity along this dimension introduces in our panel. 


\subsubsection{Selection of Comparable House Price Series}

The real-time, quarterly database on international house prices currently contains indexes for 23 countries going back to the first quarter of 1975 on (nominal and real) house prices and (nominal and real) personal disposable income (PDI) per working age (15/16-64) population. ${ }^{1}$ We use the Personal Consumption Expenditure (PCE) deflator for every country to express the nominal house price and PDI series in real terms. ${ }^{2}$ The notion of personal disposable income available to the household sector that we adopt (the PDI) and its measurement in the national accounts are explained in greater detail in Section 2.2 below.

The house price data differs significantly across countries due to characteristics such as the property type, the area covered, the property vintage, or the priced unit. Moreover, as emphasized earlier, differences also arise due to the diverse methodologies applied to construct the indexes in each country, due to the data aggregation procedures used, the frequency of the data releases or even the treatment of seasonality by the source. With the aim to facilitate further research on international house prices, the database we construct is guided by the goal of minimizing the country differences arising from the heterogeneous characteristics of the available sources while doing the least possible violence to the data itself.

To attain this goal we favor the selection of aggregate indexes that share multiple similarities in common with our benchmark rather than attempting the more intrusive (and perhaps impractical) approach of reconstructing the indexes from disaggregated data under a common methodology. We choose a representative series from multiple, publicly available sources after sorting out the data for each country for comparability in terms of concept and methodology. Then, we homogenize the country series-as best as possible - in regards to frequency, seasonal adjustment, and to correct for the presence of breaks or outliers in the data.

Selecting closely comparable house price indexes and extending the country series back to 1975 makes the panel more suitable for international comparisons across countries and across time. We select country series that are closely aligned with the features of the FHFA quarterly nationwide house price index for existing single-family houses (formerly called OFHEO house price index) in the U.S. A brief description of all house price series is given in this paper discussing the similarities and differences in the data country-by-country. We make note of the features in which discrepancies still persist, and adjust the data along other dimensions to make the reported measures more comparable. We do not attempt to change the primary source data whenever it cannot be reconciled in some aspects with the FHFA reference series by a

\footnotetext{
1 The OECD defines working-age population as equivalent to the economically-active population; a concept proposed by the International Labor Organization (ILO). As such, working-age population comprises of "all persons of either sex above a specified age" who supply labor for production purposes (whether employed, unemployed, or seeking work for the first time). The specified age above which population can be counted as economically active is often determined by law, and may differ across countries. For most countries the working age is 15-64. The notable exceptions are the U.S. (which is 16 and over) and Belgium (which is 15 and over). We do not correct for these differences in the definition of working-age population because these differences, in fact, can affect the supply of labor for production purposes and therefore are economically-relevant.

${ }^{2}$ PCE deflator data are obtained from the most recent OECD Economic Outlook database available at the time of an update. The first release is based on OECD Economic Outlook database 89. The PCE deflator for South Africa is obtained from national sources.
} 
straightforward transformation. The transformations that we do apply to the data are discussed in the next section of the paper. Some heterogeneity is inevitable under our approach-especially in concept and methodology. ${ }^{3}$

\subsubsection{Other Resources Available on House Prices}

Three major international conferences have been hosted over the past 10 years in order to discuss housing indicators and the different methodologies to construct them:

- October 27-28, 2003 - BIS-IMF Conference on Real Estate Indicators and Financial Stability - http://www.bis.org/publ/bppdf/bispap21.htm

- $\quad$ November 6-7, 2006 - OECD-IMF Workshop on Real Estate Price Indexes

- November 11-12, 2009 - Eurostat-IFC-IAOS Conference on Residential Property Price Indices http://epp.eurostat.ec.europa.eu/portal/page/portal/conferences/introduction/2009/rppi_co nference

The ideas, methods and sources argued about during those meetings can be a valuable reference for understanding the measurement of house prices across countries. Other useful references on methodology are Eurostat (2012) and the highly-regarded handbook on residential property price indexes from Eurostat; International Labour Organization; International Monetary Fund; Organisation for Economic Co-operation and Development; United Nations Economic Commission for Europe; World Bank (2013). The latter represents the most current overview of conceptual and practical issues related to the compilation and construction of house price indexes. The handbook is coordinated by the Statistical Office of the European Union (Eurostat), and published jointly under the responsibility of six international organizations: the International Labour Organization (ILO), the International Monetary Fund (IMF), the Organisation for Economic Co-operation and Development (OECD), the Statistical Office of the European Union (Eurostat), the United Nations Economic Commission for Europe (UNECE), and the InterSecretariat Working Group on Price Statistics (IWGPS) from the World Bank.

In regards to sources of international data, there already exist a number of compilations of international house price series available. One of the most comprehensive repositories of international house price data, publicly available, is maintained by the Bank for International Settlements (BIS) at http://www.bis.org/statistics/pp.htm. It includes three datasets. The detailed dataset has nominal residential property prices for 58 advanced and emerging countries at present, as released by the source (without attempting to homogenize them). For most countries the dataset contains several series (especially if a breakdown is available, or data is available from multiple compilers). Since June 2014 a dataset with the selected (nominal and real) residential property price series, and one containing long (nominal) series (with a starting date of 1970) have been additionally published beyond the detailed one. These new datasets contain a single selected series for each country that is the closest to nationwide coverage. It typically covers all types of dwellings in markets for both new and existing dwellings in the country as a whole. The long series have been constructed for a smaller set of countries by back-calculating

\footnotetext{
${ }^{3}$ The most notable deviation being Japan where, as customary, we use land prices as a proxy for the unavailable house price statistics.
} 
the selected ones with historical data with limited coverage for earlier periods. Since September 2016, the BIS has published a dataset on commercial property prices. Finally, a short note on recent developments is also published on a quarterly basis: http://www.bis.org/statistics/pp_residential.pdf. Panel data can also be obtained from international organizations - like the OECD at http://www.oecd.org/statistics/, or Eurostat which provides standardized quarterly series since 2005 for all European Union member states at http://appsso.eurostat.ec.europa.eu/nui/show.do?dataset=prc_hpi_q\&lang=en. ${ }^{4}$ The IMF combines the OECD dataset with other sources for non-OECD member countries to construct a Global House Price Index with a total of 51 advanced and emerging economies with varying concept and coverage, as illustrated here: http://www.imf.org/external/pubs/ft/fandd/2013/12/picture.htm. ${ }^{5}$

Data can also be obtained directly from official and public national sources. Private compilations of house price data for a variety of countries also exist, e.g., the Global Property Guide (GPG) website at http:/www.globalpropertyguide.com/real-estate-house-prices/ is a very valuable reference and one of the most comprehensive on the existing sources by country. ${ }^{6}$ GPG collects detailed house price data for 60 countries, including all series available for each. Other sources include Knight Frank surveys 55 countries since 2006 to produce a global house price index. More information about Knight Frank's research on real estate can be found at http://my.knightfrank.com/research-reports/global-house-price-index.aspx. Another private source of international house price data, although access to their series may require a subscription, is the website of Trading Economics at http://www.tradingeconomics.com/countrylist/housing-index. The Economist makes its data available at http://www.economist.com/houseprices. The Economist tracks house prices since 2002 and its readers can compare 21 markets on a number of house price indicators. The time-series data of The Economist, GPG and Knight Frank do not always extend as far back in time or is easily accessible for research purposes.

\footnotetext{
${ }^{4}$ A quarterly version of the OECD data has been used in a number of cross-country studies as well (see, e.g., OECD (2005) , Girouard et al. (2006), and André (2010))). The OECD cross-country dataset came about with the same intent of making heterogeneous national sources more comparable. Differences appear partly because our coverage is not limited to OECD countries and because we restrict ourselves to use only publicly available sources that can be independently replicated.

${ }^{5}$ For further background on the IMF data sources, see also Igan and Loungani (2012).

${ }^{6}$ See a summary of definitions and sources used by GPG at: http://www.globalpropertyguide.com/investmentanalysis/House-Price-Data-and-Sources.
} 


\subsubsection{More in Depth: Different Approaches to Construct a House Price Index}

\section{Summary of Standard Methodologies to Construct a House Price Index}

- Repeat sales method:

The repeat sales method compares the prices of dwellings that are sold more than once within sample. It is generally implemented pooling all the repeat sales data over all periods under observation in a regression. Methodological problems include: (a) small sample size as at least two transactions on the same property are needed in sample, but housing transactions are infrequent; (b) bias due to quality changes over time (e.g. as a result of depreciation, maintenance, renovations). The repeat sales method is used by the FHFA to construct the U.S. series that we use for reference.

- Stratification and mix-adjustment method:

The method relies on the stratification of transactions data by groups with similar characteristics in the sample, rather than tracking individual dwellings. The average transaction prices of every grouping in each period are then used as the price for dwellings with those same characteristics (even though the properties in the group are changing over time). The overall price index is then constructed by aggregating across all groups. This allows for larger samples, but stratification is still subject to a quality bias problem similar to the repeat sales method. A post-stratification of samples is then usually applied to control for the changes over time in the quality of the dwellings sold. The method including quality controls is known as mix adjustment.

- Sale price-appraisal ratio (SPAR) method:

The SPAR method combines transaction price data with appraisal information on the dwelling to calculate a transaction price-to-appraisal ratio. This ratio is used to control for the quality across properties and over time. This method may be applied on all available data, not just on the subset of dwellings reporting repeat sales. However, implementing this method requires access to a database on official property valuations providing appraisals of properties (such as through matched real estate taxation data, matched mortgage valuation data, etc.).

- Hedonic regression method:

The hedonic regression methods (which can be combined with all other methods) are econometric models to account for the heterogeneous characteristics of the dwellings and for quality changes over time. The standard method models dwelling prices as a function of the characteristics of the property and a set of time dummy variables. As data on all sample periods are pooled together, this method controls for quality bias and can be applied to samples that include non-repeat sale transaction prices. The hedonic imputation method constructs a house price index based on dwelling characteristics using the predicted value to impute a price on periods in which there are no transactions. In the housing market where sales are infrequent this allows the sample of dwellings to remain stable over time. 


\subsection{Personal Disposable Income Data: Measuring Households' Income in the National Accounts}

In addition to house price index data, we also collect series on personal disposable income (PDI) - which represent the income resources "at hand" for the household sector for current purchases - for each country, expressed per working-age population. PDI series are also reported in real terms with the personal consumption expenditure (PCE) deflator. PDI is generally the preferred measure to assess the affordability of housing, and therefore, an economically relevant variable for the study of housing demand and the determinants of house prices.

For all countries, PDI data is collected from national sources. In the U.S., the information on PDI can be found in the National Income and Product Accounts (NIPA) produced by the Bureau of Economic Analysis (BEA). ${ }^{7}$ Other countries report their national accounts and income distribution through their official statistical offices. All of the countries in the international house price database currently follow the United Nation's System of National Accounts (UNSNA), which establishes international guidelines for national accounting. This provides some consistency on the sources, although the implementation may still differ from country to country.

Heterogeneity arises most notably because some countries do not incorporate all the guidelines of UNSNA in their national accounts. Differences emerge from country-specific departures from UNSNA guidelines which we generally cannot correct for. Hence, while we rely on commonly reported (publicly available) data in order to obtain or derive the PDI per capita measures, consistency across countries exists to the extent that the reporting countries adopt similar UNSNA guidelines to construct their national accounts. We discuss those differences further in Section 2.2.1 below.

We also illustrate the different methods of extracting PDI data from various national account aggregates and describe the relevant accounting identities that relate to those aggregates, allowing for a more comprehensive interpretation of the data.

\subsubsection{Differences in the Adoption of the United Nations' System of National Accounts (UNSNA)}

The United States NIPAs have not adopted all of the guidelines for national accounting set forth by the UNSNA, and this occurs with other countries included in the international house price database as well. However, the differences between the NIPAs and UNSNA in the definition of gross domestic product (GDP) appear small-as discussed in Mead, Moses, and Moulton $(2004)^{8}$ - and the same is expected for other countries. Although the impact should not be overestimated, the differences are more significant when we compare the aggregate components of GDP or gross national product (GNP). In particular, we highlight here the differences that occur in the classification of certain groups (unincorporated firms and nonprofit institutions

\footnotetext{
${ }^{7}$ For more details about the NIPAs, see Seskin and Parker (1998).

${ }^{8}$ Once a year, the BEA prepares annual estimates on a UNSNA basis in response to a questionnaire from the Organisation for Economic Co-operation and Development (OECD). These estimates can be found at http://bea.gov/national/sna.htm, and are published by international organizations such as the OECD. While it improves the comparability of U.S. national accounts statistics with those of other countries, the exercise does not extend to quarterly data. These estimates, therefore, do not reconcile the methodological differences that exist in the quarterly data even among OECD member states.
}

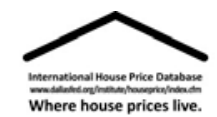


serving households (NPISHs)) and in the presentation of the national accounts, as they affect the derivations of PDI.

A. In regards to differences in classification: unincorporated firms or enterprises are, in principle, included in the UNSNA in the household sector, but appear in the business sector in the NIPAs. ${ }^{9}$ Nonprofit institutions serving households (NPISHs) ${ }^{10}$ are classified in the UNSNA either in the non-financial or the financial corporation sectors, but included in the household sector in the NIPAs. Other countries follow the same practice and bundle households with NPISHs together-for example, France. For measuring national income, however, the institutions classification used in the NIPAs changes to conform more closely with the UNSNA guidelines, which somewhat mitigates crosscountry differences in the PDIs.

The NIPAs define the personal sector to include households and the income that is earned by, or transferred to, households and all NPISHs, as well as the income of unincorporated enterprises (including owner-occupied housing). The personal sector is thus closer conceptually to the combination of the UNSNA household sector, which includes unincorporated enterprises, and the NPISH sector, which is included in the UNSNA corporation sector. As a result, the main discrepancy that remains is due to the classification of NPISHs. For most countries in the international house price database, the personal sector includes NPISHs, while other countries adhering to the UNSNA guidelines would exclude them from the household sector. ${ }^{11}$ We adopt the NIPA classification of the personal sector as the reference, but do not attempt to adjust for discrepancies in the classification of NPISHs further as they generally represent a tiny share of the economy.

B. In regards to differences in presentation: The UNSNA household disposable income (HDI) and the NIPA disposable personal income (DPI) are calculated using different methods. Both income measures include all sources of personal income, less contributions for social insurance and personal taxes. The NIPA measure includes interest and other transfers paid by persons, which are excluded from the UNSNA measure. The NIPA measure also includes pension fund contributions but does not include pension fund benefits, while the UNSNA measure excludes pension fund contributions and

\footnotetext{
${ }^{9}$ A corporation is a firm or enterprise with a legal identity separate from that of its owners and limited liability. Unincorporated firms or enterprises have no distinction between the firm and its owners, which are personally liable in case of bankruptcy. One of the major legal requirements to become a corporation is the publication of a complete set of accounts- there are also differences in taxation. The published accounts of corporations help to construct the national accounts of the corporate sector. Unincorporated enterprises tend to be small or medium-sized, and play an important role in agriculture and occupations requiring advanced technical knowledge which can be pursued in selfemployment (such as the so-called liberal professions in law, medicine, architecture, engineering, etc.). Their output contribution remains limited by the fact that as they expand, small firms tend to either disappear or transform themselves into corporations.

${ }^{10}$ NPISHs are owners of unincorporated enterprises or firms, nonprofit institutions that primarily serve individuals, religious organizations, private trust funds, and private noninsured welfare funds. For additional information, see Mead, McCully, and Reinsdorf (2003).

${ }^{11}$ Statistical offices that include NPISHs in the personal sector are those of the U.S., Australia, Belgium, Switzerland, Germany, the U.K., Israel, Korea, Norway, New Zealand, and Eurostat-which serves as our PDI source for Denmark, Spain, Finland, Ireland, Italy, Luxembourg, the Netherlands, and Sweden.
} 
includes pension fund benefits instead. Again, while we adopt the definition of disposable personal income from the NIPAs as our reference for the PDI, we do not attempt to correct for the discrepancies between HDI and DPI across countries any further.

Another difference arises because the national income (NI), which corresponds to the sum of all incomes, does not equal the net national product (NNP = GNP - depreciation of capital) given that the components are measured independently. In the NIPAs, the difference between GDP and GDI is called the statistical discrepancy. Not all other countries incorporate such an item in the income side. This is because one or more expenditure or income categories included are absorbing the difference as a residual or because the discrepancy is allocated to the income components of the national accounts. The distribution of the statistical error could affect the derivations of the PDI measures, but correcting for it goes beyond the scope of this project.

\subsubsection{From Gross Domestic Product to National Income}

GDP is the broadest measure of a country's economic activity. It represents the total final goods and services produced by the factors of production within a country for a given period, at market prices. GDP can be calculated using three separate approaches: the product (or value-added) approach, the income approach, and the expenditure approach. These three approaches must result in equivalent measures of economic activity (PRODUCT $=$ EXPENDITURE = INCOME), up to a statistical discrepancy. These relationships implied by the circular flow model are the basis for national accounting which tracks the flow of final goods and services from firms to final consumers, the opposing flow of expenditure payments from final consumers to firms, and the flow of factor payments (income) from firms to their providers of productive goods and services. National accounting also explicitly describes the participation of government as well as the linkages of an economy with the rest of the world.

The production approach measures output from the value-added of all goods and services produced in the economy. The goods and services that are produced are also consumed. The expenditure approach measures output from the value of total expenditures. Personal consumption expenditures (PCE) largely includes goods and services purchased for final use (excluding illegal transactions) in the market economy, but a portion of goods and services are incorporated through imputed values - the most important of which is rental value of owneroccupied housing. Goods and services consumed by the public sector are represented by government purchases. Gross private domestic investment measures capital purchases made by businesses. Net exports reflect the domestic consumption of goods and services produced abroad and the foreign consumption of domestically produced goods and services. ${ }^{12}$

The income approach measures the payments generated by participation in the production process - it adds up the remuneration to the different factors of production (such as labor and

\footnotetext{
${ }^{12}$ The NIPAs show GDP as the sum of personal consumption expenditures, gross private domestic investment, net exports of goods and services, and government consumption expenditures and gross investment. The UNSNA shows GDP, instead, as the sum of final consumption expenditures (by households, NPISHs, and government), gross capital formation (including gross fixed capital formation, change in inventories, and acquisitions less disposals of non-financial, non-produced assets) from private and government sources, and net exports of goods and services.
}

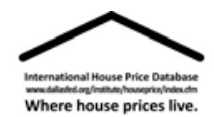


capital). However, not all income generated within an economy's borders is received by its own citizens. Gross national product (GNP) controls for this. It is equal to GDP minus factor payments received by foreign citizens from domestic production plus factor payments earned by domestic citizens from foreign production. We illustrate the different components under the income and expenditure approach in Figure 1 below.

Net national product (NNP) obtained from the product approach equals GNP minus depreciation of fixed assets (also referred to in the NIPAs as consumption of fixed capital). ${ }^{13}$ National income (NI) is the aggregate of all factor payments from the income side. NI can be calculated directly from its income components and, to explore it further, we adopt the NIPA definitions as a reference. It includes factor remuneration: employee compensation, proprietors' income, rental income of persons, corporate profits, and net interest. It also takes account of the effect of government policies on income through business current transfer payments, taxes on production and imports less government subsidies, and current surplus of government enterprises. The difference between NNP and NI amounts to statistical error and omissions.

\subsubsection{Income vs. Expenditure Accounting Identities}

From income side: GDP $=\mathrm{C}+\mathrm{G}+\mathrm{S}-\mathrm{NFP}$, From expenditure side: GDP $=\mathrm{C}+\mathrm{G}+\mathrm{I}+\mathrm{NX}$, where GDP = gross domestic product,

$\mathrm{C}=$ private consumption,

$\mathrm{G}=$ government expenditures and investment,

$\mathrm{S}=$ national (gross) saving,

$\mathrm{I}=$ private (gross) investment,

NFP = net factor payments from abroad,

$\mathrm{NX}=$ net exports.

\subsubsection{National Income Accounting Identity}

Gross National Product: GNP = GDP + NFP.

National Income: NI = GNP - capital depreciation (consumption of fixed capital) - statistical discrepancy.

\footnotetext{
13 Capital consumption adjustment for corporations and for nonfarm sole proprietorships and partnerships is the difference between capital consumption based on income tax returns and capital consumption measured at straightline depreciation, consistent service lives, and replacement cost. The tax return data are valued at historical costs and reflect changes over time in service lives and depreciation patterns as permitted by tax regulations. Inventory valuation adjustment represents the difference between the book value of inventories used up in production and the cost of replacing them.
} 


\section{Figure 1. Composition of U.S. Annual GDP (Current \$, 1975-2012) \\ GDP: Income Account \\ GDP: Expenditure Account}

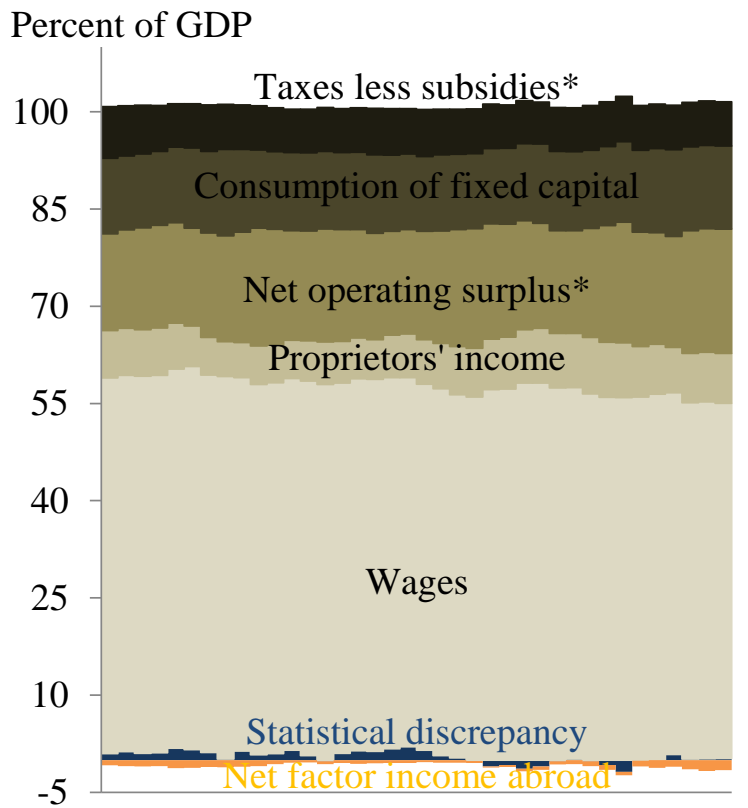

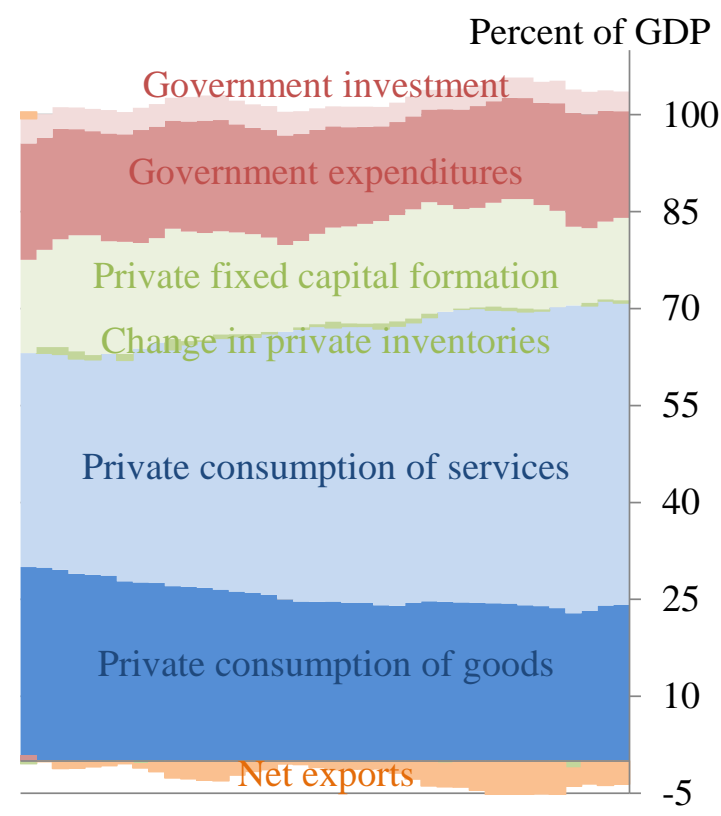

Percent of GDP

Source: U.S. Bureau of Economic Analysis, National Income and Product Accounts of the United States, and author's calculations.

* Taxes less subsidies refers to taxes on production and imports less subsidies. Net operating surplus (NOS) corresponds to the income generated by either a corporation or government enterprise net of labor compensation and taxes on production and imports. NOS includes rental income, net interest payments from businesses, corporate profits, business current transfers, and current surplus of government enterprises. The term proprietor's income or mixed income is used to denote income generated by individual owners or self-employed individuals since wage income and NOS of unincorporated enterprises owned by households are often undistinguishable.

\subsubsection{From National Income to Personal Disposable Income}

The NIPA concept of disposable personal income is used as reference for the international house price database. In the NIPA, personal income corresponds to the components of national income that are actually received by the household sector in the form of factor payments and current transfers. Households receive income by directly participating in the production of goods and services. This is measured by wages and salaries, proprietors' income, and rental income of persons. Personal income does not include employer contributions and employee and selfemployed contributions for government social insurance programs (social security and pensions, unemployment), so this is deducted from the employee compensation component of the national accounts. Households also participate in the production of goods and services through direct ownership or indirect financing of the stock of capital. The capital and financial income generated is distributed back to households in the form of personal dividend income and personal interest income.

The amount of income received is derived from the income earned in production after adjusting to reflect current transfers. Adjustments are made for transfers from businesses and the government, since including transfers among individuals would lead to double-counting in personal income. Moreover, certain nonmonetary types of income are included as part of personal income-in particular, the estimated net rental value to owner-occupants of their

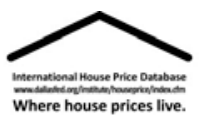


homes, but also certain services such as those provided complementary and without payment by financial intermediaries. Undistributed corporate profits are not received by the household sector and, therefore, not included in personal income. If undistributed profits are added to personal income, it is considered private income instead-that's the only difference between personal income and private income.

Personal disposable income (PDI) is the part of the personal income retained by the household sector (including the NPISHs according to the NIPA guidelines) after subtracting all direct taxes (income taxes, estate and gift taxes, and property taxes plus other miscellaneous receipts) levied by the government. PDI measures the amount of income that is actually available for current spending or saving. Under the income approach, it is calculated by subtracting personal current taxes from personal income. The income approach method reflects the sources of PDI. In turn, the expenditure approach measures the uses of PDI. Under the expenditure approach, the PDI can be computed as the sum of household final consumption expenditure (including interest and transfer payments) and household savings. ${ }^{14}$

While the definition of PDI that we use for reference is that of the NIPAs, it should be noted that discrepancies arise in the definition across countries due to differences in the national accounting methodology that each country follows as discussed in Section 2.2.1 above. Real income is the nominal PDI divided by a general price index - the personal consumption expenditure (PCE) deflator-at a given base period. Per capita income is the ratio of PDI over the total working age (15/16-64) population of the country.

\subsubsection{National Income by Institutional Sector ${ }^{15}$}

The fundamental national income accounting identities are stated in Section 2.2.2.1 and Section 2.2.2.2 above. In here, we provide a basic description of how the different income components are allocated and become disposable income of the household (personal) sector, the corporate sector, and the government sector illustrating the economic relationships that exist among them in the national accounts. A complementary illustration that describes these accounting and economic relationships in the context of the circular flow model can be found in Figure 2 below.

\footnotetext{
14 Adjustments for changing equity in pension fund reserves can also be included to insure the balance of net contributions does not enter into household savings. PDI is also the total amount of final consumption of goods and services that the household sector is able to afford in a given period (abstracting from capital transfers) without having to change their financial and non-financial asset position or their liabilities (changes that would be reflected in the Flow of Funds).

${ }^{15}$ In defining these accounting identities, for illustration purposes only (to keep the presentation simple) we abstract from business current transfer payments (net) and current surplus of government enterprises as these income sources tend to be small in the national accounts. Unlike what is recommended by the guidelines of UNSNA, the NIPAs correct the measure of disposable personal income including personal interest payments (INT ${ }^{\mathrm{h}}$ ) but we abstract from that item here as well to keep the identities simple. For similar reasons, we do not distinguish explicitly between government consumption and investment expenditures as it is done in the NIPAs.
} 
National Income: $\mathrm{NI}=\mathrm{GNP}-$ depreciation - statistical discrepancy $=\mathrm{PDI}+\mathrm{DI}^{\mathrm{corp}}+\mathrm{DI}^{\text {gov }}$

Personal Disposable Income: PDI $=\left(\mathrm{NI}-\Pi^{\text {und }}-\mathrm{DIV}^{\text {gov }}\right)-\left(\mathrm{T}^{\mathrm{corp}}+\mathrm{T}^{\mathrm{Y}}+\mathrm{T}\right)+(\mathrm{TR}-\mathrm{SSC})+\mathrm{INT}^{\text {gov }}$

Corporate Disposable Income: $\mathrm{DI}^{\mathrm{corp}}=\mathrm{NI}-$ all factor payments outside the firm $=\Pi^{\text {und }}$

Government Disposable Income: $\mathrm{DI}^{\text {gov }}=\left(\mathrm{T}^{\mathrm{corp}}+\mathrm{T}^{\mathrm{Y}}+\mathrm{T}\right)+\mathrm{DIV}^{\mathrm{gov}}-(\mathrm{TR}-\mathrm{SSC})-\mathrm{INT}^{\text {gov }}$

where $\mathrm{NI}=$ national income,

PDI = personal disposable income,

$\mathrm{DI}^{\mathrm{Corp}}=$ disposable income retained by the corporate sector,

$\mathrm{DI}^{\mathrm{gov}}=$ disposable income of the government,

$\Pi^{\text {und }}=$ undistributed profits (essentially retained earnings),

$\mathrm{DIV}^{\text {gov }}=$ government dividend receipts,

$\mathrm{T}^{\mathrm{corp}}=$ profit tax liability,

$\mathrm{T}^{\mathrm{Y}}=$ taxes on production and imports less subsidies,

$\mathrm{R}=\mathrm{T}^{\mathrm{corp}}+\mathrm{T}^{\mathrm{Y}}=$ other government revenue,

$\mathrm{T}=$ personal taxes,

$\mathrm{TR}=$ transfer payments—specifically, gov't social benefit payments to persons,

SSC $=$ contributions for social insurance,

$\mathrm{INT}^{\text {gov }}=$ net government interest payments .

\subsubsection{Savings-Investment Identity}

The income side of the national accounts is by construction reconciled with the expenditure side. Hence, the disposable income received by the different sectors has to be either invested or saved. The following economic relationships describe the linkages between disposable income and expenditures as well as between national savings and the current account (foreign savings).

National (gross) Saving: $\mathrm{S}=\mathrm{S}^{\mathrm{pvt}}+\mathrm{S}^{\mathrm{corp}}+\mathrm{S}^{\mathrm{gov}}=\mathrm{GNP}-\mathrm{C}-\mathrm{G}$

National (net) Saving: $S^{\text {net }}=S-$ capital depreciation $=(N I+$ statistical discrepancy $)-C-G$

Personal Saving: ${ }^{16} \mathrm{~S}_{\mathrm{pvt}}=\mathrm{PDI}-\mathrm{C}$

Corporate Saving: $\mathrm{S}^{\mathrm{corp}}=\mathrm{DI}^{\mathrm{corp}}+$ capital depreciation $=\Pi^{\mathrm{und}}+$ capital depreciation

Government Saving: $S_{\text {govt }}=\mathrm{DI}^{\mathrm{gov}}-\mathrm{G}$

where GNP = gross national product,

$\mathrm{C}=$ private consumption,

$\mathrm{G}=$ government expenditures and investment,

$\mathrm{S}=$ national (gross) saving.

Balance of Payments: CA $=$ NX + NFP

where $\mathrm{CA}=$ current account,

$\mathrm{NFP}=$ net factor payments from abroad,

$\mathrm{NX}=$ net exports.

Savings-Investment Identity: S = I + CA

where $\mathrm{S}=$ national (gross) saving,

$\mathrm{I}=$ private (gross) investment.

\footnotetext{
${ }^{16}$ Personal saving is defined in the NIPAs as $\mathrm{S}_{\mathrm{pvt}}=$ PDI - Personal Outlays, where Personal Outlays $=\mathrm{C}-$ Personal Interest Payments - Personal Current Transfer Payments. Personal interest payments (INT ${ }^{\mathrm{h}}$ ) and personal current transfers are generally very small, so we abstract from them in these equations without too much loss of generality.
} 
We illustrate the relation of GDP, GNP, net national product, national income, personal income, personal disposable income, and personal saving using annual U.S. data for the year 2012 in Table 1 and Table 2 below. This offers a more detailed description of the income and expenditure accounts under the NIPA guidelines than the stylized linkages described in Section 2.2.3.1 and Section 2.2.3.2.

Table 1. U.S. Income and Expenditure Account Tables from NIPA

\begin{tabular}{|c|c|c|c|c|c|}
\hline \multicolumn{3}{|l|}{ Income Account } & \multicolumn{3}{|c|}{ Expenditure Account } \\
\hline Item & $2012^{*}$ & $\%$ of GDP & Item & $2012^{*}$ & $\%$ of GDP \\
\hline Gross domestic product (GDP) & 16244.6 & $100 \%$ & Gross domestic product & 16244.6 & $100 \%$ \\
\hline Plus: Receipts of factor income from the rest of the world & 818.6 & & Personal consumption expenditures & 11149.6 & $69 \%$ \\
\hline Less: Payments of factor income to the rest of the world & 565.7 & & Personal consumption of goods & 3769.7 & $23 \%$ \\
\hline Equals: Gross national product (GNP) & 16497.4 & $102 \%$ & Personal consumption of services & 7379.9 & $45 \%$ \\
\hline Less: Consumption of fixed capital & 2542.9 & & Government purchases & 3167 & $19 \%$ \\
\hline Equals: Net national product (NNP) & 13954.6 & $86 \%$ & Government expenditures & 2548.1 & $16 \%$ \\
\hline Less: Statistical discrepancy & -17 & & Government investment & 618.9 & $4 \%$ \\
\hline Equals: National income (NI) & 13971.6 & $86 \%$ & Gross private domestic investment & 2475.2 & $15 \%$ \\
\hline Compensation of employees & 8611.6 & $53 \%$ & Private fixed capital formation & 2409.1 & $15 \%$ \\
\hline Wages and salaries & 6926.8 & & Change in private inventories & 66.1 & $0 \%$ \\
\hline Wages and salaries, dispersed to employees & 6906.0 & & Net exports of goods and services & -547.2 & $-3 \%$ \\
\hline Wages and salaries, accrued but not dispersed & 20.8 & & Equals: Exports & 2195.9 & \\
\hline Supplements to wages and salaries & 1684.9 & & Less: Imports & 2743.1 & \\
\hline Contributions for social insurance & 950.7 & & & & \\
\hline Other labor income & 734.2 & & & & \\
\hline Proprietors' income & 1224.9 & $8 \%$ & & & \\
\hline Rental income of persons & 541.2 & $3 \%$ & & & \\
\hline Corporate profits & 2009.5 & $12 \%$ & & & \\
\hline Profits tax liability & 434.8 & & & & \\
\hline Profits after tax & 1574.7 & & & & \\
\hline Net dividends & 770.3 & & & & \\
\hline Undistributed profits & 804.3 & & & & \\
\hline Net interest & 439.6 & $3 \%$ & & & \\
\hline Business current transfer payments (net) & 106.9 & $1 \%$ & & & \\
\hline To persons (net) & 41.4 & & & & \\
\hline To government (net) & 70.6 & & & & \\
\hline To rest of the world (net) & -5.1 & & & & \\
\hline Taxes on production and imports less subsidies & 1065.6 & $7 \%$ & & & \\
\hline Current surplus of government enterprises & -27.7 & $0 \%$ & & & \\
\hline
\end{tabular}

Source: U.S. Bureau of Economic Analysis, National Income and Product Accounts of the United States, and author's calculations.

*Current dollars.

\section{Table 2. Personal Disposable Income by Its Components from NIPA}

\begin{tabular}{|c|c|c|c|c|c|}
\hline \multicolumn{3}{|l|}{ Income Account } & \multicolumn{3}{|c|}{ Expenditure Account } \\
\hline Item & 2012* & $\%$ of GDP & Item & 2012* & $\%$ of GDP \\
\hline Personal income & 13431.1 & $83 \%$ & & & \\
\hline Wages and salaries, dispersed to employees & 6906.0 & $43 \%$ & & & \\
\hline Other labor income & 734.2 & $5 \%$ & & & \\
\hline Proprietors' income & 1224.9 & $8 \%$ & & & \\
\hline Rental income of persons & 541.2 & $3 \%$ & & & \\
\hline Personal dividend income & 757.0 & $5 \%$ & & & \\
\hline Net dividends from corporate profits & 770.3 & & & & \\
\hline Less: Government dividend receipts & 22.8 & & & & \\
\hline Personal interest income & 992.6 & $6 \%$ & & & \\
\hline Net interest & 439.6 & & & & \\
\hline Plus: Personal interest payments & 172.7 & & & & \\
\hline Plus: Government interest payments & 431.5 & & & & \\
\hline Less: Government interest receipts & 115.9 & & & & \\
\hline Transfer payments to persons & 2375.1 & $15 \%$ & & & \\
\hline Business current transfer payments, to persons (net) & 41.4 & & & & \\
\hline Plus: Government social benefit payments to persons & 2329.2 & & & & \\
\hline Less: Personal current taxes & 1480.4 & $9 \%$ & & & \\
\hline \multirow[t]{6}{*}{ Equals: Personal disposable income (PDI)** } & 11950.8 & $74 \%$ & Personal disposable income (PDI) & 11950.8 & $74 \%$ \\
\hline & & & Personal outlays & 11460.3 & $71 \%$ \\
\hline & & & Personal consumption expenditures & 11149.6 & $69 \%$ \\
\hline & & & Personal interest payments & 172.7 & $1 \%$ \\
\hline & & & Personal current transfer payments & 168 & $1 \%$ \\
\hline & & & Personal savings & 490.5 & $3 \%$ \\
\hline
\end{tabular}

Source: U.S. Bureau of Economic Analysis, National Income and Product Accounts of the United States, and author's calculations.

*Current dollars.

**PDI can also be computed from national income (NI). PDI = NI - wages and salaries accrued but not dispersed - contributions to social insurance - profits tax liability - government dividend receipts - undistributed profits + net government interest payments + personal interest payments - net business current transfer payments to government and rest of the world - taxes on production and imports less subsidies - current surplus of government enterprises - personal current taxes. 


\subsubsection{More in Depth: The Circular Flow and Personal Disposable Income}

Understanding personal disposable income (PDI) in the NIPAs is further illustrated in the following stylized representation of the circular flow of the economy, which emphasizes how the different income sources enter into or are excluded from the PDI measure that we take as reference for the work on the international house price database (see Figure 2). A stylized description of the accounting identities underlying Figure 2 can be found in Section 2.2.3.1 and Section 2.2.3.2.

Figure 2. A Circular Flow Representation of the Sources of Personal Disposable Income

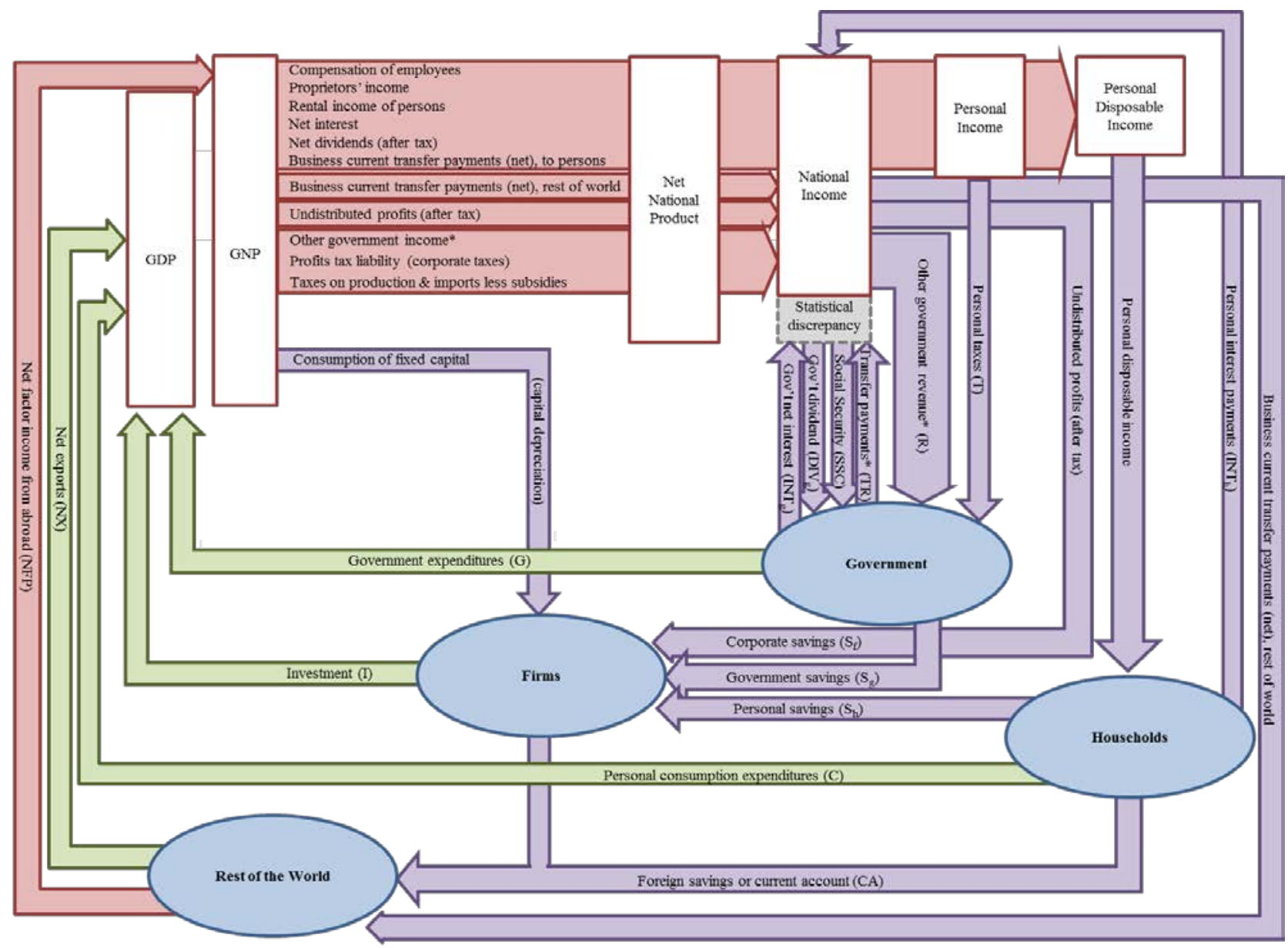

* Other government income includes business current transfer payments (net) to government and current surplus of government enterprises. Other government revenue includes other government income, profit tax liability and taxes on production and imports less subsidies. Transfer payments refer specifically to government social benefit payments to persons.

Source: Author's representation of the circular flow model based on the National Income and Product Accounts (NIPA) of the U.S. based on Gary E. Clayton (2008): "Economics: Principles and Practices," Student Center, Unit 4, Ch. 12, Figure 12.3 - Circular Flow of Economic Activity, The McGraw-Hill Companies, C2008. 


\section{Methodological Approach}

\subsection{Timing of Releases}

The international house price database is updated quarterly, but we face great heterogeneity in the timing of each country's data releases. We have found a significant number of countries report the data needed to include a new quarterly observation of the (nominal and real) house price and PDI index series three months after the end of each quarter. ${ }^{17}$ As a practical compromise between the timeliness of the release and the country coverage, we schedule the posting of the international house price database during four fixed periods each year incorporating already a three month lag. The schedule for a given year $T$, therefore, is:

Table 3. Yearly Timeline of Release Dates

\begin{tabular}{|l|l|}
\hline Last Quarter Included & Release Date \\
\hline Fourth Quarter of $\boldsymbol{T}$-1 & First full week of April of $T$ \\
\hline First Quarter of $\boldsymbol{T}$ & First full week of July of $T$ \\
\hline Second Quarter of $\boldsymbol{T}$ & First full week of October of $T$ \\
\hline Third Quarter of $\boldsymbol{T}$ & First full week of January of $T+1$ \\
\hline
\end{tabular}

We aim to have the dataset posted during the week indicated in Table 3. We will apply the same schedule for data releases every year, unless the release lag of the country data on which the panel depends were to change, requiring us to adjust this schedule to preserve both its wide coverage and representativeness. The schedule of data releases for the current and subsequent years can be found on the web.

Whenever observations are missing for a country's house price or PDI index, we complete the series for the current release with nowcasts derived with the basic structural time series (BSTS) model that we describe in Section 3.7 below. The dataset will be revised in subsequent quarters to incorporate the country data, as the corresponding quarterly observations become available.

\footnotetext{
17 Country coverage usually represents more than 80 percent of total output from all countries included in the
} sample, measured by their 2005 GDP in purchasing power parity adjusted terms according to the IMF. 


\subsection{Approach to Construct the Country Data: Step-by-Step}

The FHFA house price index series (formerly called OFHEO house price index) serves as our benchmark measure when selecting a house price index for the other countries in the database. The main selection criteria-and preference-are given to: geographic coverage (nationwide); vintage of dwellings (existing); type of dwellings (single-family); priced unit (per dwelling); availability of data (1975 - present); and frequency (quarterly). The disposable personal income series by the Bureau of Economic Analysis (BEA) serves as our benchmark measure when selecting or reconstructing the PDI index for the other countries, although not all accounting differences across countries can be fully reconciled with the BEA concept. The PDI measure for some countries is derived from national account aggregates using the accounting relationships discussed in Section 2.2 above.

The methodological decision tree found in Figure 3 below describes the steps we follow to derive consistent series by combining the available sources for each country in the panel. The same approach is applied to all series in the international house price database. The motivation behind each step is to maintain consistency across countries, while limiting data distortions as much as possible.

The reference series for each country is its most current one, since it is selected for being the most consistent with the benchmark series (FHFA house price index and disposable personal income) and for having data available up to the present. In most cases, the reference series does not extend all the way back to the first quarter of 1975, and it has to be completed with other series which we refer to as the historical series. We label the combined series that goes back to the first quarter of 1975 as the extended or the full-length series.

Old vintages of the international house price database are kept for researchers interested in realtime data analysis. 
Figure 3. Methodological Decision Tree for the Construction of Time Series Data

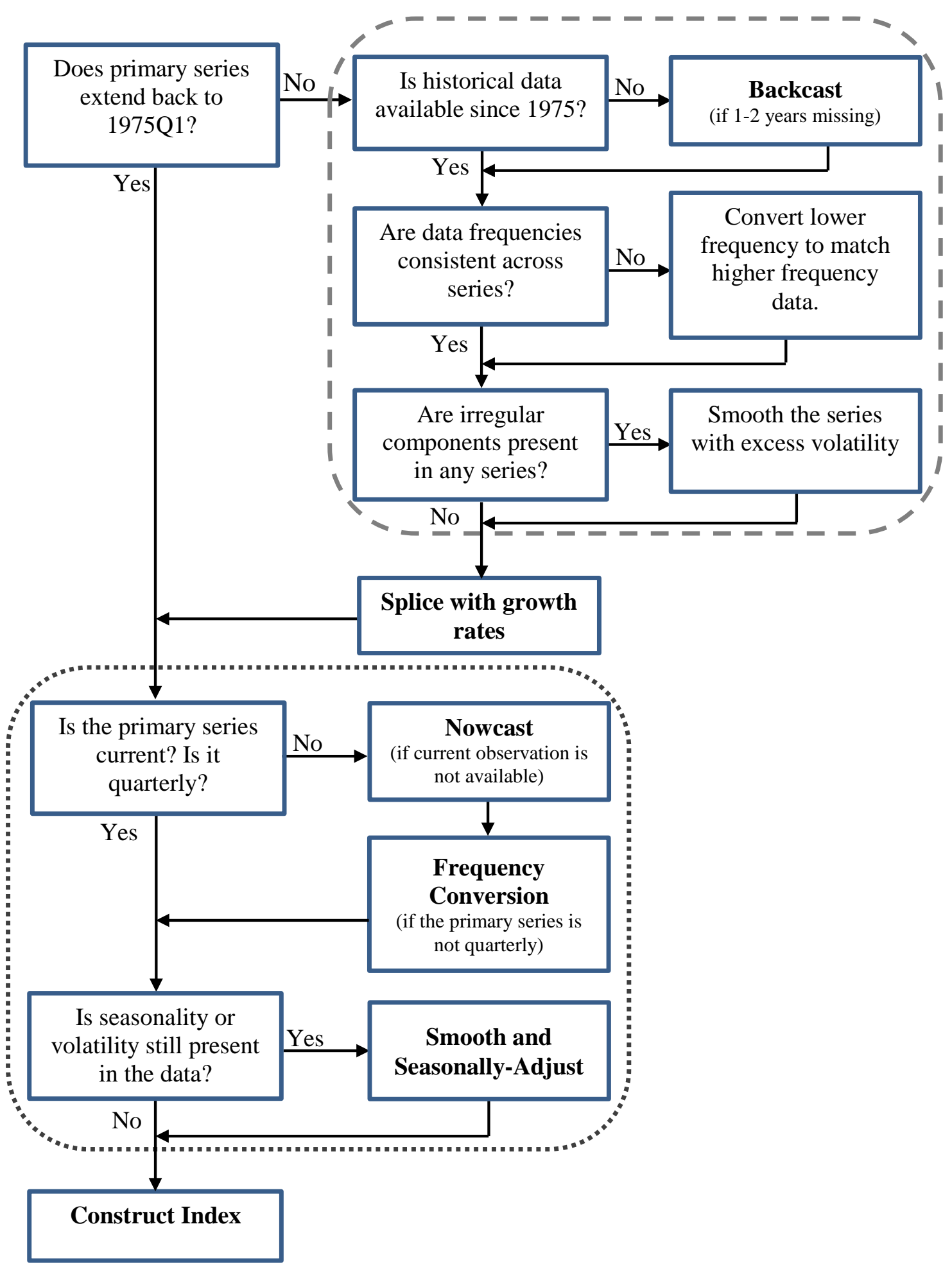




\subsection{Frequency Conversion Methods}

Frequency conversion is often required in order to report the house price and PDI indexes at a quarterly frequency. We are confronted with the problem of converting high-frequency data (monthly) to quarterly data as well as the problem of converting low-frequency data (semiannual, annual, bi-annual) to quarterly data.

If the series has a higher frequency, then we use a simple average of the monthly observations in order to report the time series at quarterly frequency. This makes use of all available data and produces observations that summarize the quarterly patterns of the data. ${ }^{18}$

Interpolation is applied to the latter problem, but it is worth pointing out that interpolating procedures can only provide estimates between known data points, since quarterly data are not observed. In other words, it tries to complete the series by fitting a curve to the known data points which can then be used to infer plausible outcomes for the unknown quarterly observations. The method of interpolation will be determined by the features that are most desirable for the interpolated data. We discuss the implementation of the frequency conversion methods in greater detail in Section 3.3.1 below.

\subsubsection{Quarterly Interpolation}

Interpolation methods are used for the conversion of low frequency to high frequency data- that is, for temporal disaggregation whenever no additional source of high frequency data is available to facilitate the conversion. ${ }^{19}$ Interpolation in the context of the international house price database can be defined as fitting a curve over measurements made at the sampled periods to infer unsampled quarters with which they must conform. Standard interpolating methods include constant piecewise, linear, polynomial (quadratic, cubic,...), and spline, among others.

If the observed time series has a lower frequency (semi-annual, annual, or bi-annual) than the database (quarterly), our preferred choice for interpolation is to use the quadratic-match average (or the quadratic-match sum) method to interpolate the data to a quarterly frequency. ${ }^{20}$

The quadratic-match methods do not guarantee that the curve fitted would satisfy non-negativity, even if the observed data points are all positive. This is a problem especially in countries that experienced periods of hyperinflation or severe inflation within the sample covered by the international house price database (such as Croatia). We resolve the issue interpolating the

\footnotetext{
${ }^{18}$ A note of caution, averaging may induce a spurious first-order serial correlation effect in the differenced series as shown by Working (1960) among others.

${ }^{19}$ Different econometric disaggregation techniques, such as the Denton (1971) and Chow and Lin (1971) approaches to cite just two of the most popular methods, can also be used for quarterization. These techniques interpolate the low frequency data at quarterly frequency using related indicator variables that are reported themselves at quarterly frequency. We generally do not have access to quarterly indicators that can be used with the available data for temporal disaggregation of the series in the international house price database.

${ }^{20}$ A note of caution, interpolating with a quadratic function introduces a systematic source of serial correlation in the regressors because data points are related to each other by a quadratic polynomial. This must be taken into account when using time series with interpolated data for the purpose of statistical inference- that is, standard errors should be made robust to autocorrelation in hypothesis testing.
} 
logged series, and then use the growth rate in log-differences to splice and extend the data backwards. In all other cases, interpolation is conducted with the series expressed in levels.

Interpolation is performed in two stages. In the first stage of interpolation, the objective is to report the current and historical series at the same frequency, so they can be spliced together. ${ }^{21}$ If the historical series is reported at a lower frequency than the current series, but the frequency of the current series is lower than quarterly, then the historical series is interpolated to the same frequency as the current series rather than at quarterly frequency. For example, in the case of Italian house prices, the historical series is reported bi-annually and the current series is reported semi-annually. In the first stage, the historical series is interpolated to a semi-annual frequency and then spliced with the current series. In the second stage of interpolation (if this step were necessary), the objective is to report the extended series at a quarterly frequency. Again, using the Italian house price series as an example, once the bi-annual series is interpolated to a semiannual frequency and spliced with the current series, the extended series is interpolated to quarterly frequency.

\subsection{Seasonal-Adjustment Method}

In order for quarterly data to be useful for researchers or for policy analysis, the series must be reported to reflect the true underlying patterns of the data. Seasonal-adjustment aims to pinpoint economically relevant features of the data (trend and cycle), but irregular components (outliers, breaks) may also be present. In which case, seasonal-adjustment might not be sufficient in removing all the irrelevant noise in an observed series. Hence, we develop and implement a smoothing algorithm based on the basic structural time series (BSTS) model, fitted to the data in order to remove both seasonality and the effect of unrelated irregular noise.

We give preference to data not seasonally-adjusted by the source because then we can apply the BSTS model in a manner that consistently treats the effect of seasonality across countries and series. The seasonal adjustment procedures used by the sources often vary by country-the U.S. Census Bureau family of seasonal adjustment procedures (such as X-12) or the Bank of Spain/Eurostat TRAMO-SEATS package-which introduce heterogeneity in the data. In cases when the original data is only reported seasonally-adjusted (such as South Africa's PDI), we use it without further correction unless the seasonal adjustment by the source appears insufficient to remove all seasonality and the irregular noise in the time series. We would then apply a variant of the BSTS model to this data in order to obtain the final seasonally-adjusted, smoothed series for the international house price database.

The specification of the BSTS model in state-space form is both simple to estimate and very flexible capturing the relevant components of the data. It produces estimates of the seasonal factors that are comparable to those obtained with other conventional methods (such as X-12 and TRAMO/SEATS), while providing an integrated framework for the removal of irregular components, and can also be used for backcasting and nowcasting. ${ }^{22}$ We further discuss the uses of the BSTS model in Section 3.7 below. For a more formal evaluation of the BSTS model for

\footnotetext{
${ }^{21}$ We provide details on the implementation of the splicing method in Section 3.5.

22 We discuss the backcasting and nowcasting uses of the BSTS model in Section 3.7.
} 
seasonal adjustment and the treatment of irregular components, the interested reader is referred to Martínez-García (2014).

If seasonality or large irregular noise components are present in the current series but not in the historical series (especially when the historical series is derived from interpolated data), we remove the seasonality and irregular components from the current series before splicing-using the BSTS model. In general, we seasonally-adjust the individual data series contained in an extended series separately whenever they display very different seasonality or irregular patterns, then splice the smoothed series. If the seasonal patterns of the individual series appear similar, they are first spliced, then seasonal adjustment is applied to the extended series. The seasonal adjustment with the BSTS model is performed on data with a frequency higher than annual, but it can be implemented with interpolated data as it removes some of the irregular patterns in the data that may follow from the implementation of the quadratic-match procedure.

\subsection{Splicing Method}

All series are spliced together using the growth rates of the longer historical series in order to extend the level of the shorter current time series backward in time. Splicing with exact growth rates is preferred, but we use log-differences in the case of countries that have undergone a period of severe inflation within the sample (such as Croatia). The historical time series are selected by availability in order to reasonably track the changes of the reference series.

Splicing the current series with the growth rates of the historical series may not extend the series as far back as 1975. In which case, the historical series is complemented with backcasted data, where additional observations - not representing more than two years-are obtained using the best fitted BSTS model for the available historical time series. Time series backcasting is used to extend the house price indexes of Spain and the Netherlands from the first quarter of 1976 back to the first quarter of $1975 .^{23}$ Before splicing the series, we perform the minimal adjustments needed to obtain consistent frequency across series and remove any irregular components or seasonality.

Nowcasting is applied primarily in order to ensure the timeliness and completeness of the international house price database release when the current series of reference for a country is missing some recent observations due to lags in reporting from the national sources or simply because the reported data is produced at a lower-than-quarterly frequency.

Nowcasting is used, for example, with the annual consumption of fixed capital series of Belgium and the U.K. The data at a lower-than-quarterly frequency is extended with a historical series and augmented with the nowcasted value for the unobserved year that includes the current quarter. Then, the series is interpolated to a quarterly frequency. If the current series is reported at quarterly frequency, but the reporting lag results in missing observations for the most recent quarters, we use nowcasted values for those missing observations. The nowcasted values will subsequently be replaced with actual data from their respective national sources, as those

${ }^{23}$ Backcasting estimates are obtained by re-ordering the original data $x_{t}$ backwards from the end of the sample $(t=$ $T)$ to the beginning of the sample $(t=1)$, and then running a regression model to forecast the data of the series $x_{t}$ prior to $t=1$.

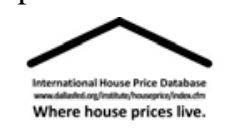


observations become available. We finally seasonally-adjust the extended quarterly series, except when the seasonal patterns or other irregular components of the data appear not to be statistically-significant.

All nowcasts and backcasts are derived from the best fitted specification of the BSTS model. This is an estimated regression model that is used for seasonal-adjustment and smoothing as well, where the underlying components of each time series-decomposed in trend, cycle, seasonal factors, and irregular noise-are fitted at each point by Maximum Likelihood and updated iteratively with the help of the Kalman filter. In Section 3.7 below, we give further interpretation to the BSTS model and a short overview of the methodology as it is implemented in the international house price database. We leave the more technical details for the interested reader to be found in Martínez-García (2014).

\subsection{Approach to Aggregate the Country Data}

All country series at quarterly frequency and extended going back to the first quarter of 1975 are then indexed to $2005=100$. The country series are aggregated to produce global indicators of the housing market, using weights that account for the size of the economy of each country incorporated in the database. We use the 2005 purchasing power-parity adjusted (annual) GDP shares of all countries in the sample as constant weights to derive our aggregate nominal house price index and our aggregate real house price index. Similarly, we use these constant GDP weights to aggregate the nominal and real PDI series. All GDP shares are obtained from the IMF World Economic Outlook database. 


\subsection{More in Depth: An Overview of the Basic Structural Time Series (BSTS) Model}

We use the BSTS approach as follows,

- The estimation of the BSTS model corrects for seasonality at quarterly frequency and also accounts for other extraneous irregular noise that may be present in the observed time series (historical or current). Noisy series and/or series with a statistically-significant quarterly seasonal pattern are reported as the combination of the smoothed trend and cycle components, therefore excluding both the noise and seasonality from the series.

- The BSTS model is used for backcasting and nowcasting in order to extend some time series at the beginning and end of their samples. The estimated model produces accurate backcasts/nowcasts with otherwise minimal effort in identification, but it is most appropriate either in short- to medium-horizons where observed data patterns are likely to continue or whenever changes in the time series occur slowly over time. Backcasts/nowcasts are used in practice with at most 1-2 years back/ahead for that reason.

\subsubsection{All-Encompassing BSTS Model Specification}

Given a time series $y_{t}, t=\{1, \ldots, T\}$, the standard BSTS model of Harvey (1989) decomposes the data additively as follows,

$$
y_{t}=\mu_{t}+c_{t}+s_{t}+e_{t}, e_{t}-N I D\left(0, \sigma_{e}^{2}\right), t=1,2, \ldots, T,
$$

where $\mu_{t}$ is the time-varying trend, which captures the long-run evolution of the series as a function of time; $c_{t}$ is the cycle, which denotes transitory movements in the series around its trend; $s_{t}$ represents the seasonal factor, which captures a recurrent movement in the series that repeats itself at fairly regular intervals; and $e_{t}$ is an irregular (and random) component called noise, error term, or disturbance term, which includes other non-modeled, exogenous, and intrinsically irrelevant factors affecting the observed series (the signal).

These four components can also be combined multiplicatively in the time series to produce the log-additive model specification,

$$
y_{t}=\exp \left(\mu_{t}\right) \exp \left(c_{t}\right) \exp \left(s_{t}\right) \exp \left(e_{t}\right), e_{t}-N I D\left(0, \sigma_{e}^{2}\right), t=1,2, \ldots, T,
$$

which has many applications in the international house price database. This log-additive model specification reduces to the additive specification in (1) whenever we work with logged values. Hence, the BSTS model can be discussed solely in its additive form even though we actually consider the log-additive case as well in our implementation.

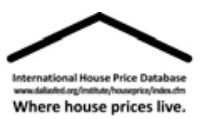


All four constituent components $\left(\mu_{t}, c_{t}, s_{t}, e_{t}\right)$ are stochastic, and the disturbances driving them are mutually uncorrelated in general. The extraneous noise component $e_{t}$ is modeled as white noise, while the trend $\mu_{t}$, cycle $c_{t}$ and seasonal factor $s_{t}$ are all assumed to follow a particular model. As stated earlier, we consider a stochastic polynomial model of order two or lower for the trend component $\mu_{t}$. We assume a covariance-stationary AR(p) process for the transitory component of the time series described by the cycle $c_{t}$. We also assume a stochastic version of the standard "seasonal factors" model adding up to a random shock to capture time-variation in the seasonality. For the reasons stated before, we consider both the additive as well as the logadditive specifications of the BSTS model under consideration but describe the modeling choices for the unobserved components $\left(\mu_{t}, c_{t}, s_{t}\right)$ on the additive case only. For more details on the exact state-space form of each variant of the BSTS model that we actually explore and a further discussion of the methodology and its advantages, the interested reader is referred to MartínezGarcía (2014).

The additive, univariate specification of the all-encompassing BSTS model is given by,

$$
\begin{aligned}
& \forall t=\{1, \ldots, T\} \\
& \left\{\begin{array}{l}
y_{t}=\mu_{t}+c_{t}+s_{t}+e_{t}, e_{t}-N I D\left(0, \sigma_{e}^{2}\right), \quad \text { signal equation (decomposition equation), } \\
\mu_{t}=\mu_{t-1}+b_{t-1}+\varepsilon_{t}, \varepsilon_{t}-N I D\left(0, \sigma_{\varepsilon}^{2}\right), \quad \text { state equation (local polynominal trend), } \\
b_{t}=b_{t-1}+\delta_{t-1}+\xi_{t}, \xi_{t}-N I D\left(0, \sigma_{\xi}^{2}\right), \\
\delta_{t}=\delta_{t-1}+\zeta_{t}, \zeta_{t}-N I D\left(0, \sigma_{\zeta}^{2}\right), \\
c_{t}=\phi_{1} c_{t-1}+\phi_{2} c_{t-1}^{1}+\vartheta_{t}, \vartheta_{t}-N I D\left(0, \sigma_{\vartheta}^{2}\right), \\
c_{t}^{1}=c_{t-1}, \\
s_{t}=-s_{t-1}-s_{t-1}^{1}-s_{t-1}^{2}+\omega_{t}, \omega_{t}-N I D\left(0, \sigma_{\omega}^{2}\right), \text { state equation (stochastic seasonal), } \\
s_{t+1}^{1}=s_{t}, \\
s_{t+1}^{2}=s_{t}^{1},
\end{array}\right.
\end{aligned}
$$

where the component $\mu_{t}$ represents the unobserved level, $b_{t}$ determines the unobserved linear term on the time-trend, and $\delta_{t}$ is the unobserved quadratic term on the time trend. For specifications with a cyclical component $c_{t}$, an $\operatorname{AR}(2)$ (or $\mathrm{AR}(1)$ ) process is used for reference. For specifications with seasonality, the quarterly seasonal component $s_{t}$ is recurrent and its time- 
invariant coefficients must sum up to a random disturbance. The random disturbances $e_{t}, \varepsilon_{j}, \xi_{t}$, $\zeta_{t}, \vartheta_{t}$, and $\omega_{t}$ are normally distributed, and mutually independent at all leads and lags.

The parameters of the model include up to six variances for the random disturbances, $\sigma_{e}^{2}>0$, $\sigma_{\varepsilon}^{2}>0, \sigma_{\xi}^{2}>0, \sigma_{\zeta}^{2}>0, \sigma_{\vartheta}^{2}>0$, and $\sigma_{\omega}^{2}>0$. The list of parameters also includes $p$ ( $p \leq 2$ in our specification of reference) autoregressive coefficients used to describe the AR(p) cyclical component of the time series. The model description is incomplete without a specification of priors for $\left(\mu_{0}, b_{0}, \delta_{0}, c_{0}, c_{0}^{1}, s_{0}, s_{0}^{1}, s_{0}^{2}\right)$, which we generally take to be diffuse priors in all our estimations. 


\subsubsection{BSTS Model Estimation, Backcasting/Nowcasting and Forecasting}

We represent all variants of the BSTS model in state-space form and estimate their time-varying, unobserved components by Maximum Likelihood. The advantage of assuming the normality of the disturbances is that it simplifies the estimation of the model in state-space form by Maximum Likelihood, and also allows us to use the Gaussian Kalman (Bucy) filter. The Kalman filter algorithm is applied to recursively update the model with new observed data that contains noise (random variation) to produce a statistically optimal prediction and forecast of the unobserved states (cycle, trend, and seasonal) that characterizes the time series along with its corresponding uncertainties. The main assumptions of the Kalman filter are that the model be a linear dynamic system and that the error term (irregular noise on the observed series) and all state disturbances have a Gaussian distribution.

Nowcasting and forecasting are fairly standard in this case. Backcasting is accomplished by reordering the original data $y_{t}$ from $t=T$ to $t=1$ (in reverse order) and then running the estimation and forecasting algorithm under the same state-space model specification chosen to fit the data. Maximum Likelihood estimation and the recursive Kalman filter are exploited to obtain estimates of the initial states and forecasts of the series in reverse order (backcasts).

\subsubsection{BSTS Model Selection}

Selecting an appropriate model specification depends on: (a) whether the data is trending or not (in other words, the series is non-stationary)? (b) whether the series has a transitory component or cycle that is stationary? (c) whether there is seasonality in the data? and (d) whether the noise and irregular components are well-approximated as independent and identically distributed Gaussian random disturbances? Model selection would consider alternative specifications of the cyclical AR(p) component and the seasonal model-including variants without them — based on standard likelihood-based selection criteria (primarily the Akaike Information Criterion), strongly favoring the less-parameterized and less-complex specification of the model. For further discussion on the goodness-of-fit in-sample and the forecast accuracy out-of-sample as well as the actual implementation of the model selection procedures, the interested reader is referred to Martínez-García (2014). 


\section{Country-Specific Information ${ }^{24}$}

\section{FU - Australia}

The Australian Bureau of Statistics (ABS) produces a house price index for new and existing, single-family dwellings located in the eight capital cities (Sydney, Melbourne, Brisbane, Adelaide, Perth, Canberra, Darwin, and Hobart). ABS uses the concept of established houses to differentiate from project homes (which are not yet completed). An established house may be existing or new. The index is created using the mix-adjusted method, with dwellings grouped by suburbs. The median price is calculated for each group according to the price that is first documented in a sales contract. This price is then weighted by the value of dwelling stock, determined by the most recent five-year census. The 2006 census is the most current publication. There is a recent break in the methodology of the series. Prior to 2002, ABS documented house prices according to the final price documented in a sales contract, weighted by the financial commitment (the value of the mortgages). The main purpose was tracking mortgage interest rates. The index is reported at a quarterly frequency starting in the second quarter of 1986.

To extend the data back to 1975, we splice the ABS house price index with growth rates of the Australian Treasury house price index, obtained upon request. The Treasury index measures prices for all types of dwellings, new and existing. The Treasury index is itself a compilation of indexes: From 1986 onwards the data draws from the ABS series described above. Prior to 1986, only six capital cities are included (Sydney, Melbourne, Brisbane, Adelaide, Perth, and Canberra; Darwin and Hobart are excluded). From 1978 to 1986, data comes from the Real Estate Institute of Australia and represents median house prices weighted by housing finance data. From 1960 to 1978, data comes from Bis-Shrapnel, a private consulting company that gathered price information from published auction sales. The index represents a weighted average of median prices in each capital city, with the same weights used to aggregate the $14^{\text {th }}$ CPI series.

None of the house price series are seasonally-adjusted by the source. We seasonally-adjust the spliced series using a BSTS model, and re-base it to 2005=100. We deflate this house price series using the personal consumption expenditure (PCE) deflator obtained from the OECD Economic Outlook database.

We complete the Australian data by reporting personal disposable income (PDI) on a per capita basis, which we compute by dividing the household disposable income series by the working age population series. Both series are reported at a quarterly frequency and originally obtained complete from the first quarter of 1975 through the OECD Economic Outlook database. The source of personal disposable income (PDI) and working age population changed with the 2012 first quarter update, affecting all subsequent updates. Gross disposable income and consumption of fixed capital for households are collected from the Australian Bureau of Statistics. These two series start in the third quarter of 1959 and come seasonally adjusted from the source. Consumption of fixed capital is subtracted from gross disposable income to compute a net disposable income series. Current working age population data is obtained from the OECD Main

\footnotetext{
${ }^{24}$ We use the two-letter country codes defined under ISO 3166-1 (published by the International Organization for Standardization (ISO) as part of the ISO 3166 standard) to identify the countries in our database.
}

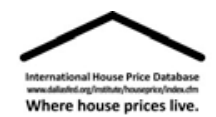


Economic Indicators database. It is reported at a quarterly frequency and begins in the first quarter of 1978. We use the quarterly growth rates of the discontinued working age population series from the OECD Outlook 90 database to extend the series to the first quarter of 1975 . We use the PCE deflator to express the PDI per capita series in real terms. Both nominal and real PDI measures are re-based to 2005=100.

\section{References:}

Abelson and Chung (2005): “The Real Story of Housing Prices in Australia from 1970-2003.” Australian Bureau of Statistics (2006): “A Guide to House Price Indexes: Australia 2006.”

Australian Bureau of Statistics (2009): "House Price Indexes: Concepts, Sources and Methods, Australia.”

Information Resources:

Reserve Bank of Australia Data

http://www.rba.gov.au/statistics/frequency/occ-paper-8.html\#section_5

Australian Bureau of Statistics Data

http://abs.gov.au/AUSSTATS/abs@.nsf/allprimarymainfeatures/52AFA5FD696482CACA25768

D0021E2C7?opendocument

Acknowledgements: Alex Beams from the Australian Treasury and Peter Abelson from Sydney University. 


\section{Ш BE - Belgium}

Directorate General of Statistics and Economic Information (DGSEI) (part of Federal Public Service (FPS) Economy), also known as Statistics Belgium, publishes a nationwide house price index for existing, single-family dwellings. Statistics Belgium gathers data from all registered sales. The aggregation of this data and construction of the index is performed by Stadim, a group of real estate analysts. The index is constructed using the mix-adjusted method.

Registered sales data is used to gather information on average price and number of existing homes at the district level. Dwellings are categorized according to type and location. Average price for each group is calculated; average prices that are unrealistic or based on less than six transactions are eliminated. The data is transformed into a Laspeyres chained price index, where districts are aggregated based on number of dwellings in the base period (the year 2005).

In 2005, the categories for dwelling type expanded. Specifically, single-family dwellings were divided into three separate categories: small, average and large. This methodological change caused a break in the series between 2004 and 2005, but affects mainly the Brussels region index and the indexes for the single-family sub-divisions. The aggregate index that we use is minimally affected. Data is reported at a quarterly frequency.

The house price series is not seasonally-adjusted by the source. We seasonally-adjust the data using a BSTS model and re-base the series to $2005=100$. We deflate this house price series using the Personal Consumption Expenditure (PCE) deflator obtained from the OECD Economic Outlook database.

We complete the Belgium data by reporting personal disposable income (PDI) on a per capita basis, which we computed by dividing the interpolated (and seasonally-adjusted) PDI by the quarterly working-age population series. Both series were originally obtained through the OECD Economic Outlook database. The source of the PDI and working age population data changed, with the 2012 first quarter update, affecting all subsequent updates. Gross disposable income and consumption of fixed capital for households is collected from Statistics Belgium. The gross disposable income series is reported at a quarterly frequency and begins in 1999. The consumption of fixed capital is reported at an annual frequency, starting in 1996. This annual consumption of fixed capital series is interpolated to a quarterly frequency using the quadraticmatch average method. The resulting series is subtracted from the gross disposable income series to compute net disposable income. The net disposable income series from Statics Belgium is largely influenced by seasonal factors, so we use a BSTS model in state-space form to identify and systematically extract the seasonal and excessively volatile components of the data. Prior to 1999, annual data for net household disposable income is obtained from the OECD Outlook database 86. This series is interpolated to a quarterly frequency using the quadratic-match average method. The resulting quarterly growth rates are used to extend the "smoothed" data from Statistics Belgium to the first quarter of 1975.

Because the consumption of fixed capital series is annual, we use a BSTS model to estimate a value for the current year. The quarterly series obtained using interpolated nowcast will be

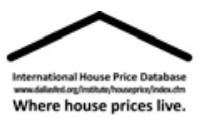


subsequently replaced as the official annual data becomes publicly available. We use the same approach in subsequent updates of the dataset.

Current working age population data is now obtained from the OECD Main Economic Indicators database. It is reported at a quarterly frequency and begins in the first quarter of 1995 . We use the quarterly growth rates of the discontinued working age population series from the OECD Outlook 90 database to extend the series to the first quarter of 1975. We use the PCE deflator to express the PDI per capita series in real terms. Both nominal and real PDI measures are re-based to $2005=100$.

Information Resources:

Statistics Belgium (in French) Data

http://statbel.fgov.be/fr/modules/publications/statistiques/economie/ventes_de_biens_immobilier s.jsp

Stadim Data

http://www.stadim.be/index.php?page=stadimdexen\&hl=en

National Bank of Belgium Data

http://www.nbb.be/belgostat/DataAccesLinker?Lang=E\&Code=Natrek

http://www.nbb.be/belgostat/DataAccesLinker?Lang=E\&Code=fedplan

Acknowledgements: Paul De Wael from Stadim. 


\section{+ CA - Canada}

The University of British Columbia (UBC) produces quarterly house price series for existing bungalows and two story executive dwellings located in ten main metropolitan areas of Canada: Victoria, Vancouver, Calgary, Edmonton, Regina, Winnipeg, Ottawa, Toronto, Montreal, and Halifax. Bungalows are defined as detached, one-story, three-bedroom dwellings with approximately 111 square meters of living space. Two-story executive dwellings are defined as a four-bedroom house with approximately 186 square meters of living space. Prices for the two types of dwellings are obtained through the Royal LePage house price survey.

Prices are determined by Royal LePage real estate experts based on their opinions of fair market value according to house price data from each location. Royal LePage offers disaggregated data grouped by area and property type. The UBC uses this data to create a house price series for each metro area by averaging the prices of detached bungalows and detached two story executive houses for each area. Metro data is offered at quarterly frequency, and goes back to the first quarter of 1975 for Victoria, Vancouver, Regina, Toronto and Montreal. We compute a national house price series by aggregating the ten house price series reported by UBC using a simple unweighted mean of all cities for which we have data in a given quarter.

A significant lag emerged in the publication of the house price series produced by the UBC. To avoid this lapse in data, we computed the Canadian house price series directly from Royal LePage disaggregated data. This affects the 2013Q1 through 2013Q4 releases. We collected data on bungalows and two-story executive dwelling prices in each of the ten metropolitan areas. Within each area, prices are reported for a particular neighborhood or sub-region. First we computed a weighted average for each dwelling type in each area. We used number of private dwellings occupied by usual residents from the 2006 Census as weights. In some cases, neighborhood and sub-region population data is compiled by the city and reported on the municipal government website. When this was not available, Census Tracts were used. In cases where prices are reported for suburbs, population data represents the regions with the highest concentration of single-family detached houses. The resulting weighted averages for the two dwelling types were averaged. The Royal LePage data is available starting in 2010Q1. We used the UBC data for each metropolitan area prior to 2010. The total population from the 2011 Census was used to aggregate the house price data across the metropolitan areas. 2011 Census data was not used to weight prices within each city due to lack of neighborhood and sub-region compilations.

The source of the current house price data has changed again. Starting in 2005, the series is based on the Multiple Listing Service ${ }^{\circledR}\left(\mathrm{MLS}^{\circledR}\right)$ Home Price Index from the Canadian Real Estate Association, which is more timely and better reflects underlying changes in house prices. This affects the 2014 first quarter release and all subsequent updates. The MLS ${ }^{\circledR}$ index is released monthly and covers 11 major housing markets: Vancouver Island, Victoria, Greater Vancouver, Fraser Valley, Calgary, Regina, Saskatoon, Greater Toronto, Ottawa, Greater Montreal, and Greater Moncton. We use the series which is aggregated for all of these markets for single-family homes. The MLS $^{\circledR}$ index is calculated using multivariate regression analysis and a hybrid model that combines the Repeat-Sales and Hedonic Price approaches. The index 
therefore controls for the contributions made by various quantitative and qualitative housing features toward the house price.

The house price series are not seasonally-adjusted by the source. We seasonally-adjust the aggregate data using the BSTS model and then transform the series into an index with a base year in 2005=100. We deflate this house price series using the Personal Consumption Expenditure (PCE) deflator obtained from the OECD Economic Outlook database.

We complete the Canadian data by including a personal disposable income (PDI) series, reported in per capita terms. To compute the PDI per capita series we divide household disposable income by the working-age population. Both series were available at a quarterly frequency and obtained from the OECD Economic Outlook database.

The source of the current PDI and working age population data has changed. This affects the PDI per capita series for the 2012 first quarter update and all subsequent updates. Net disposable income series for households and a separate net disposable income series for non-profit institutions serving households (NPISH) are collected from Statistics Canada. Before the 2017 second quarter release, both series started in the first quarter of 1981 and were added together. We used a separate discontinued series of net disposable income for households and NPISH from Statistics Canada to extend the PDI series to the first quarter of 1975. Starting with the 2017 second quarter release, the current series start in the first quarter of 1961, so we no longer use the historical series to extend the PDI series. Current working age population data is now obtained from the OECD Main Economic Indicators database. It is reported at a monthly frequency starting in January of 1995, which we average to a quarterly frequency. We use the quarterly growth rates of the discontinued working age population series from the OECD Outlook 90 database to extend the series to the first quarter of 1975. We use the PCE deflator to report the PDI per capita series in real terms. Both nominal and real PDI measures are re-based to $2005=100$.

\section{Information Resources:}

University of British Columbia (UBC) Centre for Urban Economics and Real Estate Data http://cuer.sauder.ubc.ca/cma/index.html

MLS ${ }^{\circledR}$ Home Price Index from the Canadian Real Estate Association http://homepriceindex.ca/hpi_home_en.html

Royal LePage

http://www.royallepage.ca/en/media/reports-surveys/survey-of-canadian-house-prices.aspx

Statistics Canada

http://www5.statcan.gc.ca/cansim/a01?lang=eng

http://www12.statcan.gc.ca/census-recensement/index-eng.cfm

Bank of Canada Data 
http://www.bankofcanada.ca/rates/indicators/capacity-and-inflation-pressures/real-estate-marketdefinitions/real-estate-market-historical-data/

Description of Bank of Canada Data

http://infocentre.central1.com/_html/pdf/can_housing.pdf

Acknowledgements: Prof. C. Tsuriel (Tsur) Somerville from Centre for Urban Economics and Real Estate (UBC). 


\section{$+\quad \mathrm{CH}$ - Switzerland}

The Swiss National Bank publishes a nationwide quarterly house price index for new and existing, single-family dwellings. The index is originally published by Wuest \& Partner and constructed using the mix-adjusted method. Single family homes include homes with 4 to 6 rooms. Dwellings are categorized by size, location and age. The median price for each group is determined through nationwide real estate listings. These prices are then aggregated, weighted by the moving average (a 40-quarter window) of the dwelling stock. Data is reported at a quarterly frequency.

The composition of real estate listings used to generate median price data has changed over time. The index was revised, with retroactive effects in the fourth quarter of 2005, to expand the source database. Prior to the revision, only print media was used; after the revision, this was broadened to include four internet sites (Homegate, Immoscout24, Immoclick and Immostreet). Prior to 1996, a representative sample of real estate listings was selected to represent the overall price. Now all listings are taken into account.

The house price series is not seasonally-adjusted by the source. We seasonally-adjust the data using the BSTS model and re-base the series to $2005=100$. We deflate this house price series using the Personal Consumption Expenditure (PCE) deflator obtained from the OECD Economic Outlook database.

We complete the Swiss data by reporting personal disposable income (PDI) on a per capita basis. We use two household disposable income series, the first comes from Statistics Switzerland; it is annual and begins in 1990. To extend this series back to 1975, we use a series from the OECD Economic Outlook 68 database; it is annual and covers the period 1975-2002. There is a considerable lag in the publication of current data from Statistics Switzerland. To avoid a lag in our publication, we produce nowcasts for the spliced annual series up to two years ahead. These nowcasts will be subsequently replaced once actual data becomes available. The annual data and nowcasts are interpolated to a quarterly frequency, using the quadratic-match average method.

The source of the working age population data has changed. This affects the PDI per capita series for the 2012 first quarter update and all subsequent updates. Current working age population data is now obtained from the OECD Main Economic Indicators database. It is reported at a quarterly frequency and begins in the first quarter of 2010. We use the quarterly growth rates of the discontinued working age population series from the OECD Outlook 90 database to extend the series to the first quarter of 1975. The extended household disposable income series is divided by the extended working-age population to create the quarterly PDI per capita series in nominal terms.

We use the PCE deflator to express the PDI per capita in real terms. Both nominal and real PDI series are re-based to $2005=100$. 
Information Resources:

Swiss National Bank Data

http://www.snb.ch/en/iabout/stat/statpub/statmon/stats/statmon

Wuest \& Partner (in German) Data

http://www.wuestundpartner.com/online_services/immobilienindizes/angebotspreisindex/inform ation/pdf/Methodenbeschrieb.pdf 


\section{DE - Germany}

The Deutsche Bundesbank produces an annual, nationwide house price index for existing, terraced houses. Terraced houses are defined as single-family properties with a living space of approximately 100 square meters. Only dwellings that meet comfortable living standards in medium to good locations are included. This data is obtained through BulwienGesa AG which, in turn, draws its numbers from different sources: Association of German Real Estate Agents (Immobilienverband Deutschland-IVD), Chambers of Industry and Commerce, Surveyor Committees, Building and Loan Associations, Research Institutions, their own surveys, newspaper advertisements, etc. The mix-adjusted method is used to construct the index. Dwellings are categorized by type and location. Dwellings are aggregated according to construction statistics, which are taken from the 1998 micro census for data up to 2004 and the 2002 micro census for data starting in 2005. However, since we choose to focus only on terraced houses, no aggregation across property type is made. Prices from each city are weighted by population data from 2005. Data prior to 2005 is weighted using population data from 2000. The nationwide aggregate draws data from 100 cities from the former Western Germany and 25 cities from the former Eastern Germany (all of Berlin is classified as part of Eastern Germany since 1995). The nationwide index begins in 1995 and is extended with available annual historical data from 1990 through 1994 from the same source that does not include Eastern Germany.

The source of the current house price data has changed. Starting in 2000, the series is based on the quarterly price index for existing residential property developed by the Federal Statistical Office (Destatis). This affects the 2016 second quarter release and all subsequent updates. The quarterly series uses the hedonic method and tracks the prices to be paid for existing singlefamily and two-family houses and existing dwellings in apartment blocks, including the land. It matches closely with the annual Bundesbank series that was used previously and that we retain to extend the quarterly series before 2000 .

To extend the data prior to 1990, we use another index obtained from the Bundesbank. For 19751989, we use an annual house price index for new terraced houses in West Germany (including only a group of 50 cities). This series goes back to 1975. However, because the designation of new and existing dwellings was not formally introduced until 1990, the inclusion of existing dwellings in this index cannot be completely ruled out. New dwellings in this series of West Germany for new terraced houses are aggregated based on each dwelling's estimated construction cost. Cities are weighted according to population data, using the same vintages of population data as the aggregate series for all of Germany. We splice the annual series for all of Germany with the growth rate of the longer series for West Germany, and then interpolate the resulting series to a quarterly frequency using the quadratic-match average method. We then splice the Destatis series with the growth rates of the interpolated historical series.

The house price series are not seasonally-adjusted by the source. We seasonally-adjust the spliced and interpolated series using the BSTS model and re-base the series to 2005=100. Before the 2016 second quarter release, the primary data that we used was released annually, so at least four quarters would have elapsed if we had waited for the Bundesbank official data publication. To avoid this lag and make the public release of the data more timely, we originally nowcasted the spliced annual series for Germany one period ahead using a simple AR(2) model. The 
nowcasting method used then changed, affecting the 2012 first quarter update and all subsequent updates that used the annual series. We switched to the BSTS model to add one extra yearly observation that could be jointly interpolated. The quarterly estimates obtained using interpolated nowcasts were subsequently replaced as the official annual data became publicly available.

We deflate the house price series using the Personal Consumption Expenditure (PCE). The PCE series for Germany is obtained from the OECD Economic Outlook database. It is reported at a quarterly frequency and begins in the first quarter of 1991. We use the growth rates of the West Germany PCE deflator, obtained from the OECD Economic Outlook database, to extend the German PCE deflator to the first quarter of 1975.

We complete the German data by reporting personal disposable income (PDI) on a per capita basis. We used initially the extended and interpolated quarterly PDI and working age series for Germany from the OECD Economic Outlook database. The source of the current PDI and working age population data has changed. This affects the PDI series for the 2012 first quarter update and all subsequent updates. Net disposable income is collected from the Bundesbank. The series is reported at a quarterly frequency and begins in 1991. The measure of net disposable income published by the Bundesbank includes changes in equity in pension fund reserves. To maintain consistency across countries, we subtract this component. Data on equity and pension fund reserves (from 1999-present) is obtained from Eurostat; this is extended using data from the OECD Economic Outlook database. To extend the net disposable income series back to 1975, we use the net disposable income series for West Germany published in the OECD Outlook database 88. Both PDI come seasonally adjusted from the source. Current working age population data is now obtained from the OECD Main Economic Indicators database. Working age population is reported at a quarterly frequency and begins in the first quarter of 2005. We use the quarterly growth rates of the discontinued working age population series from the OECD Outlook 90 database to extend the series to the first quarter of 1975. We divide the household disposable income by working-age population to create nominal PDI per capita. We use the PCE deflator to express the series in real terms. Both nominal and real PDI measures are rebased to 2005=100.

\section{References:}

Hoffman and Lorenz (2006): “Real Estate Price Indices in Germany: Past, Present and Future.”

\section{Information Resources:}

Federal Statistical Office (Destatis) Data

https://www.destatis.de/EN/FactsFigures/NationalEconomyEnvironment/Prices/ConstructionPric esRealPropertyPrices/ConstructionPricesRealPropertyPrices.html

Deutsche Bundesbank Data

http://www.bundesbank.de/Navigation/EN/Statistics/Time_series_databases/Enterprises_and_ho useholds/enterprises_and_households_node.html

BulwienGesa AG Data

http://www.bulwiengesa.de/index.php?id=start\&L=1

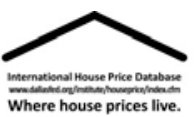




\section{† DK - Denmark}

Statistics Denmark publishes a nationwide house price index for new and existing, single-family dwellings. The index is constructed using the sale price appraisal ratio (SPAR) method. First, the ratio of the average purchase price and the average property assessment is computed for each region. Then, the index is created by dividing the ratio of the current quarter by the ratio of the previous quarter and multiplying the outcome by the index of the previous quarter (Dutot index). The appraisal value of dwelling stock is used to weight ratios from different regions. Since we choose to focus only on single-family dwellings, no aggregation across property type is possible. An improved SPAR method was implemented in the second quarter of 1992. The quarterly series from Statistics Denmark begins in the first quarter of 1992 and is indexed to 2006=100.

The Danish Central Bank - relying on data from the Ministry of Taxation (SKAT) — constructs another quarterly house price series going back to the first quarter of 1971 to be used for its MONA quarterly macroeconomic model for Denmark. The series is indexed to 1980=100 and can be obtained from the MONA databank. SKAT also uses the SPAR method to construct a house price index, though sales data is restricted to free sales (not involving family members). This MONA house price index also measures prices for new and existing, single-family dwellings. We use the growth rates of this series to extend the series from Statistics Denmark back to the first quarter of 1975.

Statistics Denmark stopped seasonally adjusting their house price index in 2009 with the introduction of an electronic land registry database. We seasonally-adjust the spliced series using the BSTS model and re-base the series to $2005=100$. We deflated this house price series using the Personal Consumption Expenditure (PCE) deflator obtained from the OECD Economic Outlook database, but this PCE deflator series was discontinued in November 2012. This affects the first quarter 2012 update and all subsequent updates. Current data is now obtained from the OECD National Accounts database. The series is reported at a quarterly frequency and begins in the first quarter of 1991. We use the quarterly growth rates of the discontinued OECD Outlook database 91 series to extend the current data to the first quarter of 1975.

We complete the Danish data by reporting personal disposable income (PDI) on a per capita basis. The current PDI series was obtained from the OECD Economic Outlook database-then interpolated, spliced and seasonally adjusted. We also took an interpolated working-age population series from the OECD Economic Outlook database. The source of the current PDI and working age population data has changed, affecting the PDI per capita series in the 2012 first quarter update and all subsequent updates. Gross disposable income and consumption of fixed capital for households is collected from Eurostat. Both series are reported at a quarterly frequency and begin in 1999. Consumption of fixed capital is subtracted from gross disposable income series to produce PDI.

The net disposable income series from Eurostat is largely influenced by seasonal factors, so we use a BSTS model in state-space form to identify and systematically extract the seasonal and excessively volatile components of the data. We use two annual series to extend the PDI series back to 1975. From 1981 to 1998 we use the net disposable income series from the OECD Outlook 86 database. From 1975 to 1980 we use the net disposable income series from the 
OECD Outlook 61 database. The two annual series are spliced together, and then interpolated to a quarterly frequency using the quadratic-match average method. The resulting quarterly growth rates are used to extend the Eurostat series.

Current working age population data is now obtained from the OECD Main Economic Indicators database. It is reported at a quarterly frequency and begins in the first quarter of 1999 . We use the quarterly growth rates of the discontinued working age population series from the OECD Economic Outlook 90 database to extend the series to the first quarter of 1975 . We then divide the spliced PDI series by the extended working age population series to create a nominal PDI per capita series. We use the PCE deflator to report the PDI per capita series in real terms. Both nominal and real PDI measures are re-based to 2005=100.

\section{References:}

Danmarks Nationalbank (2003): “MONA - A Quarterly Model of the Danish Economy.” Joensen (2006): “Danish Real Estate Price Indexes and Their Principal Users.”

\section{Information Resources:}

Statistics Denmark Data

http://www.dst.dk/en/Statistik/dokumentation/Declarations/sales-of-real-property.aspx

Denmark Tax Authority (SKAT)

http://www.skat.dk/SKAT.aspx?oId=1812700

Realkreditrådet - Association of Danish Mortgage Banks

http://www.realkreditraadet.dk/Statistics.aspx

http://www.realkreditraadet.dk/Statistics/Prices_and_trades_of_owner_occupied_homes.aspx

Eurostat Data

http://epp.eurostat.ec.europa.eu/portal/page/portal/statistics/search_database

Acknowledgements: Jacob Holmgaard from Statistics Denmark, Jan Falk Rasmussen from SKAT, and Tina Saaby Hvolbøl from the Danmarks Nationalbank. 


\section{ES - Spain}

The Ministerio de Fomento produces a nationwide house price series for all types of existing dwellings, priced per square meter. The series is constructed using the mix-adjusted method. The average price-per-square meter is calculated using appraisal agency data, based on dwellings that have been sold in the open market and are more than two years old. Dwellings are grouped by provinces. Dwelling stock information from the latest ten-year census is used to calculate the weights: 2011 is the most recent publication of the census data. The house price series is reported at a quarterly frequency and begins in the first quarter of 1995.

To extend the house price index, we use two historical series: From the first quarter of 1987 to the last quarter of 1994, we use a nationwide quarterly house price series produced by the Ministerio de Vivienda, which measures the average price (per square meter) for all dwelling types, new and existing. From 1976 to 1986, we use the annual house price series produced by Tecnigrama. The Tecnigrama series measures average prices (per square meter) for all types of new dwellings located in Madrid. Both series are converted into Euros at the fixed conversion rate, using the irrevocable exchange rate of 166.386 pesetas per euro. We combine the annual Tecnigrama series from 1976 to 1986 with the annual four quarter average of the Ministerio de Vivienda series from 1987 until 2004. We use the full combined (annual) series from 1976 to 2004 to fit a BSTS model, then backcast an annual observation for the year $1975 .{ }^{25}$ The Tecnigrama annual series backcasted to 1975 is then interpolated at quarterly frequency using the quadratic-match average method. We use the growth rates of the Ministerio de Vivienda series (from 1987 to 1994) and the growth rates of the interpolated Tecnigrama series (from 1975 to 1986) to extend the Ministerio de Fomento series to the first quarter of 1975.

The source of the historical house price series has changed. This affects the 2014 second quarter release and all subsequent updates. From the first quarter of 1975 to the last quarter of 1986, we now use the average price series based on mortgage loan data from the Instituto Nacional de Estadística facilitated by Paloma Taltavull de La Paz (University of Alicante). This series closely matches the Ministerio de Fomento data during the period in which the two sources overlap. The average mortgage loan series better reflects underlying changes in house prices nationwide in the 1970s and early 1980s than the series from Tecnigrama, which only includes prices for Madrid. It is calculated as the total amount of mortgage loans in euros divided by the number of loans.

The house price series are not seasonally-adjusted by the source. We seasonally-adjust the complete series using the BSTS model and then transform the series into an index with a base year 2005=100. We deflate this house price series using the Personal Consumption Expenditure (PCE) deflator. To construct the PCE deflator, we use the quarterly PCE deflator obtained from the OECD National Accounts database, which started in 1995. A change in the quarterly PCE deflator reported in the OECD National Accounts database occurred in January 2012. This affects our calculations for the February 2012 update and further updates. The change consists of a shortening of the quarterly PCE deflator series, which now starts in 2000 instead of 1995. To

\footnotetext{
${ }^{25}$ Backcasting is the process of extrapolating into the past the trends present in the current data. We rely on backcasting to complete missing series only when the missing data does not exceed one year and we could not find alternative sources to extend the series back to 1975. Prior to the third quarter of 2012 release, backcasting was computed with an AR(3) model.
} 
extend this series we take the annual PCE deflator from the OECD Economic Outlook database, which spans from 1960 to the present, and interpolate the series to a quarterly frequency using the quadratic-match average method. We then use the resulting growth rates to extend the quarterly PCE deflator obtained from the OECD National Accounts database back to the first quarter of 1975.

We complete the Spanish data by reporting personal disposable income (PDI) on a per capita basis. Before we were using the sum of private consumption expenditure, household savings and change in equity in pension fund reserves from the OECD Economic Outlook database. We also used interpolated working-age population series obtained from the OECD Economic Outlook database. The source of the PDI and working age population data has changed, affecting the PDI per capita series in the 2012 first quarter update and all subsequent updates. Gross disposable income and consumption of fixed capital for households is collected from Eurostat. Both series are reported at a quarterly frequency and begin in 2000. Consumption of fixed capital is subtracted from gross disposable income series to produce PDI. The series is largely influenced by seasonal factors, so we use the BSTS model in state-space form to identify and systematically extract the seasonal and excessively volatile components of the data.

To extend the PDI series to 1975 we use the net disposable income series from the OECD Outlook 70 database, which is reported at an annual frequency. We interpolate to a quarterly frequency using the quadratic-match average method. The resulting quarterly growth rates are used to extend the series. Current working age population data is now obtained from the OECD Main Economic Indicators database. It is reported at a quarterly frequency and begins in the first quarter of 1999. We use the quarterly growth rates of the discontinued working age population series from the OECD Outlook 90 database to extend the series to the first quarter of 1975 . We divide the spliced PDI series by the extended working-age population series to obtain a nominal PDI per capita series. We use the PCE deflator to express the PDI per capita series in real terms. Both nominal and real PDI measures are re-based to 2005=100.

\section{References:}

"Basic Aspects of the Methodological Design of the Housing Price Index in Spain.”

Martínez Pagés and Maza (2003): “Análisis del Precio de la Vivienda en España (Analysis of House Prices in Spain).”

Taltavull de La Paz (2014): "Vivienda y Crecimiento. Una Mirada Retrospectiva a la Formación del Mercado de la Vivienda en España (Housing and Economic Growth. Looking Back to Housing Market Formation in Spain).”

Information Resources:

Bank of Spain Data

http://www.bde.es/webbde/en/estadis/infoest/s16-nm.pdf

Eurostat Data

http://epp.eurostat.ec.europa.eu/portal/page/portal/statistics/search_database

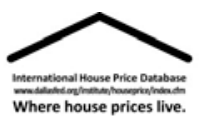


Acknowledgements: Paloma Taltavull de La Paz from the University of Alicante and Jorge Martínez Pagés and Juan Ayuso Huertas from the Bank of Spain. 


\section{国 FI - Finland}

Statistics Finland publishes a nationwide house price index for existing, single-family dwellings. Price data is collected from asset transfer statements that are compiled by the National Board of Taxes. The data that is first published for a given quarter is preliminary and represents approximately two thirds of the total transactions for that period, though coverage varies by area. This data is revised with the publication of the following quarter. Prices are expressed on a persquare meter basis and quoted in euros. Data prior to 1999 has been converted to Euros using the irrevocable exchange rate of 5.94573 Finnish markka per euro. A dwelling refers to a room or suite of rooms that is equipped with a kitchen, kitchenette or cooking area and is intended for year-round habitation. An existing dwelling refers to a dwelling that has been completed prior to one year before the examined year. A price index on new dwellings did not become available until 2005.

Statistics Finland combines hedonic and mix-adjusted methods. The mix-adjustment method cannot control for all changes in the quality of dwellings sold. Quality adjustments are achieved by grouping dwellings by similar characteristics, but adding groups causes the number of observations to decline. Hedonic regressions can be used with a broad based grouping of dwellings to control for the varying dwelling characteristics that remain. Dwellings are first grouped by type, number of rooms and location, as these characteristics are thought to be the biggest determinants of price. A hedonic regression is then used to estimate the price index of each group, with the base period of 1985 used as a reference for dwelling characteristics. Each index is then weighted by the value of the dwelling stock. Data for the dwelling stock is obtained through the Population Register Centre's register of buildings and dwellings.

The time series was revised retrospectively from the beginning of 2005 to take into account the changes in municipalities that took place in 2009. Improvements in the management of registers also contributed to an increase in the number of dwelling transactions used in the statistics since 2005. The index is reported at a quarterly frequency and begins in the first quarter of 1985.

To extend the series, we use the nationwide house price index for existing apartments (flats) per square meter. This index is also produced by Statistics Finland, using the same hedonic and mixadjusted method; however, the base year for this index is 1970. Also, all prices from 1970 to 1986 (including the index on single-family houses) are based on information from real estate agents, which lacks the classification detail that the tax statements offer. Starting in 1987, all price data is based on tax transfer statements. Prices are expressed on a per-square meter basis and quoted in Euros. Data prior to 1999 has been converted to Euros using the irrevocable exchange rate of 5.94573 markka per euro. We splice the single-family dwelling series with the growth rates of the series for existing flats to extend the series back to the first quarter of 1975.

The house price series are not seasonally-adjusted by the source. We seasonally-adjust the spliced series using the BSTS model and re-base it to $2005=100$. We deflate this house price series using the Personal Consumption Expenditure (PCE) deflator obtained from the OECD Economic Outlook database.

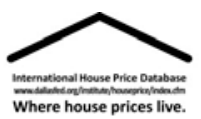


We complete the Finnish data with data on personal disposable income (PDI) reported in per capita terms. We used the interpolated PDI and working-age population from the OECD Economic Outlook database. The source of the current PDI and working age population data has changed, affecting the PDI per capita series in the 2012 first quarter update and all subsequent updates. Gross disposable income and consumption of fixed capital for households is collected from Eurostat. Both series are reported at a quarterly frequency and begin in 1999. Consumption of fixed capital is subtracted from gross disposable income series to produce PDI. The series is largely influenced by seasonal factors, so we use the BSTS model in state-space form to identify and systematically extract the seasonal and excessively volatile components of the data.

To extend the PDI series to 1975 we use the net disposable income series from Statistics Finland, which is reported at an annual frequency. We interpolate to a quarterly frequency using the quadratic-match average method. The resulting quarterly growth rates are used to extend the series. Current working age population data is now obtained from the OECD Main Economic Indicators database. It is reported at a quarterly frequency and begins in the first quarter of 1998. We use the quarterly growth rates of the discontinued working age population series from the OECD Outlook 90 database to extend the series to the first quarter of 1975. We divide the PDI series by the quarterly working-age population series to create the nominal PDI per capita series. We use the PCE deflator to report the PDI per capita in real terms. Both nominal and real PDI measures are re-based to $2005=100$.

\section{References:}

Saarnio (2006): “Housing Price Statistics at Statistics Finland.”

\section{Information Resources:}

Statistics Finland Data

http://www.stat.fi/til/ashi/2011/02/ashi_2011_02_2011-07-

29_laa_001_en.html\#2.Methodologicaldescription

Statistics Finland Data

http://193.166.171.75/database/StatFin/kan/vtp/vtp_en.asp

Eurostat Data

http://epp.eurostat.ec.europa.eu/portal/page/portal/statistics/search_database

Acknowledgements: Petri Kettunen from Statistics Finland. 


\section{Ш FR - France}

The Institut National de la Statistique et des Études Économiques (INSEE) produces a nationwide house price index for all types of existing dwellings (detached houses and apartments). ${ }^{26}$ The index is calculated using the hedonic method, where the price of each dwelling is defined by a combination of a fixed number of characteristics, such as location and quality of the dwelling. Dwelling prices are quoted in Euros. Mix-adjustment techniques are also implemented, as dwellings are grouped in zones where prices are more homogeneous and price evolutions are roughly parallel. In each group a reference stock of dwellings is created from all dwellings sold during 1998-2001. Price data for dwellings sold within a current period is adjusted to be representative of the dwelling characteristics in the reference stock, capturing the price movements of a fixed set of dwellings regardless of whether they have been sold at a given date. Data is reported at a quarterly frequency and begins in the first quarter of 1996.

To extend the data, we use a nationwide house price index produced by the Conseil Général de l'Environnement et du Développement Durable (CGEDD) for existing apartments and individual houses. ${ }^{27}$ The CGEDD series is reported at an annual frequency, and constructed using the repeat sales method prior to 1999. Under the repeat sales method used until 1999, apartments included in the index must have been sold more than once, since the method compares a dwelling's most recent (current) transaction price with its previous transaction price. Only existing apartments that were more than 5 years old at the time of the previous transaction were included. Dwelling prices are quoted in Euros, using the irrevocable exchange rate of 6.55957 francs per euro. After 1999, annualized values of the quarterly INSEE index are used in the CGEDD series. We interpolate the annual CGEDD series at quarterly frequency with the quadratic-match average method and use its growth rates to extend the quarterly INSEE series.

A change in the quarterly house price index produced by the INSEE occurred in Q3 2011. This affects our calculations for the February 2012 update and future updates. The index is now reported with a base on the first quarter $2010=100$. The house price series are not seasonallyadjusted by the sources. We seasonally-adjust the spliced series using the Census X-12 multiplicative method and re-base it to $2005=100$. We deflate this house price series using the Personal Consumption Expenditure (PCE) deflator from the OECD Economic Outlook database.

We complete the French data with data on personal disposable income (PDI) reported on a per capita basis. We obtained an extended PDI and working age population series from the OECD Economic Outlook database. The source of the current PDI and working age population data has changed, affecting the PDI per capita series in the 2012 first quarter update and all subsequent updates. Gross disposable income for households is obtained from INSEE and consumption of fixed capital for households from Eurostat. Both series are reported at a quarterly frequency. The gross disposable income series begins in 1949, and the consumption of fixed capital series begins

\footnotetext{
${ }^{26}$ A single-family dwelling refers to housing intended to be occupied by a single household, and consists usually of just one dwelling unit. A detached house or dwelling refers to a house that does not share an inside wall with any other dwelling. It, therefore, excludes dwellings such as duplexes, linked houses (semi-detached) as well as all terraced houses (row houses) and most apartment blocks (where each building unit can be assigned to a singlefamily but the entire building can hold multiple single-family units).

${ }^{27}$ CGEDD falls under the jurisdiction of the Ministry of Ecology, Sustainable Development, Transport and Housing (French: Ministère de l'Écologie, du Développement Durable, des Transports et du Logement, MEDDTL).
} 
in 1980 as of the 2016 first quarter update (previously 1999). To extend the consumption of fixed capital series, we computed the difference between the gross measure from INSEE and the net measure from the OECD. Annual data from the OECD Outlook 79 database (from 1975-1977) was spliced with annual data from the OECD Outlook 86 database (from 1978-1998). The spliced annual series was interpolated to a quarterly frequency using the quadratic-match average method. This interpolated series was subtracted from the gross disposable income, and the resulting series was used to extend the consumption of fixed capital data from Eurostat. The extended consumption of fixed capital series was subtracted from gross disposable income series to produce net PDI. The source of the historical PDI data has changed, affecting the 2015 third quarter update and all subsequent updates. We now use an annual consumption of fixed capital series from the OECD before 1980 (1999 before the 2016 first quarter update). The data starts in 1978, and since we could not find reliable data to extend the series backwards, we had to make an exception and backcast three years of data. The resulting series is interpolated to a quarterly frequency and subtracted from the gross disposable income series to produce net PDI.

All quarterly data comes seasonally adjusted from the source. Current working age population data is now obtained from the OECD Main Economic Indicators database. It is reported at a quarterly frequency and begins in the first quarter of 2003. We use the quarterly growth rates of the discontinued working age population series from the OECD Outlook 90 database to extend the series to the first quarter of 1975 . We divide this extended series by the quarterly workingage population taken from the OECD Economic Outlook database to obtain a nominal PDI per capita. We use the PCE deflator to express the series in real terms. Both nominal and real measures are re-based to $2005=100$.

\section{References:}

Gouriéroux and Laferrère (2006): "Managing Hedonic Housing Price Indexes: The French Experience."

\section{Information Resources:}

INSEE Data

http://www.indices.insee.fr/bsweb/servlet/bsweb?action=BS_RECHGUIDEE\&BS_IDARBO=05 $\underline{000000000000}$

Note on base change: http://www.insee.fr/fr/indicateurs/ind96/prixloge_m.pdf

CGEDD Data (contains long-historical series as well)

http://www.cgedd.developpement-durable.gouv.fr/rubrique.php3?id_rubrique=137

Eurostat Consumption of Fixed Capital Data

http://epp.eurostat.ec.europa.eu/portal/page/portal/statistics/search_database

Acknowledgements: Jacques Friggit from CGEDD. 
Before 2012, the Department of Communities and Local Government produced a nationwide house price index for all types of dwellings, new and existing (Table 590, 592). In 2012 the production of the house price series was transferred to the Office of National Statistics (ONS). Nationwide refers to the United Kingdom of Great Britain and Northern Ireland. The index was constructed using the mix-adjusted method. Dwellings were grouped based on age, location, and type of dwelling. The average price for each group was determined by completed mortgages. The groups were then weighted according to the number of transactions over the previous three years, using a Laspeyres index. Sales data was gathered from the Land Registry. Weights were recalculated every year, so the index was annually chained linked.

Data was collected from banks and building societies through the Regulated Mortgage Survey. Prior to 1992, survey participants only included building societies. This was extended as larger building societies converted into banks. The ONS index represents all completed mortgages of survey participants. Prior to 2005, participants did not report $100 \%$ of mortgage completions. A 5\% representative sample was submitted until 2001. Select lenders then started reporting all completions, which were incorporated in the index starting in 2003. Starting with the second quarter of 2002, the quarterly index was calculated from the average of the monthly mix-adjusted series. Data is reported quarterly from the second quarter of 1968 through the first quarter of 2016.

The source of the current house price data has changed. The new series is based on the "UK House Price Index (HPI),” starting with the April 2016 release. The UK HPI series combined and came to replace the previous house price indices that were separately published by the Land Registry and the ONS with data going back to 2005. The UK HPI is jointly produced by the Land Registry, Land and Property Services Northern Ireland, ONS, and Registers of Scotland. The new monthly HPI is hedonic and mix-adjusted, using additional property attributes data, such as floor space of a property, that make it more consistent with international best practices as defined by Eurostat. This affects the 2016 second quarter release and all subsequent updates.

To extend the UK HPI data from 2005 back to 1975, we splice the current HPI with growth rates of the previous ONS series that goes back to 1968. None of the house price series are seasonallyadjusted by the source. We seasonally-adjust the series using the BSTS model and re-base it to 2005=100. We deflate this house price series using the Personal Consumption Expenditure (PCE) deflator obtained from the OECD Economic Outlook database.

We complete the United Kingdom data by including personal disposable income (PDI) series reported on a per capita basis. We created a net household disposable income series using the gross household disposable income series from the OECD Economic Outlook database less an extended consumption of fixed capital from the IMF International Financial Statistics (IFS) database. The working age population series was obtained from the OECD Economic Outlook database. The source of the current household disposable income and working age population data changed, affecting the PDI per capita series in the 2012 first quarter update and all subsequent updates. Gross disposable income for households is obtained now directly from the United Kingdom's Office of National Statistics. The series is reported at a quarterly frequency 
beginning in the first quarter of 1955. Consumption of fixed capital for households was also obtained from the United Kingdom's Office of National Statistics. This series is annual and begins in 1948. We interpolated this annual series to a quarterly frequency, using the quadraticmatch average method. We subtracted the interpolated consumption of fixed capital series from the gross disposable income series to create PDI.

Since the consumption of fixed capital series was released annually, at least four quarters would elapse if we waited for the official data publication. To avoid this lag and make the public release of the data timelier, we nowcasted the annual series one year ahead using the BSTS model to add one extra observation that could be jointly interpolated. The quarterly estimates obtained using interpolated nowcasts were subsequently replaced as the official annual data became publicly available.

The source of the consumption of fixed capital data has changed again. Starting in 1999, the PDI series is constructed using quarterly consumption of fixed capital data from Eurostat. This affects the 2014 second quarter release and all subsequent updates. We use the interpolated consumption of fixed capital series from the ONS to extend the data back to 1975.

Current working age population data is now obtained from the OECD Main Economic Indicators database. It is reported at a quarterly frequency and begins in the second quarter of 1999. We use the quarterly growth rates of the discontinued working age population series from the OECD Outlook 90 database to extend the series to the first quarter of 1975. We divide the net PDI by the quarterly working-age population series, producing a nominal PDI series in per capita terms. We use the PCE deflator to express the series in real terms. Both nominal and real PDI measures are indexed to $2005=100$.

\section{Information Resources:}

UK House Price Index Data

https://www.gov.uk/government/collections/uk-house-price-index-reports https://www.gov.uk/government/publications/about-the-uk-house-price-index/about-the-ukhouse-price-index https://www.ons.gov.uk/economy/inflationandpriceindices/articles/explainingtheimpactofthenew ukhousepriceindex/may2016

https://www.ons.gov.uk/economy/inflationandpriceindices/methodologies/developmentofasingle officialhousepriceindex

Department of Communities and Local Government Data https://www.gov.uk/housing-market-and-house-price-information-notes-and-definitions

Office for National Statistics (ONS) Data

http://www.ons.gov.uk/ons/datasets-and-tables/index.html

Eurostat Data

http://epp.eurostat.ec.europa.eu/portal/page/portal/statistics/search_database 


\section{EHR - Croatia}

The Croatian National Bank (CNB) produces a nationwide house price index for all types of dwellings. Data on real estate transactions are obtained from Burza Nekretnina (Real Estate Exchange Database), an association of real estate agencies. In addition to a dwelling's (asking and received) price, Burza Nekretnina collects data on its location (region, county, part of city/town) and characteristics (floor area, number of rooms, date of construction, dwelling type). This data is combined to produce a hedonic house price index, controlling for varying dwelling characteristics in the price fluctuations. Part of the fluctuations in dwelling prices can be attributed to varying dwelling characteristics, so abstracting from those produces a more economically-relevant measurement of house prices.

Dwellings are first grouped according to 4 sub-regions, thought to have similar characteristics: the City of Zagreb, the Adriatic Coast, Other urban areas and Other rural areas. Regression analysis is used to strip out the dwelling's price from the contribution of the floor space, the period in which a dwelling was sold, and the dwelling's characteristics and location within a region. Housing characteristics and location are held constant over time identifying the pure price component of housing (per square-meter) with the estimated coefficients of a dummy time variable, holding characteristics and location constant over time so that changes in the composition of the traded housing sample could not be confounded with the fundamental changes in house prices. This variant of the hedonic method is known as the time dummy index.

An index is computed for each region, then weighted by that region's share of total transactions. The City of Zagreb has the most transactions (receiving a 65\% percent share in the overall index), the majority of which (around 85\%) are for apartments. The Adriatic Coast represents $22 \%$ of the overall index, the other urban $8 \%$ and the other rural $5 \%$. Transactions are only for dwellings advertised by real estate agencies on Burza Nekretnina's internet site.

The CNB house price index from Burza Nekretnina is reported at a quarterly frequency, begins in the first quarter of 1997, and is constructed with all housing units (houses and apartments, old and used) included in the database.

The source of the current house price data has changed. Starting in 2008, the series is based on the house price index developed by the Croatian Bureau of Statistics in cooperation with the CNB. The CNB index was discontinued after the second quarter of 2015. This affects the 2016 first quarter release and all subsequent updates. Another quarter of data was added to the beginning of the new series, so it now starts in the fourth quarter of 2007. This affects the 2018 third quarter release and all subsequent updates. The new series and the previous CNB series both use the hedonic method. The new HPI series is based on a much more detailed and comprehensive database. It covers all data on dwelling transactions (houses and flats/apartments) on the territory of the Republic of Croatia that are registered on the basis of the Notification Real Estate Transfer Tax in the Tax Administration of the Ministry of Finance according to predefined deadlines. Weights are calculated using the prices of dwellings that were bought in the last quarter of the previous year. To extend the series back to the first quarter of 1975, we use the previous CNB series back to 1997 and a longer nationwide house price series produced by Yugoslavia's Federal Bureau of Statistics/Croatian Bureau of National Statistics that measures

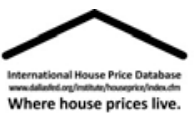


the average price per square meter for new dwellings. Price data for the longer historical series is based on the settled (instead of the asking) price, which is recorded for the purpose of assessing real estate transaction taxes. Only transactions conducted on the primary market (new construction) are included and out of these transactions only dwellings built by construction corporations are included. This series is reported at an annual frequency beginning in 1965, and remains to this day_although reported semi-annually since the 2000s.

The geographic coverage for this historical series prior to Croatia's independence from the former Yugoslavia corresponds with the present day boundaries for Croatia, so there is no break in coverage in this regard. House prices are quoted in Kuna-the current local currency unit of Croatia-beginning in 1993. House prices for prior periods are reported in the currency of the former Yugoslavia_-Dinars in 1965, Dinars (1:100 denomination relative to 1965) from 1966 till 1989, Dinars (1:1000 denomination relative to 1989) from 1990 till 1992, and Croatian Kuna (1:1000 denomination relative to 1992) until now.

In the former Yugoslavia (including Croatia), the real estate market was quite liberal during the 1965-1990 period. After the seventies, the majority of dwellings were built for the market. The historical series from Yugoslavia's Federal Bureau of Statistics is, therefore, somewhat unique because the former Yugoslavia allowed for transactions to be determined by market forces to an extent that is not seen in other former communist countries outside of Yugoslavia where the reported house prices were largely regulated/administered prices. To be sure, Croatia's housing market nowadays is significantly different than the one that operated during the Socialist period in Yugoslavia so naturally price measurements reflect the transformation underwent which we cannot correct for.

The annual historical time series is interpolated to a quarterly frequency using the quadraticmatch average method. However, due to the hyperinflation episode experienced by Yugoslavia from 1990, we interpolate the natural log of the house price index instead of the level to prevent the distortion caused by high inflation from resulting in counterfactual interpolated data (including negative observations). The subsequent quarterly growth rates are used to extend the current house price index back to the first quarter of 1975. The house price series are not seasonally-adjusted by the source. We seasonally-adjust the complete series using the BSTS model and then transform the series into an index with a base year 2005=100.

We deflate this house price series using the Personal Consumption Expenditure (PCE) deflator for Croatia. To re-construct the PCE deflator, we use the quarterly PCE deflator, produced by Eurostat, that begins in the first quarter of 2000. We extend this series using the annual PCE deflator, also produced by Eurostat, which begins in 1995. This series is spliced with the annual Retail Price Index, produced by the Croatian Bureau of National Statistics. The spliced annual series is interpolated to a quarterly frequency using the quadratic-match average method. However, due to the hyperinflation episode from 1990, we interpolate the natural log of the price index to prevent the distortion from creeping in. The subsequent quarterly growth rates are used to extend the current PCE deflator back to the first quarter of 1975.

We complete the Croatian data by reporting personal disposable income (PDI) on a per capita basis. The Croatian Bureau of National Statistics reports the average disposable income per 
household at an annual frequency beginning in 1998. To obtain a measure of total household disposable income, we estimate the number of households by dividing the consumption expenditures reported in the national accounts by the series of average consumption expenditures per household, then multiply the estimated number of households by the average disposable income per household. To extend the data back to 1975 we use net monthly earnings averaged at annual frequency from Yugoslavia's Federal Bureau of Statistics/Croatian Bureau of National Statistics.

Net earnings are compensation of employees excluding taxes and social and health insurance contributions, ${ }^{28}$ which are considered the best proxy available to measure the PDI given that generally it represents the largest source of household's disposable income. During the communist years, basically household disposable income was based on salaries, interests earned in banks, renting real estates and remittances from emigrants but no stocks or bonds-we have data on net salaries only. Data are reported at an annual frequency and represent annual averages of monthly net earnings for the entire household sector. The two annual series are spliced together, and the spliced annual series is interpolated to a quarterly frequency using the quadratic-match average method. However, due to the hyperinflation episode in the early 1990s, we interpolate the natural log of the income data to prevent the effects of the distortion.

Since the primary data on PDI is released annually, at least four quarters would elapse if we waited for the Croatian Bureau of National Statistics' official data release. To avoid this lag and make the public release of the Croatian data more timely, we nowcast the spliced annual series using the BSTS model to add one extra yearly observation that can be jointly interpolated to extend the series to the current quarter. The quarterly estimates obtained using interpolated nowcasts will be subsequently replaced as the official annual data becomes publicly available.

To report the PDI series on a per capita basis, we use data on working-age population published by the United Nations - Department of Economic and Social Affairs (Population Division). ${ }^{29}$ The series is produced at an annual frequency (while the OECD series that we use for reference in other countries tend to be reported quarterly). We interpolate the working-age population series to quarterly frequency using the quadratic-match average method.

The source of the current PDI has changed. This affects the PDI per capita series for the 2014 first quarter update and all subsequent updates. Net disposable income series for households and non-profit institutions serving households (NPISH) is collected from Eurostat. The series is annual and starts in 2002. We use the total available household income series to extend the data back to 1998 and the average monthly paid off net earnings to extend the data back to 1975.

\section{References:}

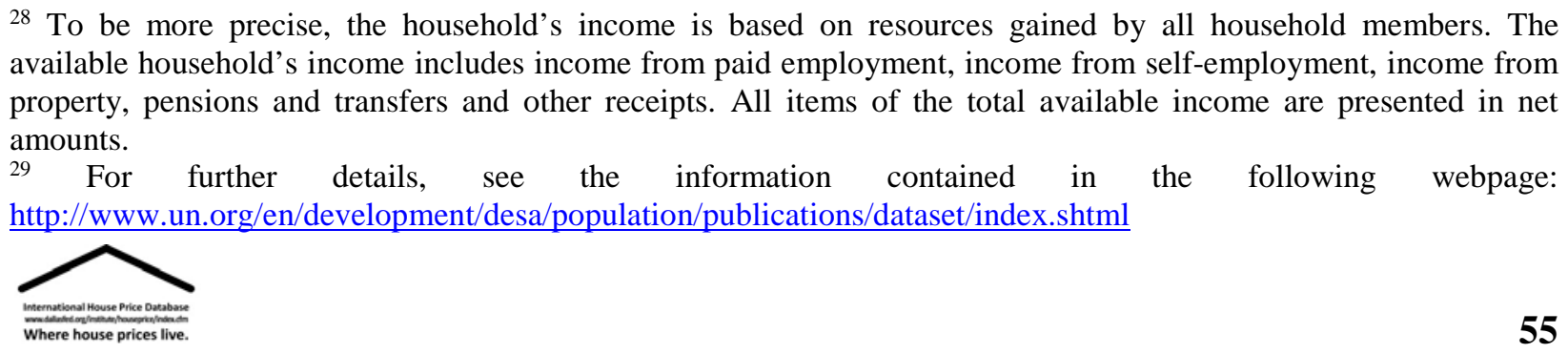


Kunovac et al. (2008): "Use of the Hedonic Method to Calculate an Index of Real Estate Prices in Croatia."

Nestić (2005): "Income Distribution in Croatia: What Do the Household Budget Survey Data Tells Us?”

Posedel and Vizek (2010): "The Nonlinear House Price Adjustment Process in Developed and Transition Countries.”

Information Resources:

Croatian Bureau of Statistics

http://www.dzs.hr/Hrv_Eng/publication/2012/03-01-05_02_2012.htm

http://www.dzs.hr/Hrv_Eng/publication/2013/09-01-01_07_2013.htm

http://www.dzs.hr/Hrv_Eng/publication/2015/13-01-02_01_2015.htm

Eurostat Data

http://epp.eurostat.ec.europa.eu/portal/page/portal/statistics/search_database

Acknowledgements: Prof. Josip Tica, University of Zagreb. 


\section{ए IE - Ireland}

The Department of State for Environment, Community and Local Government produces a nationwide house price series for all types of existing (second-hand) dwellings. The average price for houses and apartments is based on data supplied by mortgage lending agencies. The series is quoted in Euros. Data prior is converted to euros, using the irrevocable exchange rate of 0.787564 pounds per euro. Dwelling prices are determined from loans that have been approved by lending agencies, and not necessarily loans that have been paid. Prices reported by mortgage agencies are broken down by area. The aggregate series is constructed from an unweighted average of each area. The series is reported at a quarterly frequency going back to the first quarter of 1978 and at annual frequency going back to 1974. We interpolate the annual series for Ireland to a quarterly frequency with the quadratic-match average method and use its growth rates to extend the quarterly series back to the first quarter of 1975.

The Central Statistics Office (CSO) of Ireland produces a nationwide house price index for existing, single-family dwellings. The average price of a dwelling is determined by drawdown mortgage data supplied by eight of the main Mortgage Lending Institutions. ${ }^{30}$ It is estimated that this sample of mortgage data covers at least $75 \%$ of the housing market. The hedonic method is used to construct the index. This controls for movements in the price level attributed to location, building type, floor area, number of bedrooms and first time buyer. Prices are weighted based on transaction values during the previous year. Each month the weights are adjusted by the estimated change in average price, producing an annual chain-linked, Laspeyres-type index. The CSO index is reported at a monthly frequency and begins in January 2005. We average the monthly observations (using a simple arithmetic average) to obtain quarterly observations.

At the dataset update on the third quarter of 2013, the gap between the house price series produced by the department of Stat for Environment, Community and Local Government and the Central Statistics Office (CSO) of Ireland had become particularly significant. The fact that the Department of State for Environment, Community and Local Government is unweighted makes it very sensitive to changes in the volume and composition of houses traded. While we initially adopted this series as our series of reference for consistency purposes, we have decided to combine that series with the shorter one from the CSO in order to get a more consistent indicator of the pure price fluctuations in Ireland. We splice the Department of State for Environment, Community and Local Government quarterly series with the CSO index starting in the first quarter of 2005. The combined series in seasonally adjusted then rebased to 2005=100.

The house price series are not seasonally-adjusted by the source. We seasonally-adjust the spliced series using the BSTS model and transform it into an index with base year 2005 $=100$. We deflate this house price series using the Personal Consumption Expenditure (PCE) deflator. We use the current quarterly PCE deflator obtained from the OECD Economic Outlook database that begins in the first quarter of 1990. To extend the series we use the growth rates of an earlier quarterly PCE deflator series obtained from the OECD Economic Outlook 88 database.

\footnotetext{
${ }^{30}$ Under a drawdown mortgage structure, the borrower receives an initial lump sum payment that is smaller than the total loan amount. The borrower can make subsequent withdraws until the total loan amount is reached. Interest payments are made at the loan's expiration, allowing interest to compound; however, interest only accrues on the withdrawn portion of the loan.
}

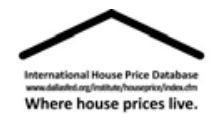


We complete the data for Ireland with data on personal disposable income (PDI) reported in per capita terms. To create the PDI series we employed the annual household disposable income series from the OECD Economic Outlook database extended back to 1975, to create a population series we use an extended working-age population series from the OECD Economic Outlook database. The source of the current PDI and working age population data has changed, affecting the PDI per capita series in the 2012 first quarter update and all subsequent updates. Gross disposable income and consumption of fixed capital for households is collected from Eurostat. Both series are reported at a quarterly frequency and begin in 2002. Consumption of fixed capital is subtracted from gross disposable income series to produce PDI. The series is largely influenced by seasonal factors, so we use a structural time series model in state-space form to identify and systematically extract the seasonal and excessively volatile components of the data. To extend the PDI series back to 1975, we use the annual disposable income series from the OECD Economic Outlook 70 database that starts in 1977 and two annual series obtained from Statistics Ireland-personal consumption of goods and services and personal savings - that both start in 1975. These two series from Statistics Ireland are added together to create a PDI measure proxy based on the main uses of the personal disposable income. This PDI measure is used to extend the OECD disposable income series. This extended annual series is interpolated and spliced with the current quarterly data.

Current working age population data is now obtained from the OECD Main Economic Indicators database. It is reported at a quarterly frequency and begins in the second quarter of 1999. To extend the current data, we use two annual series from Statistics Ireland-population of persons aged 15 and older and populations of persons aged 65 and older. We subtract the latter series from the former to create an annual working-age population series. This series is interpolated using the quadratic-match average method. The resulting quarterly growth rates are used to extend the current working-age population series back to the first quarter of 1975 . We divide the resulting PDI series by the working-age population series to create a nominal PDI per capita. We use the PCE deflator to express the series in real terms. Both nominal and real PDI measures are re-based to $2005=100$.

\section{Information Resources:}

The Department of State for Environment, Community and Local Government Data http://www.environ.ie/en/Publications/StatisticsandRegularPublications/HousingStatistics/

Central Statistics Office (CSO) of Ireland Data http://www.cso.ie/en/releasesandpublications/prices/ http://www.cso.ie/en/media/csoie/releasespublications/documents/prices/2012/rppi_dec2012.pdf

Eurostat Data

http://epp.eurostat.ec.europa.eu/portal/page/portal/statistics/search_database

Acknowledgements: Brian McCann from Ireland's Central Statistics Office. Malcolm Hillis from Ireland's Department of the Environment and Local Government. 


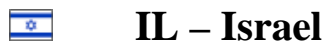

The Central Bureau of Statistics (CBS) of Israel produces an official monthly hedonic nationwide home price index starting in 1994. The Index of Prices of Dwellings is constructed using data from the Catalog of Real Estate Prices, a system through which information about purchases of dwellings is gathered by the Capital Gains Tax Bureaus throughout the country. These data on transactions include new dwellings and dwellings whose ownership changed. The sample consists of 67 urban localities which have: 1) 20,000 or more residents, 2) 5,000 or more dwellings, according to the inventory of dwellings in Israel as listed in the Municipal Taxation List, and 3) a reasonable number of transactions relative to the number of dwellings. The index excludes dwellings built by individuals, transactions performed through a group of buyers, transactions from public companies, and dwellings with no market value. The Index of Prices of Dwellings is calculated using a hedonic regression that considers the characteristics of the dwellings and adjusts for differences in their quality. We average the monthly observations (with a simple arithmetic average) to obtain quarterly observations.

In order to reflect house prices prior to 1994, we follow Dovman, Ribon, and Yakhin (2012) and splice the current Index of Prices of Dwellings with a historical monthly index from the CBS. Data on housing prices prior to 1994 is available through the Owner Occupied Housing Services Price Index. This index is a part of the CPI and until 1999 it was based on a measure of housing prices. ${ }^{31}$ The prices used in this index are adjusted for the quality and size of the home. We average the monthly observations (with a simple arithmetic average) to obtain quarterly observations.

We splice the series of the Index of Prices of Dwellings with the growth rates of the Owner Occupied Housing Services (OOHS) Price Index historical series. The house price series are not seasonally-adjusted by the source. We seasonally-adjust the spliced series using the BSTS model and re-base it to 2005=100. We deflate this house price series using the Personal Consumption Expenditure (PCE) deflator.

To construct the PCE deflator, we use quarterly data obtained from the OECD Economic Outlook database, which starts in 1995. To extend this OECD series, we use the growth rates from the quarterly PCE deflator series from the CBS, which spans from 1980 to the present. To extend the combined series back to 1975, we use the growth rates of the quarterly average of monthly CPI data from the CBS before 1980 . We seasonally-adjust the spliced series using the BSTS model and re-base it to $2005=100 .^{32}$

We complete the Israeli data by including a personal disposable income (PDI) series, reported in per capita terms. To create the PDI per capita series we divide household disposable income by the working-age population. Annual PDI data is obtained from the CBS as net private disposable

\footnotetext{
31 Since 1999 the Owner Occupied Housing Services (OOHS) Price Index is based on data on renewed rent contracts.

32 The Hebrew calendar does not overlap with the Gregorian calendar. For this reason holidays in Israel fall on different Gregorian dates each year (for example, Passover typically falls in March or April). This "problem" of moving holidays for seasonal adjustment is less relevant for the quarterly data that we report.
} 
income, rather than personal disposable income, which includes undistributed profits. ${ }^{33}$ For 1995 to the present, we use the System of National Accounts 2008 (SNA 2008) data from the CBS. To extend the PDI series, we use the growth rates of the SNA 1968 data from the CBS to get the PDI series back to 1974 (since we lose three quarters in the interpolation process from annual to quarterly). The PDI is derived using annual data, hence we use the BSTS model to nowcast one extra annual observation, which can be jointly interpolated. Nowcasted values will be subsequently replaced as soon as the official yearly data becomes available. The smoothed series is then interpolated to a quarterly frequency using the cubic-match last procedure. The interpolated series is then divided by the working-age population to get a per capita series and re-indexed to $2005=100$.

We obtain working-age population data at a quarterly frequency from the OECD starting in 1995. To extend the series back to 1975, we interpolate the annual working-age population series from the United Nations to a quarterly frequency using the quadratic-match average procedure. These series are spliced together using the growth rates of the interpolated historical series. We use the PCE deflator to report the PDI series in real terms. Both nominal and real measures are re-based to $2005=100$.

\section{References:}

Dovman, Ribon, and Yakhin (2012): "The Housing Market in Israel 2008-2010: Are House Prices a 'Bubble'?”

\section{Information Resources:}

Israeli Central Bureau of Statistics Data

http://www.cbs.gov.il/ts/databank/databank_main_func_e.html

Israeli Central Bureau of Statistics Methodology

http://www1.cbs.gov.il/www/price_new/a1_3_e.pdf

Acknowledgements: Itamar Caspi and Sigal Ribon from the Bank of Israel.

\footnotetext{
${ }^{33}$ Data on personal disposable income (PDI) from the CBS is unavailable for the moment.
} 


\section{Ш IT - Italy}

The Italian research institute Nomisma produces a house price series based on all types of dwellings, new and existing. Only dwellings located in 13 main metropolitan areas are included (Bari, Bologna, Cagliari, Catania, Firenze, Genova, Milano, Napoli, Padova, Palermo, Roma, Torino and Venetia). The series is semi-annual, collected in May and October from a sample of real estate agencies. Dwellings are grouped by type and location within a city. Prices for each group are reported per square meter and represent the average sale price. Dwelling prices are quoted in Euros, using the fixed conversion rate with the Lire prior to 1999. These prices are then weighted according to the groups' location within each city. The 4 locations (and weights) are luxury areas (1/15), town center (2/15), between town center and outskirts (4/15), and outskirts (8/15). The 13 cities are aggregated using population weights from the 1982 Census.

To obtain data prior to 1988, we gather data from the "Annuario immobiliare" published by the Il Consulente Immobiliare for the same 13 cities. Il Consulente Immobiliare is maintained by the Italian business newspaper Il Sole 24 Ore. The prices (per-square-meter) refer to new dwellings only. Dwellings are grouped by their location within the city. No aggregation is made by the Il Consulente Immobiliare, so we apply the Nomisma approach to combine the price data within each city. We select the same 13 metropolitan areas that are included in the Nomisma series. Since no distinction is made for dwellings located in luxury areas, we distribute the luxury area weight equally among the three remaining areas resulting in the following weight distribution: town center (7/45), between the town center and outskirts (13/45), and outskirts (25/45). We then calculate a weighted average of the 13 cities using 1982 population data for each city, published by the national statistics office. Data is reported in Italian lire at a bi-annual frequency from 1967 to 2001 and in Euros at annual frequency from 2002 to 2009. We convert the averaged bi-annual series to Euros, using the irrevocable exchange rate of 1936.27 Lire per euro.

The series from Il Consulente Immobiliare is interpolated to a semi-annual frequency with the quadratic-match average method and spliced with the semi-annual Nomisma series. This spliced semi-annual series is then interpolated to a quarterly frequency using the quadratic-math average method. The house price series are not seasonally-adjusted by the sources. We seasonally-adjust the interpolated and spliced series using the BSTS model and transform the series to an index with base year $2005=100$.

Since the primary data is released semi-annually, at least two quarters would elapse before there is sufficient information to include all countries in the database. To avoid this lag and make the public release of the data more timely, we nowcast the spliced semi-annual series for Italy one period ahead, using the BSTS model that can be jointly interpolated with the actual data ${ }^{34}$. The quarterly estimates obtained using interpolated nowcasts will be subsequently replaced as the official Nomisma semi-annual data becomes publicly available. We deflate this house price series using the Personal Consumption Expenditure (PCE) deflator obtained from the OECD Economic Outlook database.

We complete the Italian data with personal disposable income (PDI) reported in per capita terms. The interpolated PDI and working age population series came from the OECD Economic

\footnotetext{
${ }^{34}$ Prior to the third quarter of 2012 release, nowcasting was computed with an AR(2) model.
}

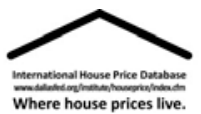


Outlook database. The source of the current PDI and working age population data has changed, affecting the PDI per capita series in the 2012 first quarter update and all subsequent updates. Gross disposable income and consumption of fixed capital for households is collected from Eurostat. Both series are reported at a quarterly frequency since 1999. Consumption of fixed capital is subtracted from gross disposable income to produce PDI. The series is largely influenced by seasonal factors, so we use the BSTS model to identify and systematically extract the seasonal and excessively volatile components of the data. To extend the PDI series to 1975 we use the net disposable income series from the OECD Outlook 86 database, which is reported at an annual frequency. We interpolate to a quarterly frequency using the quadratic-match average method. The resulting quarterly growth rates are used to extend the series.

Current working age population data is now obtained from the OECD Main Economic Indicators database. It is reported at a quarterly frequency and begins in the first quarter of 1998 . We use the quarterly growth rates of the discontinued working age population series from the OECD Outlook 90 database to extend the series to the first quarter of 1975. We use the PCE deflator to report the nominal PDI per capita in real terms. Both nominal and real PDI measures are rebased to $2005=100$.

\section{References:}

Cannari et al. (2006): "House Prices in Italy: The Statistics Used at the Bank of Italy." Il Consulente Immobiliare (2010): "Valori Immobiliari. February 2010.”

\section{Information Resources:}

Bank of Italy Data

http://www.bancaditalia.it/statistiche;internal\&action=_setlanguage.action?LANGUAGE=en

Nomisma Data (in Italian)

http://www.nomisma.it/

Il Sole 24 Ore Data (in Italian)

http://www.immobili24.ilsole24ore.com/

Population Data

http://demo.istat.it/dat81-91/PROVIN/Index.htm

Eurostat Data

http://epp.eurostat.ec.europa.eu/portal/page/portal/statistics/search_database

Acknowledgements: Silvio Contessi from the Federal Reserve Bank of St. Louis. Piera Perin from Il Sole 24 Ore S.p.A. 


\section{JP - Japan}

The Ministry of Land, Infrastructure, Transport and Tourism (MLIT) in Japan produces a nationwide residential property price index for new and existing, single-family (detached) houses based on transaction data. The data includes transactions between private bodies and excludes transactions with public bodies. The pure price series is calculated with the hedonic method, which adjusts for variation in quality of individual properties. The index is reported at a monthly frequency and starts in April 2008, indexed to 2010=100. We use the index aggregated into a quarterly frequency by taking the arithmetic mean of the corresponding months. The house price series is not seasonally-adjusted by the source. We seasonally-adjust the data using the BSTS model. We began using this data in the 2018 first quarter release.

To extend the data back to 1975, we splice the MLIT house price index with growth rates of the nationwide, residential urban land price index dating back to 1955 published by the Japan Real Estate Institute (JREI). Prior to the 2018 first quarter release, we relied exclusively upon the JREI data to construct our index for Japan. It is based on appraisals of residential urban land, where the market value is determined as if the land was vacant. The index is based on the average price change of three appraisals made according to urban area rankings (superior, average and inferior). Residential land located in a "medium" neighborhood from each rank is appraised. Thus, mix-adjusted techniques are used in the construction of this index. Prices are reported per-square-meter in an attempt to control for changes in price that are associated with varying plot size. The index is published at a semi-annual frequency, updated at the end of March and the end of September. The index is calculated by multiplying the index of the preceding period by the average percentage change during the subsequent half a year. We interpolate the semi-annual series using the quadratic-match average method to obtain a consistent quarterly series for Japanese house prices.

Prior to the 2018 first quarter release, since the primary data for the JREI is released semiannually, at least two quarters would have elapsed before there was sufficient information to include all countries in the database. To avoid this lag and make the public release of the data timelier, we nowcasted the semi-annual series for Japan one period ahead using the BSTS model. ${ }^{35}$ The quarterly estimates obtained using interpolated nowcasts were subsequently replaced as the official semi-annual JREI data became publicly available. We re-base the spliced index to 2005=100 and deflate this house price series using the Personal Consumption Expenditure (PCE) deflator obtained from the OECD Economic Outlook database.

We complete the Japanese data by including a personal disposable income (PDI) series, reported in per capita terms. Household disposable income and working-age population were obtained from the OECD Economic Outlook database. The source of the PDI series and the working age population data have changed. This affects the PDI per capita series for the 2012 first quarter update and all subsequent updates. The PDI series is obtained from the Japanese Cabinet Office. It is reported at a quarterly frequency beginning in 2001, but it is only updated annually. The series is largely influenced by seasonal factors, so we use the BSTS model in state-space form to identify and systematically extract the seasonal and excessively volatile components of the data. The same BSTS model is used to estimate quarterly values in between the annual updates, which

${ }^{35}$ Prior to the third quarter of 2012 release, nowcasting was computed with an AR(3) model.

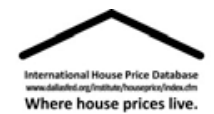


are subsequently replaced after actual data becomes available. The series is extended by the PDI series obtained from the OECD Outlook 91 database. Working age population data are now obtained from the OECD Main Economic Indicators database. The series is reported at a monthly frequency beginning in January of 1970, which we average to a quarterly frequency. We use the PCE deflator to report the PDI series in real terms. Both nominal and real PDI measures are re-based to $2005=100$.

Information Resources:

Japan Real Estate Institute Data

http://www.reinet.or.jp/en/index.html

Ministry of Land, Infrastructure, Transport and Tourism Data

http://www.mlit.go.jp/toukeijouhou/chojou/stat-e.htm

http://www.mlit.go.jp/common/001194770.pdf

http://tochi.mlit.go.jp/english/index.html

Japan Cabinet Office Data

http://www.esri.cao.go.jp/en/sna/data/kakuhou/files/2010/24annual_report_e.html

Acknowledgements: Chikako Baba from the IMF and Yodo Masato from the Japanese Ministry of Land, Infrastructure, Transport and Tourism. 


\section{KR - South Korea}

The Bank of Korea publishes a nationwide house price index for all types of dwellings, new and existing, produced by the Kookmin Bank. The Kookmin Bank is a descendant of the Korean Housing Bank (KHB). The KHB was privatized after the 1997 crisis in South Korea, and it merged to become the Kookmin Bank in 2001. The mix-adjustment/stratification method is used to construct the Kookmin Bank index. Dwellings are grouped according to location and type. Three types of dwellings are identified: detached dwellings, row houses (terraced houses) and apartments. The average purchase price for each group is then determined using real estate survey data. The dwelling stock from June 2011 is used as the base weight. The Kookmin Bank data starts in January 1986 and is released monthly. We average the monthly observations (with a simple arithmetic average) to obtain quarterly observations.

In order to reflect house prices prior to 1986, we splice the current Kookmin Bank house price series with a historical annual index documented by Kyung-Hwan Kim (1993). The data reported in Kim (1993) is constructed by combining three separate annual price indexes published by the KHB. The house price index for 1982-1990 is based on information provided by real estate agents, based on actual transactions and estimated prices. Neither the property type nor the vintage could be determined from the source. The index for 1978-1981 is based on the KHB standard construction cost, excluding land. The index for 1974-1977 is a weighted average of the total factor construction cost (including land) for single-family dwellings and apartments. The priced unit for both construction cost series could not be determined from the source. We interpolate this series at quarterly frequency using the quadratic-match average method.

We splice the Kookmin Bank series with the growth rates of the interpolated historical series from Kyung-Hwan Kim (1993). The house price series are not seasonally-adjusted by the source. We seasonally-adjust the spliced series using the BSTS model and re-base it to $2005=100$. We deflate this house price series using the Personal Consumption Expenditure (PCE) deflator obtained from the OECD Economic Outlook database.

We complete the South Korean data by including a personal disposable income (PDI) series, reported in per capita terms. To create the PDI per capita series we divide household disposable income by the working-age population. Both series were available at a quarterly frequency and obtained from the OECD Outlook database. A change in the quarterly PDI series obtained from the OECD Economic Outlook database occurred in December 2011. This affects our calculations for the February 2012 update and all future updates. The series is now reported at an annual frequency.

The source of the PDI data and working age population data has changed. This affects the PDI per capita series for the 2012 first quarter update and all subsequent updates. PDI data is now obtained from the Bank of Korea. The series is reported at an annual frequency and begins in 1975. Current working age population data is now obtained from the OECD Main Economic Indicators database. It is reported at a quarterly frequency and begins in the first quarter of 2003. We use the quarterly growth rates of the discontinued working age population series from the OECD Outlook 90 database to extend the series to the first quarter of 1975.

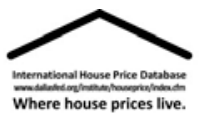


We use the PCE deflator to report the PDI series in real terms. Both nominal and real measures are re-based to $2005=100$. Since the PDI per capita is now derived using annual data on household disposable income, we use the BSTS model to nowcast one extra annual observation, which can be jointly interpolated. Nowcasted values will be subsequently replaced as soon as the official yearly data becomes available. We use the same approach in subsequent updates of the dataset.

References:

Kim (1993): “Housing Prices, Affordability and Government Policy in Korea.”

Information Resources:

KB Financial Group Inc. (formerly Kookmin Bank Corp.)

https://www.kbfg.com/Eng/Report/Fbannual/Kbfg/2012/list.jsp

Bank of Korea (Economic Statistics System database, ECOS)

http://ecos.bok.or.kr/EIndex_en.jsp

Acknowledgements: Joong-Shik Kang from the IMF. 


\section{$\Xi \quad$ LU - Luxembourg}

The data for Luxembourg was added to the database in the 2012Q1 release. House price data comes from l'Observatoire de l'Habitat, which produces a nationwide house price index for new and existing single-family dwellings. Prices are determined through newspaper and select internet advertisements. The mix-adjustment method is used to construct the index. Dwellings are grouped by number of bedrooms and weighted by market representation. The index is quarterly and starts in the first quarter of 2005.

To extend the index to the first quarter of 1975, we use the annual index produced by the Central Bank of Luxembourg. This series has nationwide coverage and includes data on all types (singlefamily houses, apartment and apartment buildings) of new and existing dwellings. Prices are derived from transactions recorded by l'Administration de l'Enregistrement et des Domaines (AED). We interpolate this annual series to a quarterly frequency using the quadratic-match average method and extend the current series with the resulting quarterly growth rates.

Neither house price series is seasonally-adjusted by the source. We seasonally-adjust the spliced series using a BSTS model then re-base it to $2005=100$. We deflate this house price series using the Personal Consumption Expenditure (PCE) deflator. To construct the PCE deflator, we use quarterly data obtained from Eurostat, which starts in 1995. To extend this Eurostat series we use the annual PCE deflator from the OECD Economic Outlook database, which spans from 1960 to the present. We interpolate this series to a quarterly frequency using the quadratic-match average method. We then use the resulting quarterly growth rates to extend the PCE deflator from Eurostat back to the first quarter of 1975.

The time coverage of Luxembourg's personal disposable income (PDI) data is limited. PDI is reported for Luxembourg by Eurostat, from 2006 to 2009. Therefore, we rely on a combination of data from Luxembourg and Belgium to infer a PDI series for Luxembourg since 1975:

First step: Compute Net National Disposable Income for Luxembourg since $1975^{36}$. Luxembourg's national measure of disposable income is used to compute a PDI estimate. National disposable income data is published by Eurostat starting in 1995. To extend the series back to 1975, we start with Gross National Income (GNI) for Luxembourg, which is an annual series obtained from OECD national accounts beginning in 1970. By definition, national disposable income equals national income plus net factor income from abroad. Lacking data on net factor income from abroad for Luxembourg, we proxy national disposable income using Belgium data. We compute the ratio of gross national disposable income to GNI for Belgium. Both Belgium series are obtained from OECD national accounts, reported at an annual frequency and beginning in 1970. Then, GNI for Luxembourg is multiplied by the Belgium ratio to compute an adjusted measure of gross national disposable income. We subtract consumption of fixed capital (which is an annual series obtained from the OECD national accounts beginning in 1970) to convert the gross measure to a net measure.

Second step: Compute the ratio of Personal Disposable Income (PDI) to Net National Disposable Income (NDI).

${ }^{36}$ Net National Disposable Income equals National Income plus Net Current Transfers from the rest of the world.

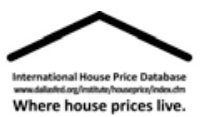


The PDI data from Eurostat only covers the 2006-2009 period, so the PDI/Net National Disposable Income ratio can only be computed between 2006 and 2009. To extend the PDI/NDI ratio for Luxembourg we compute the same ratio for Belgium. Household disposable income data is obtained from Statistics Belgium and the OECD Outlook 86 database and NDI data is obtained from the current OECD national accounts database for Belgium. Both series are annual and begin in 1970. We use the Belgium PDI/NDI ratio to extend the ratio for Luxembourg both forwards and backwards.

Third step: Multiply the PDI/NDI ratio with the Net National Disposable Income.

This extended PDI/NDI ratio for Luxembourg is finally multiplied by the extended National Disposable Income series described in step one in order to compute a proxy for the PDI series of Luxembourg.

Since the PDI series we construct here is based on annual data, at least four quarters would elapse if we waited for the official data publication. To avoid this lag and make the public release of the data timelier, we use a structural time series model to add one extra yearly observation that can be jointly interpolated. The quarterly estimates obtained using interpolated nowcasts will be subsequently replaced as the official annual data become publicly available. We interpolate our estimate of the PDI of Luxembourg to a quarterly frequency using quadratic-match average. Since Belgium data is used to construct the Luxembourg PDI series when data is not available, we also apply a 4 quarter centered moving average to smooth some of the kinks that may appear in the data. The PDI series that we report for Luxembourg should be viewed as merely indicative at this stage, and will be replaced as soon as an official (publicly available) PDI series is found.

To compute the PDI per capita series we divide the PDI by the working-age population. For 2007 onwards the working-age population data is obtained from the most recent OECD Main Economic Indicators database. We use the quarterly growth rates of the discontinued OECD Outlook 90 database to extend the series to 1975. The PDI per capita series is rebased to $2005=100$.

\section{Information Resources:}

l'Observatoire de l'Habitat Data (in French) http://observatoire.ceps.lu/index.cfm?pageKw=serie3

Banque Centrale du Luxembourg - Methodology (in French) http://www.bcl.lu/fr/publications/bulletins_bcl/Bulletin_BCL_2011_3/Bulletin_BCL_2011_3.pd $\underline{\mathrm{f}}$

Acknowledgments: Claude Lamboray from STATEC (Institut National de la STATistique et des Études ÉConomiques du Luxembourg). 


\section{NL - Netherlands}

Statistics Netherlands publishes a nationwide house price index for existing, single-family dwellings dating back to 1995. The index is calculated using the sales price appraisal ratio (SPAR) method. A dwelling's appraisal value is determined by tax records and is paired with the dwelling's transaction price. The index is weighted by the value of housing stock indicated by the appraisal value in the base year of 2005. The ratio of sales price to appraisal value is recorded for all dwellings sold during the base year. This serves as the denominator for the index. For all dwellings sold during a current period, a ratio of their current sales price to base year appraisal value is determined. This serves as the numerator. The sales price and appraisal value for each dwelling are first summed and then the ratio of the sums is calculated, making it a valueweighted index. The index is reported at monthly frequency, and we average it (with a simple arithmetic average) to obtain quarterly observations.

To extend the data prior to January 1995, we splice the Statistic Netherland index with the nationwide house price index produced by the Kadaster-The Dutch Land Registry. The Kadaster index measures prices for all types of existing dwellings. Since January 1992, it is constructed using the repeat sales method. Data prior to 1992 is based on a series produced by the Netherlands' Association of Real Estate Brokers and Real Estate Experts (Nederlandse Vereniging van Makelaars, NVM) and represents the median selling price of dwellings sold exclusively by NVM agents (which on average are more expensive). The Kadaster extended its repeat sales index by interpolating the NVM data with a constant factor then splicing the resulting series. The NVM-Kadster index is reported monthly, starting in January 1976. We average the full monthly index (with a simple arithmetic average) to obtain quarterly observations from the first quarter of 1976 until the present. We then fit a BSTS model to the data, which we use to backcast observations for the four quarters of $1975 .{ }^{37}$ We use the growth rates implied by the backcasted estimates and the NVM-Kadatser series to extend the current series from Statistics Netherlands back to the first quarter of 1975.

The house price series are not seasonally-adjusted by the source. We seasonally-adjust the spliced series using the BSTS model and re-base it to 2005 $=100$. We deflate this house price series using the Personal Consumption Expenditure (PCE) deflator obtained from the OECD Economic Outlook database.

We complete the data for the Netherlands data by including personal disposable income (PDI) reported in per capita terms. We used an interpolate PDI series and a working age population series from the OECD Economic Outlook database. The source of the current PDI and working age population data has changed, affecting the PDI per capita series in the 2012 first quarter update and all subsequent updates. Gross disposable income and consumption of fixed capital for households is collected from Eurostat. Both series are reported at a quarterly frequency and begin in 2005. Consumption of fixed capital is subtracted from gross disposable income series to produce PDI. The series is largely influenced by seasonal factors, so we use the BSTS model in state-space form to identify and systematically extract the seasonal and excessively volatile components of the data.

${ }^{37}$ Prior to the third quarter of 2012 release, backcasting was computed with an AR(2) model.

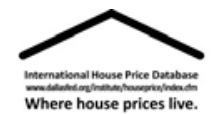


To extend the PDI series back to 1975 we use the net disposable income series from the OECD Outlook 86 database, which is reported at an annual frequency. We interpolate to a quarterly frequency using the quadratic-match average method. The resulting quarterly growth rates are used to extend the Eurostat series. Current working age population data is now obtained from the OECD Main Economic Indicators database. It is reported at a quarterly frequency and begins in the first quarter of 2000. We use the quarterly growth rates of the discontinued working age population series from the OECD Outlook 90 database to extend the series to the first quarter of 1975.

To compute the PDI per capita series we divide the PDI by the working-age population. We deflate this series with the PCE deflator to obtain PDI per capita in real terms. Both nominal and real measures are re-based to $2005=100$.

\section{References:}

van der Wal, ter Steege, and Kroese (2006): "Two Ways to Construct a House Price Index for the Netherlands: The Repeat Sales and the Sales Price Appraisal Ratio.”

\section{Information Resources:}

Statistics Netherlands Data

http://www.cbs.nl/NR/rdonlyres/A49D8542-26EC-40FD-9093-

82A519247F4B/0/MethodebeschrijvingPrijsindexBestaandeKoopwoningene.pdf

Kadaster Data

http://www.kadaster.nl/window.html?inhoud=/english/

Nederlandse Vereniging van Makelaars (NVM) Data

http://nieuws.nvm.nl/over_nvm/english.aspx

Eurostat Data

http://epp.eurostat.ec.europa.eu/portal/page/portal/statistics/search_database 


\section{NO - Norway}

Statistics Norway publishes a nationwide house price index for existing, detached houses. The index is constructed using the hedonic method with mix-adjustment techniques. Regression analysis is used to describe the relationship between a dwelling's market price and its individual characteristics. The hedonic model used by Statistics Norway includes a limited number of explanatory variables. No attempt is made to adjust for a dwelling's quality or age, only dwelling size and location factor into pricing estimates. To account for this limitation, mix adjustment techniques are used. Dwellings are first divided by type and price level, and regression analysis for each group of dwellings is performed. The price (per dwelling) is estimated relative to base year characteristics. Each group is weighted by the value of the housing stock. The base year is updated in the second quarter of every year, forming an annually chain-linked index. Starting in 2012, the series excludes sales of new dwellings, which make up between 1-3 percent of the observations.

The weighting scheme has undergone revisions. From 1997 to 2002, the total housing stock was used to weight the index. From 1992 to 1997, the number of sales transactions was used as a weight. There have also been revisions to the sources of data. Prior to 2002, Statistics Norway obtained price data from two different sources, the Ground Property, Address and Building (GAB) Register and a questionnaire distributed directly to the contractors. The house price index is now based on data obtained through FINN.no, which gathers data from multiple real estate agencies: the Norwegian Association of Real Estate Agents (NEF), the Association of Real Estate Undertakings (EFF), and the Norwegian Federation of Cooperative Housing Associations (NBBL). This allows more transactions to be included in the calculation of the index, and a more timely release of the index.

The Statistics Norway house price index is reported at a quarterly frequency and begins in the first quarter of 1992. To extend the data, we use a house price series put together for the Norges Bank's RIMINI model of the Norwegian economy and obtained upon request. The Norges Bank data is itself a compilation of four nationwide house price indexes. From 1987-2004, it corresponds to the house price index constructed by the Norges Eindomsmeglerforbund (NEF) real estate agency, based on voluntary reports of real estate agents regarding sales of dwellings. From 1984-1986, the index uses data gathered by the GAB register. From 1979-1983 the series uses the price index for building costs compiled by Statistics Norway. From 1972-1978, this series is constructed using the deflator for the housing rent component of the CPI.

The house price series are quarterly, but not seasonally-adjusted by the different sources. We splice the Statistics Norway house price series using the growth rates from the Norges Bank series. We seasonally-adjust the spliced series method BSTS model and re-base it to 2005=100. We deflate this house price series using the Personal Consumption Expenditure (PCE) deflator obtained from the OECD Economic Outlook database.

We complete the Norwegian data by including personal disposable income (PDI) reported in per capita terms. We originally used interpolated PDI data and working age population data from the OECD Economic Outlook database. The source of the current PDI and working age population data changed, affecting the PDI per capita series in the 2012 first quarter update and all 
subsequent updates. Net disposable income data for households is collected from Statistics Norway. The series is reported at a quarterly frequency starting in 2002. The series is largely influenced by seasonal factors, so we use the BSTS model in state-space form to identify and systematically extract the seasonal and excessively volatile components of the data..

We use two annual series to extend the PDI series from Statistics Norway back to 1975. From 1978 to 2001 we use the net disposable income series from Statistics Norway. From 1975 to 1977 we use the net disposable income series from the OECD Outlook 86 database. The two annual series are spliced together. This spliced series is then interpolated to a quarterly frequency using the quadratic-match average method. The resulting quarterly growth rates are used to extend the series.

Current working age population data is now obtained from the OECD Main Economic Indicators database. It is reported at a quarterly frequency and begins in the first quarter of 2000. We use the quarterly growth rates of the discontinued working age population series from the OECD Outlook 90 database to extend the series to the first quarter of 1975. To compute the PDI per capita series we divide the PDI by the working-age population. We use the PCE deflator to report PDI per capita in real terms. Both nominal and real PDI measures are re-based to $2005=100$.

\section{References:}

Brodin (1989): "Mikrokonsumfunksjonen i Rikmod. (Micro-Consumption Function in Rikmod).”

\section{Information Resources:}

Statistics Norway Data http://www.ssb.no/english/subjects/08/02/30/nos_d372_en/nos_d372_en.pdf http://www.ssb.no/vis/bpi_en/about.html

http://www.ssb.no/knri_en/

http://www.ssb.no/nri_en/

Norges Bank Data

http://www.norges-bank.no/en/price-stability/historical-monetary-statistics/house-price-indicies/

Acknowledgements: Oyvind Eitheim from the Norges Bank and Ragnar Nymoen from the University of Oslo. 


\section{NZ - New Zealand}

The Reserve Bank of New Zealand publishes a nationwide house price index for new and existing, detached houses. ${ }^{38}$ The index is produced using data provided by Quotable Value Limited (QV), a state-owned enterprise that collects all data based on territorial authorities' recorded sales prices and property valuations. The Reserve Bank of New Zealand uses this data to construct a house price index following the sales price appraisal ratio (SPAR) method.

The collective sales price of all dwellings sold during a period is divided by their collective appraisal value, which is equivalent to weighting the individual ratios by the value of dwelling stock. The current base period is the fourth quarter of 2003. The methodology for calculating the index changed in the third quarter of 2004. Prior to this date, the aggregated sales price appraisal ratio was weighted by a moving average of sales price data from previous periods. Now the weights correspond to those of the base period, the fourth quarter of 2003.

The transaction data obtained from QV is available from the 1980s onwards, but data that complies with the current standards of the Reserve Bank of New Zealand is only available since 1995. Therefore, to extend the QV series the Reserve Bank of New Zealand performs backdating estimations to produce data prior to the third quarter of 1995 . The house price index is reported at a quarterly frequency.

The house price series is not seasonally-adjusted by the source. We seasonally-adjust the series using the BSTS model and re-base it to $2005=100$. We deflate this house price series using the Personal Consumption Expenditure (PCE) deflator obtained from the OECD Economic Outlook database.

We complete the New Zealand data by including personal disposable income (PDI) reported on a per capita basis. An annual household disposable income series is obtained through Statistics New Zealand. This series is available starting in 1978. To extend the series we use historical data on household disposable income obtained from the OECD Economic Outlook 71 database. The extended annual series is interpolated using the quadratic-match average method. Statistics New Zealand began publishing household disposable income data at a quarterly frequency since 2013. This is incorporated in the release for the first quarter of 2013 and all subsequent updates. The quarterly series begins in the fourth quarter of 1998 and is seasonally adjusted by the source. We use the spliced and interpolated annual series to extend the current series back to the first quarter of 1975.

To create nominal PDI per capita, we divide the resulting PDI series by the quarterly workingage population series. We obtained working age population from the OECD Economic Outlook database before. The source of the working age population data has changed, affecting the PDI per capita series in the 2012 first quarter update and all subsequent updates. Current working age population data is now obtained from the OECD Main Economic Indicators database. It is reported at a quarterly frequency and begins in the first quarter of 1986. We use the quarterly growth rates of the discontinued working age population series from the OECD Outlook 90

${ }^{38}$ The Reserve Bank of New Zealand uses the term detached house to differentiate these single-family dwellings from apartments and flats.

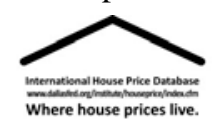


database to extend the series to the first quarter of 1975. We use the PCE deflator to report PDI per capita in real terms. Both nominal and real PDI measures are re-based to $2005=100$.

Information Resources:

Reserve Bank of New Zealand Data

http://www.rbnz.govt.nz/keygraphs/Fig4.html

Reserve Bank of New Zealand - Methodology on old and new house price index http://www.rbnz.govt.nz/keygraphs/1697975.html

Reserve Bank of New Zealand - Description of backdating estimation method http://www.rbnz.govt.nz/keygraphs/1689413.html

Statistics New Zealand PDI Data

http://rbnz.govt.nz/statistics/az/2989610.html 
Statistics Sweden publishes a nationwide house price index for new and existing, one- and twofamily dwellings. This includes detached houses, terraced houses and linked buildings. The index is constructed by first grouping dwellings by similar characteristics, implementing a mixadjustment technique. However, the main method of index construction is the sales price appraisal ratio (SPAR) method. Since the SPAR method does not control for the compositional changes of dwellings sold, mix-adjustment techniques are combined with the SPAR method. Dwellings are first grouped according to type and location, then the ratio of the average sales price and average appraisal value is computed for each group.

In Sweden, appraisal data is provided by the official real estate registry. This is used to group dwellings by assessed value and region. Appraisal data is then coupled with current transaction data, to produce a ratio of the average sale price and average appraisal value for each dwelling group. Dwelling stock is used to weight each ratio. Dwellings are re-appraised each year, which creates an annually chain-linked index (Laspeyres). An annual index is available from 1975 onwards, and a quarterly index is available beginning in the first quarter of 1986. We interpolate the annual index at quarterly frequency using the quadratic-match average method and use the resulting growth rates to extend the current quarterly series back to the first quarter of 1975 .

The house price series is not seasonally-adjusted by the source. We seasonally-adjust the series using the BSTS model and re-base it to 2005=100. We deflate this house price series using the Personal Consumption Expenditure (PCE) deflator obtained from the OECD Economic Outlook database.

We complete the data for Sweden by including a personal disposable income (PDI) series, reported in per capita terms. To create this per capita series, we used the PDI and working age population series from the OECD Economic Outlook database. The source of the current PDI and working age population data changed, affecting the PDI per capita series in the 2012 first quarter update and all subsequent updates. Net disposable income data for households was collected from Statistics Sweden, reported at a quarterly frequency starting in 1993. The source has changed again for the current PDI data, affecting the PDI per capita series in the 2013 second quarter update and all subsequent updates. Gross disposable income and consumption of fixed capital for households are now collected from Eurostat. Both series are reported at a quarterly frequency and began in 1999 until the 2017 third quarter update. Starting with the 2017 third quarter update, the series start in the first quarter of 1980. Consumption of fixed capital is subtracted from the gross disposable income series to produce PDI. The series is largely influenced by seasonal factors, so we use a structural time series model in state-space form to identify and systematically extract the seasonal and excessively volatile components of the data.

To extend the PDI series back to 1975 we use the net disposable income series from the OECD Outlook 86 database, which is reported at an annual frequency. We interpolate it to a quarterly frequency using the quadratic-match average method. The resulting quarterly growth rates are used to extend the current series. Current working age population data is now obtained from the OECD Main Economic Indicators database as of the 2012 first quarter update. It is reported at a quarterly frequency and begins in the first quarter of 2001. We use the quarterly growth rates of 
the discontinued working age population series from the OECD Outlook 90 database to extend the series to the first quarter of 1975.

To calculate the per capita series, we divide the PDI by the working-age population. We use the PCE deflator to report the PDI per capita in real terms. Both nominal and real PDI measures are re-based to $2005=100$.

Information Resources:

Statistics Sweden Data (in Swedish)

http://www.scb.se/Statistik/BO/BO0501/2011K01/BO0501_2011K01_SM_BO40SM1102.pdf

Eurostat Data

http://epp.eurostat.ec.europa.eu/portal/page/portal/statistics/search_database 
The Federal Housing Finance Agency (FHFA) publishes a nationwide house price index for existing, single-family dwellings (formerly called OFHEO house price index). Prices are measured with mortgage data provided by the Federal National Mortgage Association (Fannie Mae) and the Federal Home Loan Mortgage Corporation (Freddie Mac)—based on conforming, conventional mortgages that are purchased or securitized. "Conforming" refers to mortgages that meet the underwriting guidelines of Fannie Mae and Freddie Mac and do not exceed the conforming loan limit set by the Federal Housing Financial Board. "Conventional" refers to mortgages that are neither insured nor guaranteed by a government entity. The index is constructed using the repeat sales method, which documents changes in market prices using dwellings sold more than once-meaning that the FHFA price index measures average price changes in repeat sales or refinancing on the same properties.

Dwellings sold within a sample period are pooled together, and a univariate dummy regression model is postulated to explain the price changes between the sales transactions. The FHFA weighted repeat sales method attempts to control for price changes that occur with renovation and depreciation, and also attempts to lessen the price variance associated with infrequent transactions. The FHFA series is reported quarterly going back to 1975 . The house price series is not seasonally-adjusted by the source. We seasonally-adjust the series using the BSTS model and re-base it to $2005=100$. We deflate this house price series using the Personal Consumption Expenditure (PCE) deflator obtained from the OECD Economic Outlook database.

We complete the data for the United States by including a personal disposable income (PDI) series, reported in per capita terms. The PDI and working age population series came from the OECD Economic Outlook database. The source of the PDI and working age population has changed. This affects the PDI series for the 2012 first quarter update and all subsequent updates. We use personal disposable income for the household sector (including NPISHs) published by the Bureau of Economic Analysis (BEA). This series is reported at a quarterly frequency starting in 1947 and seasonally adjusted by the source. Current working age population data is now obtained from the Bureau of Labor statistics (BLS). This series is reported at a monthly frequency beginning in 1948. Working age is defined as 16 years and older in the U.S., while the series used for most other countries includes 15-64 years old. We take the monthly averages to express the working-age population series at a quarterly frequency. To create the PDI per capita series we divide the PDI by the working-age population. We use the PCE deflator to report the PDI in real terms. Both nominal and real measures are indexed to 2005=100.

\section{Information Resources:}

Federal Housing Finance Agency (FHFA) House Price Data

http://www.fhfa.gov/default.aspx?page $=84$

Bureau of Economic Analysis (BEA) PDI Data

http://www.bea.gov/iTable/index_nipa.cfm

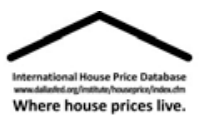




\section{$\exists \quad$ ZA - South Africa}

The data for South Africa was added for the first time in the release corresponding to the first quarter of 2012. Before the 2017 second quarter release, all house price data came from ABSA Group Limited (formerly Amalgamated Banks of South Africa Limited), which produced a nationwide house price index for new and existing, single-family dwellings. In this index, house prices are based on loans approved by ABSA and represent the total purchase price of a house. To create the index, houses are first grouped according to size: small (80-140 square meters), medium (141-220 square meters), and large (221-400 square meters). The three indexes are computed individually, and then weighted by the volume of approved loan applications during the current period. Dwellings sold for over 3.6 million Rand are excluded from the index. This cutoff point has been revised over the years to account for house price growth and consumer price inflation. In 2011, the cutoff point was 3.5 million rand. In 2010, it was 3.1 million rand.

The index is reported at monthly frequency and starts in January 1966. We transform the index to a quarterly frequency by taking the arithmetic mean of the corresponding months, starting in the first quarter of 1975 . The house price index is seasonally adjusted by the source using the X11 method.

The source of the current house price data has changed. Starting in 2001, the series is based on the house price index developed by South Africa's First National Bank (FNB). The ABSA index was discontinued after November 2016. This affects the 2017 second quarter release and all subsequent updates. The FNB series is based on transaction price data from homes financed by FNB. The minimum size cut-off for full title stands (plots of lands) is 200 square meters, and the maximum size is 4000 square meters. The minimum price cut-off is 20,000 rand, and the maximum price cut-off is 10 million rand. Until the 2018 second quarter release, the FNB House Price Index was compiled from 18 sub-segment average house price time series. The 5-year moving average of the sub-segments' volumes was used to weight them to limit the impact of transaction volume shifts across segments. Starting with the 2018 second quarter release, FNB's preferred index methodology is repeat sales instead of stratified mean. The index is reported at a monthly frequency and starts in January 2001. We use the index aggregated into a quarterly frequency by taking the arithmetic mean of the corresponding months. The index is very lightly smoothed by the source using a Hodrick-Prescott smoothing function with a lambda of 5 . We retain the ABSA series to extend the quarterly series before 2001 . We re-base the spliced index to $2005=100$ and deflate this series using the personal consumption expenditure (PCE) deflator obtained from the South African Reserve Bank.

We complete the data for South Africa by including a personal disposable income (PDI) series, reported in per capita terms. We use household disposable income data published by the South African Reserve Bank. The series is reported at a quarterly frequency and begins in the first quarter of 1960. This series is seasonally adjusted by the source. Current working age (15-64) population data is obtained from Statistics South Africa. The series is reported at a quarterly frequency starting in the first quarter of 2008. To extend this data we use an annual working age population series obtained from the United Nations (U.N.), where working age population is also defined as those aged 15-64. We interpolate the U.N. annual series to a quarterly frequency using quadratic-match average and use the resulting quarterly growth rates to extend the OECD series 
back to the first quarter of 1975 . Then, we divide PDI by working age population to create a PDI per capita measure. We use the PCE deflator obtained from the South African Reserve Bank to report the PDI in real terms. The series is reported at a quarterly frequency and begins in 1960. Both nominal and real measures are indexed to $2005=100$.

Information Resources:

FNB Methodology

https://blog.fnb.co.za/wp-content/uploads/2016/08/FNB-Property-

Barometer_FNB_HPI_Methodologies_2_Aug_2016.pdf

ABSA Group Limited Data

http://www.absa.co.za/Absacoza/Economic-Research/Property-Research

Reserve Bank of South Africa Data

http://www.resbank.co.za/Research/Statistics/Pages/OnlineDownloadFacility.aspx

Acknowledgements: Jacques Du Toit from ABSA Group Limited. 


\section{Bibliography}

Abelson, Peter and Demi Chung (2005): "The Real Story of Housing Prices in Australia from 1970-2003.” Australia Economic Review 39:265-281.

André, Christophe (2010): “A Bird's Eye View of OECD Housing Markets.” OECD Working Paper No. 746.

Australian Bureau of Statistics (2006): “A Guide to House Price Indexes: Australia 2006.” Paris.

Australian Bureau of Statistics (2009): "House Price Indexes: Concepts, Sources and Methods, Australia.”.

(http://www.ausstats.abs.gov.au/Ausstats/subscriber.nsf/0/ADD9C64F4B4E7DD4CA257 6890007E7B6/\$File/64640_2009.pdf).

Baltagi, Badi H. (2008): Econometric Analysis of Panel Data. John Wiley \& Sons.

Baxter, Michael A. (1998): "Interpolating Annual Data into Monthly or Quarterly Data." GSS Methodology Series No. 6, Office for National Statistics.

Bian, Timothy Y. and Pedro Gete (2014): "What Drives Housing Dynamics in China? A Sign Restrictions VAR Approach.” Mimeo, Georgetown University.

Brodin, Anders (1989): "Mikrokonsumfunksjonen i Rikmod.” Arbeidsnotat 1989/1. Oslo: Norges Bank.

Cannari, Luigi, Ivan Faiella, Roberto Sabbatini, and Francesco Zollino (2006): "House Prices in Italy: The Statistics Used at the Bank of Italy.” Paris.

Chamberlin, Graeme (2010): "Methods Explained: Temporal Disaggregation.” Economic and Labor Market Review 4(11):106-121.

Chow, G. C. and A. Lin (1971): "Best Linear Unbiased Interpolation, Distribution and Extrapolation of Time Series by Related Series." Review of Economics and Statistics 53:372-375.

Danmarks Nationalbank (2003): “MONA - A Quarterly Model of the Danish Economy.” Information Desk, Havnegade 5, DK-1093, Copenhagen K. (http://www.nationalbanken.dk/C1256BE9004F6416/side/CF0EF4908189F49AC1256E3 C0036A030/\$file/mona_web_UK.pdf).

Davis, Morris A. (2010): "Housing and the Business Cycle." in The New Palgrave Dictionary of Economics. Online Edition. Palgrave Macmillan.

Davis, Morris A. and Jonathan Heathcote (2005): "Housing and the Business Cycle." International Economic Review 46(3):751-784.

Denton, F. T. (1971): "Adjustment of Monthly or Quarterly Series to Annual Totals: An Approach Based on Quadratic Minimization.” Journal of the American Statistical Association 66:92-102.

Dovman, Polina, Sigal Ribon, and Yossi Yakhin (2012): "The Housing Market in Israel 20082010: Are House Prices a 'Bubble'?” Israel Economic Review 10(1):1-38.

European Commission (2011): "Handbook on Residential Property Prices Indices." Eurostat. Retrieved December 1, 2013 (http://epp.eurostat.ec.europa.eu/portal/page/portal/hicp/methodology/owner_occupied_h ousing_hpi/rppi_handbook).

Eurostat. (2012): Detailed Technical Manual on Owner-Occupied Housing for Harmonised Index of Consumer Prices. Eurostat - European Commission. (http://epp.eurostat.ec.europa.eu/portal/page/portal/hicp/methodology/hps/owner_occupie d_housing). 
Eurostat; International Labour Organization; International Monetary Fund; Organisation for Economic Co-operation and Development; United Nations Economic Commission for Europe; World Bank. (2013): Handbook on Residential Property Prices Indices (RPPIs). Belgium: $\quad$ Eurostat - $\quad$ European Commission. (http://epp.eurostat.ec.europa.eu/portal/page/portal/product_details/publication?p_product _code=KS-RA-12-022).

Girouard, Nathalie, Mike Kennedy, Paul van den Noord, and Christophe André (2006): "Recent House Price Developments: The Role of Fundamentals.” OECD Economics Department Working Paper No. 475.

González Veiga, Ignacio (2006): "Basic Aspects of the Methodological Design of the Housing Price Index in Spain.” Paris.

Gouriéroux, Christian and Anne Laferrère (2006): "Managing Hedonic Housing Price Indexes: The French Experience.” Paris.

Greville, T.N.E. (1967): “Spline Functions, Interpolation, and Numerical Quadrature.” in Mathematical Methods for Digital Computers. New York: Wiley.

Harvey, Andrew C. (1989): Forecasting, Structural Time Series Models and the Kalman Filter. Cambridge: Cambridge University Press.

Hoffman, Johannes and Andreas Lorenz (2006): "Real Estate Price Indices in Germany: Past, Present and Future.” Paris.

Igan, Deniz and Prakash Loungani (2012): “Global Housing Cycles.” International Monetary Fund Working Paper 12/217.

Il Consulente Immobiliare (2010): “Valori Immobiliari. February 2010.”.

Joensen, Joen (2006): “Danish Real Estate Price Indexes and Their Principal Users.” Paris.

Kim, Kyung-Hwan (1993): "Housing Prices, Affordability and Government Policy in Korea.” Journal of Real Estate Finance and Economics 6(1):55-72.

Kunovac, Davor, Enes Đozović, Gorana Lukinić, and Andreja Pufnik (2008): "Use of the Hedonic Method to Calculate an Index of Real Estate Prices in Croatia." Croatian National Bank Working Papers W-19. (http://www.hnb.hr/publikac/istrazivanja/w019.pdf).

Martínez Pagés, Jorge and Luis Á. Maza (2003): “Análisis del Precio de la Vivienda en España (Analysis of House Prices in Spain).” Documento de Trabajo del Banco de España $n^{o}$ 0307.

(http://www.bde.es/webbde/SES/Secciones/Publicaciones/PublicacionesSeriadas/Docum entosTrabajo/03/Fic/dt0307.pdf).

Martínez-García, Enrique (2014): “An Application of the Basic Structural Time Series Methodology for Seasonal Adjustment.” Federal Reserve Bank of Dallas, Mimeo.

Mead, Charles I., Clinton P. McCully, and Marshall B. Reinsdorf (2003): "Income and Outlays of Households and of Nonprofit Institutions Serving Households.” Survey of Current Business 13-17. (www.bea.gov/scb/pdf/2003/04April/0403household.pdf).

Mead, Charles I., Karin E. Moses, and Brent R. Moulton (2004): "The NIPAs and the System of National Accounts.” Survey of Current Business 17-32. (https://www.bea.gov/scb/pdf/2004/12December/1204_NIPA\&SNA.pdf).

Nestić, Danijel (2005): "Income Distribution in Croatia: What Do the Household Budget Survey Data Tells Us?” Financial Theory and Practice 29(1):39-53.

OECD (2005): “III. Recent House Price Developments: The Role of Fundamentals.” OECD Economic Outlook No. 78 OECD Publishing.

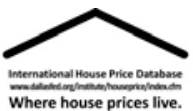


Orlik, Thomas. (2012): Understanding China's Economic Indicators: Translating the Data into Investment Opportunities. Upper Saddle River, New Jersey: Pearson Education LTD.

Posedel, Petra and Maruška Vizek (2010): "The Nonlinear House Price Adjustment Process in Developed and Transition Countries.” Ekonomski Institut Zagreb (EIZ) Working Papers 1001.

Saarnio, Mikko (2006): "Housing Price Statistics at Statistics Finland.” Paris.

Seskin, Eugene P. and Robert P. Parker (1998): "A Guide to the NIPA's." Survey of Current Business 26-68. (http://bea.gov/scb/account_articles/national/0398niw/maintext.htm).

Taltavull de La Paz, Paloma (2014): "Vivienda y Crecimiento. Una Mirada Retrospectiva a la Formación del Mercado de la Vivienda en España." in Ensayos sobre Economía Española (Homenaje al Profesor José Luis García Delgado), edited by J.A. Alonso and R. Myro. Madrid: Thomson-Reuters.

van der Wal, Erna, Dick ter Steege, and Bert Kroese (2006): "Two Ways to Construct a House Price Index for the Netherlands: The Repeat Sales and the Sales Price Appraisal Ratio.” Paris.

Working, H. (1960): "Note on the Correlation of First Differences of Averages in a Random Chain.” Econometrica 28(4):916-918.

Wu, Jing, Yongheng Deng, and Hongyu Liu (2012): "House Price Index Construction in the Nascent Housing Market: The Case of China." National University of Singapore, IRES2011-017. 


\section{Appendix A. Summary of the National Sources of House Price Data}

\section{Table A.1 Summary of the National Sources of House Price Data}

House Price Definition

AU - Australia

$\square$ BE - Belgium

- CA - Canada

$+\mathrm{CH}$ - Switzerland

DE - Germany

† DK - Denmark

$\square$ ES - Spain

四 FI - Finland

Ш FR - France
$\mathrm{AU}^{\mathrm{c}}$ - Weighted average of 8 capital cities, new and existing detached house price index, per dwelling $A U^{\mathrm{h}}$ - Weighted average of 6 capital cities, new and existing dwelling price index, per dwelling

$\mathrm{BE}^{\mathrm{c}}$ - Nationwide existing single-family

house price index, per dwelling

$\mathrm{CA}^{\mathrm{c}}$ - 11 metropolitan areas, new and existing single-family house price index, per dwelling $\mathrm{CA}^{\mathrm{h}}$ - 10 metropolitan areas, "fair" price of existing detached bungalows and two story executive dwellings, per dwelling

$\mathrm{CH}^{\mathrm{c}}$ - Nationwide new and existing single-family house price index, per dwelling

$\mathrm{DE}^{\mathrm{c}}$ - Nationwide existing dwelling price index, pure price

$\mathrm{DE}^{\mathrm{h} 1}$ - Nationwide existing terraced house price index, per dwelling

$\mathrm{DE}^{\mathrm{h} 2}-\mathrm{W}$. Germany existing terraced house price index, per dwelling

$\mathrm{DE}^{\mathrm{h} 3}-\mathrm{W}$. Germany new terraced house price index, per dwelling

$D^{c}$ - Nationwide new and existing single-family house price index, per dwelling $\mathrm{DK}^{\mathrm{h}}$ - Nationwide new and existing single-family house price index, per dwelling

$E S^{c}$ - Nationwide average price of existing dwellings, per square meter

$\mathrm{ES}^{\mathrm{h}}{ }^{1}$ - Nationwide average price of new and existing dwellings, per square meter

$\mathrm{ES}^{\mathrm{h} 2}$ - Nationwide average mortgage loans

$\mathrm{FI}^{\mathrm{c}}$ - Nationwide existing single-family

house price index, per square meter

$\mathrm{FI}^{\mathrm{h}}$ - Nationwide existing apartment price index, per square meter

$\mathrm{FR}^{\mathrm{c}}$ - Nationwide existing detached house and apartment price index, per dwelling $\mathrm{FR}^{\mathrm{h}}$ - Nationwide existing apartment price index, per dwelling
Source and Time Coverage

Australia Bureau of Statistics

1986Q3-present

Australian Treasury

1960Q3-present

Statistics Belgium

1973Q1-present

Canadian Real Estate Association 2005Q1-present

University of British Columbia

1975Q1-2013Q1

Swiss National Bank

1970Q1-present

Federal Statistical Office (Destatis)

2000Q1-present

Deutsche Bundesbank 1995-present (annual)

Deutsche Bundesbank 1990-2014 (annual)

Deutsche Bundesbank

1975-present (annual)

Statistics Denmark 1992Q1-present

Danmarks Nationalbank

1971Q1-present

Ministerio de Fomento

1995Q1-present

Ministerio de la Vivienda

1987Q1-2004Q4

Instituto Nacional de Estadística

1962Q1-1987Q4

Statistics Finland

1985Q1-present

Statistics Finland

1970Q1-2009Q4

INSEE

1996Q1-present

CEGDD - Ministère de l’Écologie 1936-2009 (annual)

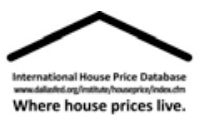


橉 GB - United Kingdom $\mathrm{GB}^{\mathrm{c}}$ - Nationwide new and existing dwelling price index, per dwelling

$\mathrm{GB}^{\mathrm{h} 1}$ - Nationwide new and existing dwelling price index, per dwelling

$\mathrm{HR}^{\mathrm{c}}$ - Nationwide existing dwelling price index, pure price

$\mathrm{HR}^{\mathrm{h} 1}$ - Nationwide new and existing dwelling price index, pure price

$\mathrm{HR}^{\mathrm{h} 2}$ - Nationwide average price of new dwellings, per square meter

$\mathrm{IE}^{\mathrm{c}}$ - Nationwide average price of existing dwellings, per dwelling

$\mathrm{IE}^{\mathrm{h} 1}$ - Nationwide average price of existing dwellings, per dwelling

$\mathrm{IE}^{\mathrm{h} 2}$ - Nationwide average price of existing dwellings, per dwelling

$\mathrm{IL}^{\mathrm{c}}$ - Nationwide new and existing dwelling price index, per dwelling $\mathrm{IL}^{\mathrm{h}}$ - Nationwide new and existing dwelling price index, per dwelling

IT $^{\mathrm{c}}$ - 13 main metropolitan area average price of new and existing dwellings, per square meter $\mathrm{IT}^{\mathrm{h}}$ - 13 main metropolitan area average price of new dwellings, per square meter

$\mathrm{JP}^{\mathrm{c}}$ - Nationwide new and existing detached house price index, pure price

$\mathrm{JP}^{\mathrm{h}}$ - Nationwide urban residential land price index, per square meter

$\mathrm{KR}^{\mathrm{c}}$ - Nationwide new and existing dwelling price index, per dwelling $\mathrm{KR}^{\mathrm{h}}$ - Kyung-Hwan Kim (1993) index:

- Nationwide quoted transactions and estimations of real estate agents

- Nationwide standard construction costs (excluding land)

- Nationwide weighted average of total factor costs single-family house and apartment construction
Land Registry, Land and Property Services Northern Ireland, Office for National Statistics, and Registers of Scotland 2005M1-present Office for National Statistics 1968Q2-2016Q1

Croatian Bureau of Statistics, Croatian National Bank 2007Q4-present

Croatian National Bank 1997Q1-2015Q2

Croatian Bureau of National Statistics 1965-2011 (annual)

Central Statistics Office 2005M1-present Department of Environment, Community \& Local Government 1978Q1-present

Department of Environment, Community \& Local Government 1974-2009 (annual)

Central Bureau of Statistics 1994Q1-present

Central Bureau of Statistics 1975Q1-2014Q1

Nomisma 1988S1-present Il Consulente Immobiliare 1967-2001 (bi-annual)

Ministry of Land, Infrastructure, Transport and Tourism 2008M4-present Japan Real Estate Institute 1955S1-present

Kookmin Bank 1986M1-present

Korea Housing Bank 1982-1990 (annual) Korea Housing Bank 1978-1981 (annual) Korea Housing Bank 1974-1977 (annual) 
LU - Luxembourg

NL - Netherlands

NO - Norway

NZ - New Zealand

$\uplus$ SE - Sweden

鹿昰 US - United States

ZA - S. Africa
LUc- Nationwide new and existing house price index, per dwelling

LU $^{\text {h }}$ - Nationwide new and existing dwelling price index, per dwelling

$\mathrm{NL}^{\mathrm{c}}$ - Nationwide existing single-family house price index, per dwelling $\mathrm{NL}^{\mathrm{h}}$ - Nationwide average price of existing dwellings, per dwelling

$\mathrm{NO}^{\mathrm{c}}$ - Nationwide new and existing detached house price index, per dwelling $\mathrm{NO}^{\mathrm{h}}$ - Norges Bank forecasting model index:

- Nationwide sales reports of Norges

Eindomsmeglerforbund real estate agents

- Dwelling price based on national property register

- Nationwide building cost index

- Housing rent component of the Consumer Price Index

$\mathrm{NZ}^{\mathrm{C}}$ - Nationwide new and existing detached house price index, per dwelling

$\mathrm{SE}^{\mathrm{c}}$ - Nationwide new and existing one- and two-family house price index, per dwelling $\mathrm{SE}^{\mathrm{h}}$ - Nationwide new and existing one- and two-family house price index, per dwelling

US $^{\mathrm{c}}$ - Nationwide existing single-family house price index, per dwelling

$Z^{c}$ - Nationwide new and existing house price index, per dwelling $\mathrm{ZA}^{\mathrm{h}}$ - Nationwide new and existing single-family house price index, per dwelling
L'Observatoire de l'Habitat 2005Q1-present Banque centrale du Luxembourg 1974-2009 (annual)

Statistics Netherlands 1995M1-present

Kadaster

1976M1-2010M12

Statistics Norway

1992Q1-present

Norges Eindomsmeglerforbund 1987Q1-2003Q4

GAB Register 1984Q1-1986Q4

Statistics Norway 1979Q1-1983Q4

Statistics Norway

1972Q1-1978Q4

Reserve Bank of New Zealand 1962Q2-present

Statistics Sweden

1986Q1-present

Statistics Sweden

1975-2010 (annual)

FHFA

1975Q1-present

FNB

2001M1-present

ABSA

1966M1-2016M11

Note: Time series backcasting is used to extend the house price index of the Netherlands from the first quarter of 1976 back to the first quarter of 1975. Time series nowcasting is used for Italy in order to complete the quarterly dataset and avoid long lags in its public release. Nowcasting are subsequently replaced with actual data from the national sources, as it becomes available. 
Appendix B. Table Summaries of House Price Data as Reported from National Sources

Table B.1 Frequency of House Price Data

\begin{tabular}{|c|c|c|c|c|c|c|}
\hline & Series & Monthly & Quarterly & Annual & Other & Adjustments \\
\hline \multirow[t]{2}{*}{ AU - Australia } & $\mathrm{AU}^{\mathrm{c}}$ & & $\checkmark$ & & & \\
\hline & $\mathrm{AU}^{\mathrm{h}}$ & & $\checkmark$ & & & \\
\hline Ш BE - Belgium & $\mathrm{BE}^{\mathrm{c}}$ & & $\checkmark$ & & & \\
\hline \multirow[t]{2}{*}{ CA - Canada } & $\mathrm{CA}^{\mathrm{c}}$ & $\checkmark$ & & & & Average \\
\hline & $\mathrm{CA}^{\mathrm{h}}$ & & $\checkmark$ & & & \\
\hline$+\mathrm{CH}$ - Switzerland & $\mathrm{CH}^{\mathrm{c}}$ & & $\checkmark$ & & & \\
\hline \multirow[t]{4}{*}{$\square \mathrm{DE}$ - Germany } & $\mathrm{DE}^{\mathrm{c}}$ & & $\checkmark$ & & & \\
\hline & $\mathrm{DE}^{\mathrm{h} 1}$ & & & $\checkmark$ & & Interpolate \\
\hline & $\mathrm{DE}^{\mathrm{h} 2}$ & & & $\checkmark$ & & Interpolate \\
\hline & $\mathrm{DE}^{\mathrm{h} 3}$ & & & $\checkmark$ & & Interpolate \\
\hline \multirow[t]{2}{*}{ \# DK - Denmark } & $\mathrm{DK}^{\mathrm{c}}$ & & $\checkmark$ & & & \\
\hline & $\mathrm{DK}^{\mathrm{h}}$ & & $\checkmark$ & & & \\
\hline \multirow[t]{3}{*}{$\square$ ES - Spain } & $\mathrm{ES}^{\mathrm{c}}$ & & $\checkmark$ & & & \\
\hline & $\mathrm{ES}^{\mathrm{h} 1}$ & & $\checkmark$ & & & \\
\hline & $\mathrm{ES}^{\mathrm{h} 2}$ & & $\checkmark$ & & & \\
\hline \multirow[t]{2}{*}{ 田 FI - Finland } & $\mathrm{FI}^{\mathrm{c}}$ & & $\checkmark$ & & & \\
\hline & $\mathrm{FI}^{\mathrm{h}}$ & & $\checkmark$ & & & \\
\hline \multirow[t]{2}{*}{ Ш FR - France } & $\mathrm{FR}^{\mathrm{c}}$ & & $\checkmark$ & & & \\
\hline & $\mathrm{FR}^{\mathrm{h}}$ & & & $\checkmark$ & & Interpolate \\
\hline
\end{tabular}

橉 GB - United Kingdom GB $^{\mathrm{c}}$

$$
\mathrm{GB}^{\mathrm{h} 1}
$$

EHR - Croatia

$\mathrm{HR}^{\mathrm{c}}$

$\mathrm{HR}^{\mathrm{h} 1}$ 


\begin{tabular}{|c|c|c|c|c|c|c|}
\hline & Series & Monthly & Quarterly & Annual & Other & Adjustments \\
\hline & $\mathrm{HR}^{\mathrm{h} 2}$ & & & $\checkmark$ & & Interpolate \\
\hline \multirow{3}{*}{$\square$ IE - Ireland } & $\mathrm{IE}^{\mathrm{c}}$ & $\checkmark$ & & & & \\
\hline & $\mathrm{IE}^{\mathrm{h} 1}$ & & $\checkmark$ & & & \\
\hline & $\mathrm{IE}^{\mathrm{h} 2}$ & & & $\checkmark$ & & Interpolate \\
\hline \multirow[t]{2}{*}{ IL - Israel } & $\mathrm{IL}^{\mathrm{c}}$ & $\checkmark$ & & & & Average \\
\hline & $\mathrm{IL}^{\mathrm{h}}$ & $\checkmark$ & & & & Average \\
\hline \multirow[t]{2}{*}{$\square$ IT - Italy } & $\mathrm{IT}^{\mathrm{c}}$ & & & & $\checkmark$ & Interpolate \\
\hline & $\mathrm{IT}^{\mathrm{h}}$ & & & & $\checkmark$ & Interpolate \\
\hline \multirow[t]{2}{*}{$\bullet$ JP - Japan } & $\mathrm{JP}^{\mathrm{c}}$ & $\checkmark$ & & & & Average \\
\hline & $\mathrm{JP}^{\mathrm{h}}$ & & & & $\checkmark$ & Interpolate \\
\hline \multirow[t]{2}{*}{ KR - S. Korea } & $\mathrm{KR}^{\mathrm{c}}$ & $\checkmark$ & & & & Average \\
\hline & $\mathrm{KR}^{\mathrm{h}}$ & & & $\checkmark$ & & Interpolate \\
\hline \multirow[t]{2}{*}{$\square$ LU - Luxembourg } & $\mathrm{LU}^{\mathrm{c}}$ & & $\checkmark$ & & & \\
\hline & $\mathrm{LU}^{\mathrm{h}}$ & & & $\checkmark$ & & Interpolate \\
\hline \multirow{2}{*}{ NL - Netherlands } & $\mathrm{NL}^{\mathrm{c}}$ & $\checkmark$ & & & & Average \\
\hline & $\mathrm{NL}^{\mathrm{h}}$ & $\checkmark$ & & & & Average \\
\hline \multirow[t]{2}{*}{ 䡒 NO - Norway } & $\mathrm{NO}^{\mathrm{c}}$ & & $\checkmark$ & & & \\
\hline & $\mathrm{NO}^{\mathrm{h}}$ & & $\checkmark$ & & & \\
\hline NZ - New Zealand & $\mathrm{NZ}^{\mathrm{c}}$ & & $\checkmark$ & & & \\
\hline \multirow[t]{2}{*}{ SE - Sweden } & $\mathrm{SE}^{\mathrm{c}}$ & & $\checkmark$ & & & \\
\hline & $S E^{h}$ & & $\checkmark$ & & & \\
\hline 鹿昰 US - United States & $\mathrm{US}^{\mathrm{c}}$ & & $\checkmark$ & & & \\
\hline \multirow[t]{2}{*}{ ZA - S. Africa } & $\mathrm{ZA}^{\mathrm{c}}$ & $\checkmark$ & & & & Average \\
\hline & $\mathrm{ZA}^{\mathrm{h}}$ & $\checkmark$ & & & & Average \\
\hline
\end{tabular}

Note: We interpolate the series indicated using the quadratic-match average method at quarterly frequency. IT ${ }^{\mathrm{c}}$ is semi-annual data, $\mathrm{IT}^{\mathrm{h}}$ is bi-annual data, and $\mathrm{JP}^{\mathrm{h}}$ is semi-annual data.

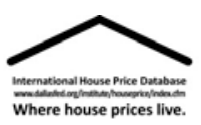




\begin{tabular}{|c|c|c|}
\hline 20 AU - Australia & $\begin{array}{l}A U^{\mathrm{c}} \\
\mathrm{A} U^{\mathrm{h}}\end{array}$ & $\begin{array}{l}\text { Index }(2003 / 2004=100) \text {, Australian Dollar } \\
\text { Index }(2004 Q 2-Q 3=100) \text {, Australian Dollar }\end{array}$ \\
\hline D BE - Belgium & $\mathrm{BE}^{\mathrm{c}}$ & Index (2005=100), Euro \\
\hline \# CA - Canada & $\begin{array}{l}\mathrm{CA}^{\mathrm{c}} \\
\mathrm{CA}^{\mathrm{h}}\end{array}$ & $\begin{array}{l}\text { Index ( } 2005 \text { Jan=100), Canadian Dollar } \\
\text { Average price, Canadian Dollar }\end{array}$ \\
\hline$+\mathrm{CH}$ - Switzerland & $\mathrm{CH}^{\mathrm{c}}$ & Index (1970Q1=100), Swiss Francs \\
\hline$\square$ DE - Germany & $\begin{array}{l}\mathrm{DE}^{\mathrm{c}} \\
\mathrm{DE}^{\mathrm{h} 1} \\
\mathrm{DE}^{\mathrm{h} 2} \\
\mathrm{DE}^{\mathrm{h} 3}\end{array}$ & $\begin{array}{l}\text { Index }(2010=100) \text {, Euro } \\
\text { Index }(2005=100) \text {, Euro } \\
\text { Index }(2005=100) \text {, Euro } \\
\text { Index }(2005=100) \text {, Euro }\end{array}$ \\
\hline Ð DK - Denmark & $\begin{array}{l}\mathrm{DK}^{\mathrm{c}} \\
\mathrm{DK}^{\mathrm{h}}\end{array}$ & $\begin{array}{l}\text { Index }(2006=100) \text {, Kroner } \\
\text { Index }(1980=100) \text {, Kroner }\end{array}$ \\
\hline$\square$ ES - Spain & $\begin{array}{l}\mathrm{ES}^{\mathrm{c}} \\
\mathrm{ES}^{\mathrm{h} 1} \\
\mathrm{ES}^{\mathrm{h} 2}\end{array}$ & $\begin{array}{l}\text { Average Price, Euro } \\
\text { Average Price, Euro } \\
\text { Average Price, Euro }\end{array}$ \\
\hline 田 FI - Finland & $\begin{array}{l}\mathrm{FI}^{\mathrm{c}} \\
\mathrm{FI}^{\mathrm{h}}\end{array}$ & $\begin{array}{l}\text { Index }(1985=100) \text {, Euro } \\
\text { Index }(1970=100) \text {, Euro }\end{array}$ \\
\hline Ш FR - France & $\begin{array}{l}\mathrm{FR}^{\mathrm{c}} \\
\mathrm{FR}^{\mathrm{h}}\end{array}$ & $\begin{array}{l}\text { Index }(2010 Q 1=100) \text {, Euro } \\
\text { Index }(2000=1) \text {, Euro }\end{array}$ \\
\hline 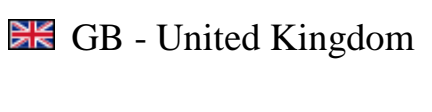 & $\begin{array}{l}\mathrm{GB}^{\mathrm{c}} \\
\mathrm{GB}^{\mathrm{h} 1}\end{array}$ & $\begin{array}{l}\text { Index (2015 Jan=100), Pound } \\
\text { Index (2002Q1=100), Pound }\end{array}$ \\
\hline EHR - Croatia & $\begin{array}{l}\mathrm{HR}^{\mathrm{c}} \\
\mathrm{HR}^{\mathrm{h} 1} \\
\mathrm{HR}^{\mathrm{h} 2}\end{array}$ & $\begin{array}{l}\text { Index }(2010=100) \\
\text { Index }(2010=100) \\
\text { Average Price, Kuna }\end{array}$ \\
\hline$\square$ IE - Ireland & $\begin{array}{l}\mathrm{IE}^{\mathrm{c}} \\
\mathrm{IE}^{\mathrm{h} 1} \\
\mathrm{IE}^{\mathrm{h} 2}\end{array}$ & $\begin{array}{l}\text { Index (2005M1=100), Euro } \\
\text { Average Price, Euro } \\
\text { Average Price, Euro }\end{array}$ \\
\hline IL - Israel & $\begin{array}{l}\mathrm{IL}^{\mathrm{c}} \\
\mathrm{IL} \mathrm{L}^{\mathrm{h}}\end{array}$ & $\begin{array}{l}\text { Index }(1993=100) \text {, Israeli New Shekel } \\
\text { Index }(2012=100) \text {, Israeli New Shekel }\end{array}$ \\
\hline Ш IT - Italy & $\begin{array}{l}\mathrm{IT}^{\mathrm{c}} \\
\mathrm{IT}^{\mathrm{h}}\end{array}$ & $\begin{array}{l}\text { Average Price, Euro } \\
\text { Average Price, Italian Lire }\end{array}$ \\
\hline$\bullet$ JP - Japan & $\begin{array}{l}J^{\mathrm{c}} \\
J^{\mathrm{h}}\end{array}$ & $\begin{array}{l}\text { Index }(2010=100) \text {, Yen } \\
\text { Index }(2000 S 1=100) \text {, Yen }\end{array}$ \\
\hline
\end{tabular}

Rebase to $2005=100$

Rebase to $2005=100$

Rebase to $2005=100$

Rebase to $2005=100$

Base to $2005=100$

Rebase to 2005 $=100$

Rebase to $2005=100$

Rebase to 2005 $=100$

Rebase to 2005 $=100$

Rebase to 2005 $=100$

Rebase to 2005 $=100$

Rebase to 2005 $=100$

Rebase to $2005=100$

Rebase to 2005 $=100$

Convert to Euros

Rebase to 2005 $=100$ 


\begin{tabular}{|c|c|c|c|}
\hline \multirow[t]{2}{*}{ KR - S. Korea } & $\mathrm{KR}^{\mathrm{c}}$ & Index (2011 Jun=100), Won & \multirow[t]{2}{*}{ Rebase to $2005=100$} \\
\hline & $\mathrm{KR}^{\mathrm{h}}$ & Index (1974=100), Won & \\
\hline \multirow[t]{2}{*}{$\square$ LU - Luxembourg } & $\mathrm{LU}^{\mathrm{c}}$ & Index (2005Q1=100), Euro & \multirow[t]{2}{*}{ Rebase to $2005=100$} \\
\hline & $\mathrm{LU}^{\mathrm{h}}$ & Index (1995=100), Euro & \\
\hline \multirow[t]{2}{*}{ NL - Netherlands } & $\mathrm{NL}^{\mathrm{c}}$ & Index (2005=100), Euro & \\
\hline & $\mathrm{NL}^{\mathrm{h}}$ & Average Price, Euro & \\
\hline \multirow[t]{2}{*}{ NO - Norway } & $\mathrm{NO}^{\mathrm{c}}$ & Index $(2005=100)$, Kroner & \\
\hline & $\mathrm{NO}^{\mathrm{h}}$ & Index $(2000=100)$, Kroner & \\
\hline NZ - New Zealand & $\mathrm{NZ}^{\mathrm{c}}$ & Index (2003Q4=100), New Zealand Dollar & Rebase to $2005=100$ \\
\hline \multirow[t]{2}{*}{ 四 SE - Sweden } & $\mathrm{SE}^{\mathrm{c}}$ & Index $(1981=100)$, Kronor & \multirow[t]{2}{*}{ Rebase to $2005=100$} \\
\hline & $\mathrm{SE}^{\mathrm{h}}$ & Index $(1981=100)$, Kronor & \\
\hline 瀶 US - United States & US $^{c}$ & Index $(1980 Q 1=100)$, United States Dollar & Rebase to $2005=100$ \\
\hline \multirow[t]{2}{*}{$\Xi$ ZA - S. Africa } & $\mathrm{ZA}^{\mathrm{c}}$ & Index (January 2001=100), Rand & Rebase to $2005=100$ \\
\hline & $\mathrm{ZA}^{\mathrm{h}}$ & Index $(2000=100)$, Rand & Rebase to $2005=100$ \\
\hline
\end{tabular}

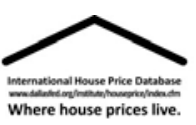




\section{Table B.3 Geographic Coverage of House Price Data}

\begin{tabular}{|c|c|c|c|c|}
\hline & Series & Nationwide & Other & Coverage \\
\hline \multirow[t]{2}{*}{ AU - Australia } & $\mathrm{AU}^{\mathrm{c}}$ & & $\checkmark$ & 8 capital cities \\
\hline & $A U^{h}$ & & $\checkmark$ & 6 capital cities \\
\hline$\square$ BE - Belgium & $\mathrm{BE}^{\mathrm{c}}$ & $\checkmark$ & & \\
\hline \multirow[t]{2}{*}{ \# CA - Canada } & $\mathrm{CA}^{\mathrm{c}}$ & & $\checkmark$ & 11 metropolitan areas \\
\hline & $\mathrm{CA}^{\mathrm{h}}$ & & $\checkmark$ & 10 metropolitan cities \\
\hline$+\mathrm{CH}$ - Switzerland & $\mathrm{CH}^{\mathrm{c}}$ & $\checkmark$ & & \\
\hline \multirow[t]{4}{*}{$\square$ DE - Germany } & $\mathrm{DE}^{\mathrm{c}}$ & $\checkmark$ & & \\
\hline & $\mathrm{DE}^{\mathrm{h} 1}$ & $\checkmark$ & & \\
\hline & $\mathrm{DE}^{\mathrm{h} 2}$ & & $\checkmark$ & West Germany \\
\hline & $\mathrm{DE}^{\mathrm{h} 3}$ & & $\checkmark$ & West Germany \\
\hline \multirow[t]{2}{*}{ Ð DK - Denmark } & $\mathrm{DK}^{\mathrm{c}}$ & $\checkmark$ & & \\
\hline & $\mathrm{DK}^{\mathrm{h}}$ & $\checkmark$ & & \\
\hline \multirow[t]{3}{*}{ ES - Spain } & $\mathrm{ES}^{\mathrm{c}}$ & $\checkmark$ & & \\
\hline & $\mathrm{ES}^{\mathrm{h} 1}$ & $\checkmark$ & & \\
\hline & $\mathrm{ES}^{\mathrm{h} 2}$ & $\checkmark$ & & \\
\hline \multirow[t]{2}{*}{ 四 FI - Finland } & $\mathrm{FI}^{\mathrm{c}}$ & $\checkmark$ & & \\
\hline & $\mathrm{FI}^{\mathrm{h}}$ & $\checkmark$ & & \\
\hline \multirow[t]{2}{*}{$\square$ FR - France } & $\mathrm{FR}^{\mathrm{c}}$ & $\checkmark$ & & \\
\hline & $\mathrm{FR}^{\mathrm{h}}$ & $\checkmark$ & & \\
\hline \multirow[t]{2}{*}{ 橉 GB - United Kingdom } & $\mathrm{GB}^{\mathrm{c}}$ & $\checkmark$ & & \\
\hline & $\mathrm{GB}^{\mathrm{h} 1}$ & $\checkmark$ & & \\
\hline \multirow[t]{3}{*}{ ENR - Croatia } & $\mathrm{HR}^{\mathrm{c}}$ & $\checkmark$ & & \\
\hline & $\mathrm{HR}^{\mathrm{h} 1}$ & $\checkmark$ & & \\
\hline & $\mathrm{HR}^{\mathrm{h} 2}$ & $\checkmark$ & & \\
\hline
\end{tabular}



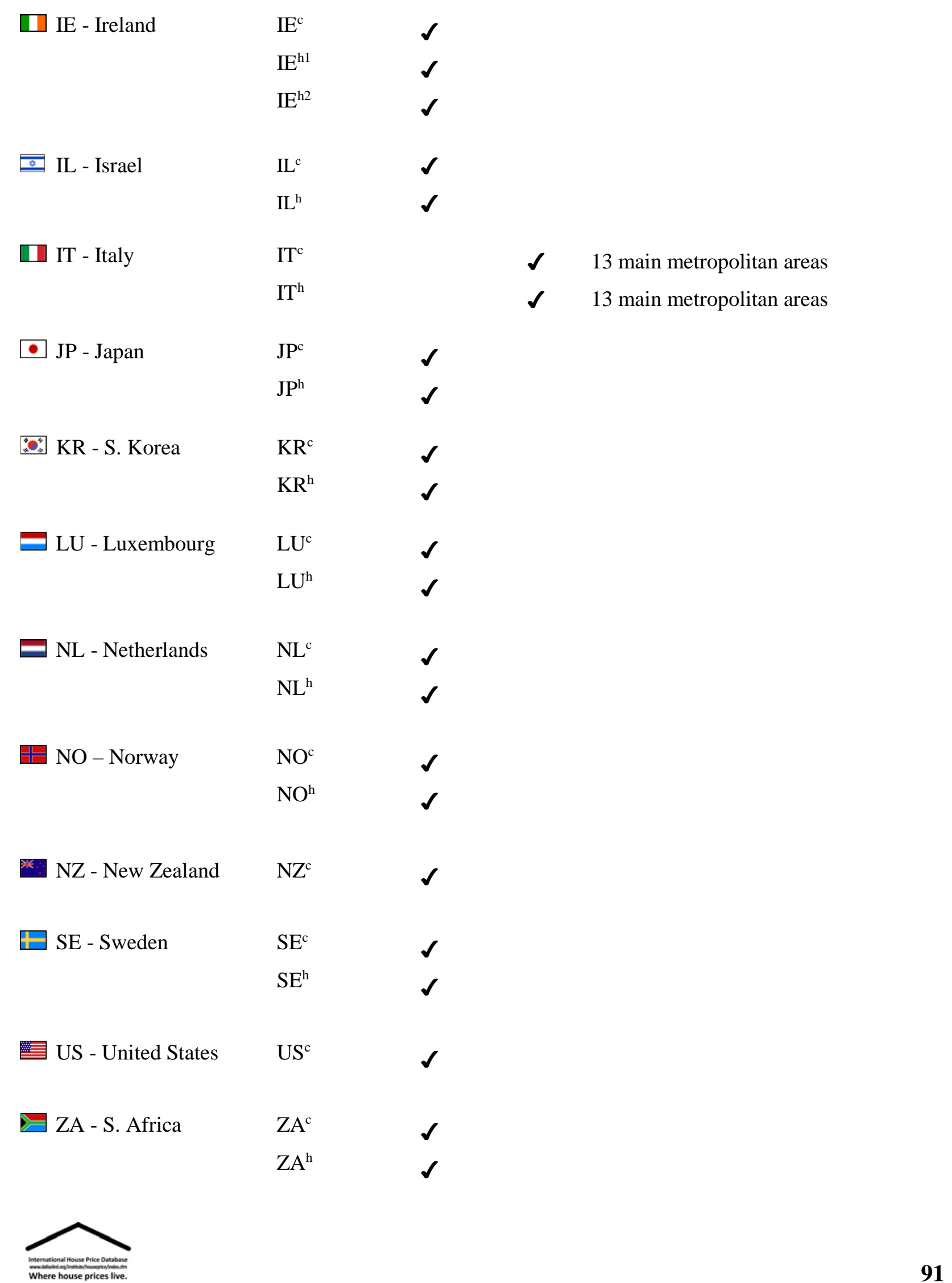


\section{Table B.4 Property Type Included in House Price Data}

Series Single-Family All Dwellings Other

AU - Australia

$\mathrm{AU}^{\mathrm{c}}$

$A U^{h}$

$\checkmark$

AU

$\mathrm{BE}^{\mathrm{c}}$

$\checkmark$

— CA - Canada

$\mathrm{CA}^{\mathrm{c}}$

$\mathrm{CA}^{\mathrm{h}}$

$\checkmark$

$+\mathrm{CH}$ - Switzerland

$\mathrm{CH}^{\mathrm{c}}$

$\checkmark$

$\square$ DE - Germany

$\mathrm{DE}^{\mathrm{c}}$

$\mathrm{DE}^{\mathrm{h} 1}$

$\mathrm{DE}^{\mathrm{h} 2}$

$\mathrm{DE}^{\mathrm{h} 3}$

$\checkmark$

Ш BE - Belgium

(

由 DK - Denmark

$\mathrm{DK}^{\mathrm{c}}$

$\mathrm{DK}^{\mathrm{h}}$

$\checkmark$

DKe

$\checkmark$

$\square$ ES - Spain

$\mathrm{ES}^{\mathrm{c}}$

$\mathrm{ES}^{\mathrm{h} 1}$

ES $^{\text {h2 }}$

$\checkmark$

$\checkmark$

$\checkmark$

FI - Finland

$\mathrm{FI}^{\mathrm{c}}$

$\mathrm{FI}^{\mathrm{h}}$

2
2
2

Ш FR - France

$\mathrm{FR}^{\mathrm{c}}$

$\mathrm{FR}^{\mathrm{h}}$

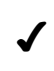

橉 GB - United Kingdom $\mathrm{GB}^{\mathrm{c}}$

$\mathrm{GB}^{\mathrm{h} 1}$

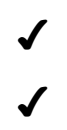

Ex HR - Croatia

$\mathrm{HR}^{\mathrm{c}}$

$\mathrm{HR}^{\mathrm{h}} 1$

$\mathrm{HR}^{\mathrm{h} 2}$

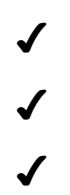


$\square$ IE - Ireland

$\mathrm{IE}^{\mathrm{c}}$
$\mathrm{IE}^{\mathrm{h} 1}$
$\mathrm{IE}^{\mathrm{h} 2}$

$\checkmark$

$\mathrm{E}^{\mathrm{h}}$

$\checkmark$

$\mathrm{E}^{\mathrm{h} 2}$

$\checkmark$

$\$$ IL - Israel

$\mathrm{IL}^{\mathrm{c}}$

$\mathrm{IL}^{\mathrm{h}}$

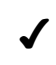

$\checkmark$

Ш IT - Italy

IT $^{\mathrm{c}}$

$\mathrm{IT}^{\mathrm{h}}$

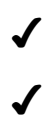

$\bullet$ JP - Japan

$\mathrm{JP}^{\mathrm{c}}$

$\mathrm{JP}^{\mathrm{h}}$

\section{$\checkmark$}

$\mathrm{KR}^{\mathrm{c}}$

$\mathrm{KR}^{\mathrm{h}}$

ㄴU - Luxembourg
$\mathrm{LU}^{\mathrm{c}}$
$L U^{\mathrm{h}}$

NL - Netherlands

$\mathrm{NL}^{\mathrm{c}}$

$\mathrm{NL}^{\mathrm{h}}$

$\checkmark$

NO - Norway

$\mathrm{NO}^{\mathrm{c}}$

$\mathrm{NO}^{\mathrm{h}}$

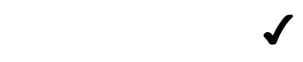

KR - S. Korea

$\mathrm{NZ}^{\mathrm{c}}$

$\boxplus$ SE - Sweden

$\mathrm{SE}^{\mathrm{c}}$

$\mathrm{SE}^{\mathrm{h}}$

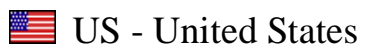

US $^{\mathrm{c}}$

$\exists$ ZA - S. Africa

$\mathrm{ZA}^{\mathrm{c}}$

$\mathrm{ZA}^{\mathrm{h}}$

Note: $\mathrm{FI}^{\mathrm{h}}$ measures old blocks of flats. $\mathrm{FI}^{\mathrm{h}}$ measures apartments. $\mathrm{JP}^{\mathrm{h}}$ measures residential urban land. The type of dwellings $\mathrm{KR}^{\mathrm{h}}$ and $\mathrm{ZA}^{\mathrm{c}}$ measure cannot be determined. $\mathrm{SE}^{\mathrm{c}}$ and $\mathrm{SE}^{\mathrm{h}}$ measure one and two-family dwellings. $\mathrm{DE}^{\mathrm{c}}$ measures single-family and two-family houses and existing dwellings in apartment blocks, including the land.

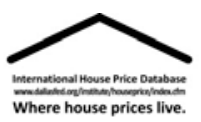


Table B.5 Property Vintage of House Price Data

Series Existing New New \& Existing Other

AU - Australia

$\mathrm{AU}^{\mathrm{c}}$

$A U^{\mathrm{h}}$

$\checkmark$

$\square$ BE - Belgium

$\mathrm{BE}^{\mathrm{c}}$

$\checkmark$

4 CA - Canada

$\mathrm{CA}^{\mathrm{c}}$

$\mathrm{CA}^{\mathrm{h}}$

$\checkmark$

$+\mathrm{CH}$ - Switzerland

$\mathrm{CH}^{\mathrm{c}}$

$\square$ DE - Germany

$\begin{array}{ll}\mathrm{DE}^{\mathrm{c}} & \checkmark \\ \mathrm{DE}^{\mathrm{h} 1} & \checkmark \\ \mathrm{DE}^{\mathrm{h} 2} & \checkmark \\ \mathrm{DE}^{\mathrm{h} 3} & \end{array}$

\# DK - Denmark

$\mathrm{DK}^{\mathrm{c}}$

$\mathrm{DK}^{\mathrm{h}}$

$\checkmark$

$\square$ ES - Spain

$$
\begin{aligned}
& \mathrm{ES}^{\mathrm{c}} \\
& \mathrm{ES}^{\mathrm{h} 1} \\
& \mathrm{ES}^{\mathrm{h} 2}
\end{aligned}
$$

$\checkmark$

田 FI - Finland

$\mathrm{FI}^{\mathrm{c}}$

$\mathrm{FI}^{\mathrm{h}}$

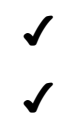

WR - France

$\begin{array}{ll}\mathrm{FR}^{\mathrm{c}} & \checkmark \\ \mathrm{FR}^{\mathrm{h}} & \checkmark\end{array}$

GB - United Kingdom $\mathrm{GB}^{\mathrm{c}}$

$\mathrm{GB}^{\mathrm{h} 1}$

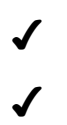

EHR - Croatia

$$
\begin{aligned}
& \mathrm{HR}^{\mathrm{c}} \\
& \mathrm{HR}^{\mathrm{h} 1} \\
& \mathrm{HR}^{\mathrm{h} 2}
\end{aligned}
$$




\section{Series Existing New New \& Existing Other}

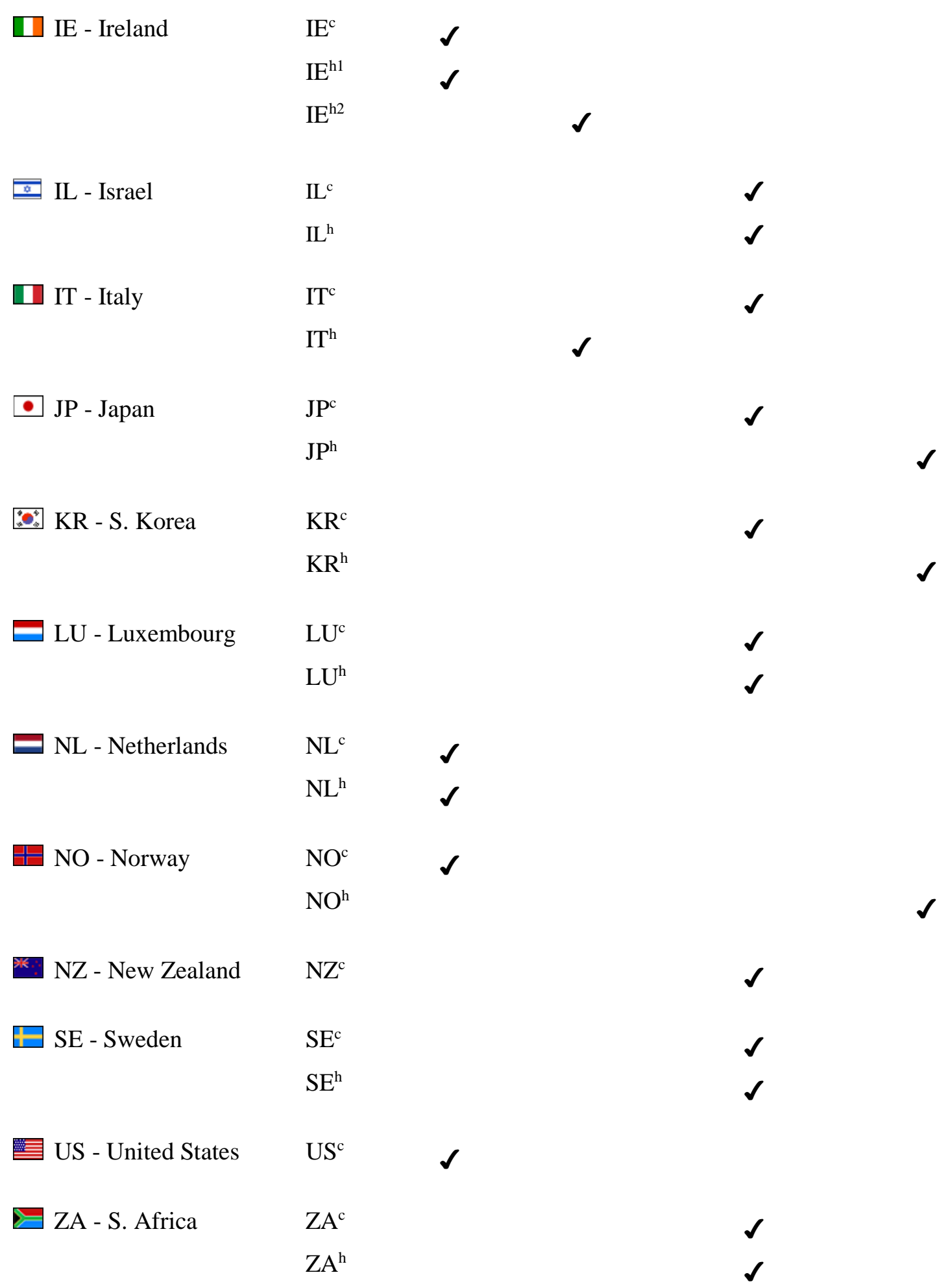

Note: $\mathrm{JP}^{\mathrm{h}}$ measures surveyed sites according to actual land use. $\mathrm{KR}^{\mathrm{h}}$ vintage cannot be determined from the source. $\mathrm{NO}^{\mathrm{h}}$ vintage cannot be determined from the source.

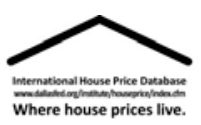




\section{Table B.6 Priced Units of House Price Data}

\begin{tabular}{|c|c|c|c|c|}
\hline & Series & Per Dwelling & Per Square Meter & Other \\
\hline \multirow[t]{2}{*}{ AU - Australia } & $\mathrm{AU}^{\mathrm{c}}$ & $\checkmark$ & & \\
\hline & $A U^{h}$ & $\checkmark$ & & \\
\hline$\square$ BE - Belgium & $\mathrm{BE}^{\mathrm{c}}$ & $\checkmark$ & & \\
\hline \multirow[t]{2}{*}{$\oplus$ CA - Canada } & $\mathrm{CA}^{\mathrm{c}}$ & $\checkmark$ & & \\
\hline & $\mathrm{CA}^{\mathrm{h}}$ & $\checkmark$ & & \\
\hline$+\mathrm{CH}$ - Switzerland & $\mathrm{CH}^{\mathrm{c}}$ & $\checkmark$ & & \\
\hline \multirow[t]{4}{*}{$\square$ DE - Germany } & $\mathrm{DE}^{\mathrm{c}}$ & & & $\checkmark$ \\
\hline & $\mathrm{DE}^{\mathrm{h} 1}$ & $\checkmark$ & & \\
\hline & $\mathrm{DE}^{\mathrm{h} 2}$ & $\checkmark$ & & \\
\hline & $\mathrm{DE}^{\mathrm{h} 3}$ & $\checkmark$ & & \\
\hline \multirow[t]{2}{*}{ \# DK - Denmark } & $\mathrm{DK}^{\mathrm{c}}$ & $\checkmark$ & & \\
\hline & $\mathrm{DK}^{\mathrm{h}}$ & $\checkmark$ & & \\
\hline \multirow[t]{3}{*}{ ES - Spain } & $\mathrm{ES}^{\mathrm{c}}$ & & $\checkmark$ & \\
\hline & $\mathrm{ES}^{\mathrm{h} 1}$ & & $\checkmark$ & \\
\hline & $\mathrm{ES}^{\mathrm{h} 2}$ & $\checkmark$ & & \\
\hline \multirow[t]{2}{*}{ 田 FI - Finland } & $\mathrm{FI}^{\mathrm{c}}$ & & $\checkmark$ & \\
\hline & $\mathrm{FI}^{\mathrm{h}}$ & & $\checkmark$ & \\
\hline \multirow[t]{2}{*}{$\square$ FR - France } & $\mathrm{FR}^{\mathrm{c}}$ & $\checkmark$ & & \\
\hline & $\mathrm{FR}^{\mathrm{h}}$ & $\checkmark$ & & \\
\hline \multirow[t]{2}{*}{ 橉 GB - United Kingdom } & $\mathrm{GB}^{\mathrm{c}}$ & $\checkmark$ & & \\
\hline & $\mathrm{GB}^{\mathrm{h} 1}$ & $\checkmark$ & & \\
\hline \multirow[t]{3}{*}{$\mathrm{E}$ HR - Croatia } & $\mathrm{HR}^{\mathrm{c}}$ & & & $\checkmark$ \\
\hline & $\mathrm{HR}^{\mathrm{h} 1}$ & & & $\checkmark$ \\
\hline & $\mathrm{HR}^{\mathrm{h} 2}$ & & $\checkmark$ & \\
\hline
\end{tabular}




\section{Series Per Dwelling Per Square Meter Other}

\begin{tabular}{|c|c|c|c|c|}
\hline \multirow{3}{*}{$\square$ IE - Ireland } & $\mathrm{IE}^{\mathrm{c}}$ & $\checkmark$ & & \\
\hline & $\mathrm{IE}^{\mathrm{h} 1}$ & $\checkmark$ & & \\
\hline & $\mathrm{IE}^{\mathrm{h} 2}$ & $\checkmark$ & & \\
\hline \multirow[t]{2}{*}{ IL - Israel } & $\mathrm{IL}^{\mathrm{c}}$ & $\checkmark$ & & \\
\hline & $\mathrm{IL}^{\mathrm{h}}$ & $\checkmark$ & & \\
\hline \multirow[t]{2}{*}{ ШT - Italy } & $\mathrm{IT}^{\mathrm{c}}$ & & $\checkmark$ & \\
\hline & $\mathrm{IT}^{\mathrm{h}}$ & & $\checkmark$ & \\
\hline \multirow{2}{*}{$\bullet$ JP - Japan } & $J^{\mathrm{c}}$ & & & $\checkmark$ \\
\hline & $\mathrm{JP}^{\mathrm{h}}$ & & & $\boldsymbol{J}$ \\
\hline \multirow[t]{2}{*}{ KR - S. Korea } & $\mathrm{KR}^{\mathrm{c}}$ & $\checkmark$ & & \\
\hline & $\mathrm{KR}^{\mathrm{h}}$ & & & $\checkmark$ \\
\hline \multirow[t]{2}{*}{ LU - Luxembourg } & $\mathrm{LU}^{\mathrm{c}}$ & $\checkmark$ & & \\
\hline & $\mathrm{LU}^{\mathrm{h}}$ & $\checkmark$ & & \\
\hline \multirow[t]{2}{*}{ NL - Netherlands } & $\mathrm{NL}^{\mathrm{c}}$ & $\checkmark$ & & \\
\hline & $\mathrm{NL}^{\mathrm{h}}$ & $\checkmark$ & & \\
\hline \multirow[t]{2}{*}{ NO - Norway } & $\mathrm{NO}^{\mathrm{c}}$ & $\checkmark$ & & \\
\hline & $\mathrm{NO}^{\mathrm{h}}$ & & & $\checkmark$ \\
\hline NZ - New Zealand & $\mathrm{NZ}^{\mathrm{c}}$ & $\checkmark$ & & \\
\hline \multirow[t]{2}{*}{ E SE - Sweden } & $\mathrm{SE}^{\mathrm{c}}$ & $\checkmark$ & & \\
\hline & $\mathrm{SE}^{\mathrm{h}}$ & $\checkmark$ & & \\
\hline 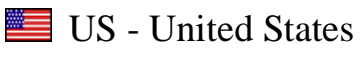 & $\mathrm{US}^{\mathrm{c}}$ & $\checkmark$ & & \\
\hline \multirow[t]{2}{*}{$\Xi$ ZA - S. Africa } & $\mathrm{ZA}^{\mathrm{c}}$ & $\checkmark$ & & \\
\hline & $\mathrm{ZA}^{\mathrm{h}}$ & $\checkmark$ & & \\
\hline
\end{tabular}

Note: JP ${ }^{\mathrm{c}}$ priced unit is pure price calculated with the hedonic method. $\mathrm{JP}^{\mathrm{h}}$ priced unit is per square meter of residential land. $\mathrm{KR}^{\mathrm{h}}$ priced unit cannot be determined from the source. $\mathrm{HR}^{\mathrm{c}}$ and $\mathrm{HR}^{\mathrm{h} 1}$ priced unit is pure price calculated with the hedonic method. $\mathrm{NO}^{\mathrm{h}}$ priced unit cannot be determined from the source. $\mathrm{DE}^{\mathrm{c}}$ priced unit is pure price calculated with the hedonic method.

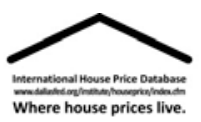


Table B.7 Index Methodology of House Price Data

AU - Australia

$\mathrm{AU}^{\mathrm{c}}$

$\mathrm{AU}^{\mathrm{h}}$

$\checkmark$

Ш BE - Belgium

$\mathrm{BE}^{\mathrm{c}}$

- CA - Canada

$\mathrm{CA}^{\mathrm{c}}$
$\mathrm{CA}^{\mathrm{h}}$

$\checkmark$

$+\mathrm{CH}$ - Switzerland

$\mathrm{CH}^{\mathrm{c}}$

$\checkmark$

$\square$ DE - Germany

$\mathrm{DE}^{\mathrm{c}}$

$\mathrm{DE}^{\mathrm{h} 1}$

$\mathrm{DE}^{\mathrm{h} 2}$

$\mathrm{DE}^{\mathrm{h} 3}$

$\checkmark$

† DK - Denmark

$\mathrm{DK}^{\mathrm{c}}$

$\mathrm{DK}^{\mathrm{h}}$

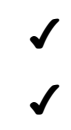

ES - Spain

$\mathrm{ES}^{\mathrm{c}}$

$\mathrm{ES}^{\mathrm{h} 1}$

$\mathrm{ES}^{\mathrm{h} 2}$

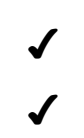

田 FI - Finland

$\mathrm{FI}^{\mathrm{C}}$

$\mathrm{FI}^{\mathrm{h}}$

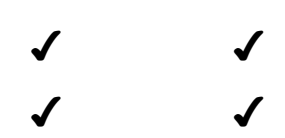

$\square$ FR - France

$\mathrm{FR}^{\mathrm{c}}$

$\checkmark$

$\checkmark$

$\mathrm{FR}^{\mathrm{h}}$

$\checkmark$

橉 GB - United Kingdom GB $^{\mathrm{c}}$

$\mathrm{GB}^{\mathrm{h} 1}$

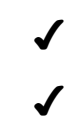

$\checkmark$

E HR - Croatia

$\mathrm{HR}^{\mathrm{c}}$

$\mathrm{HR}^{\mathrm{h} 1}$

$\mathrm{HR}^{\mathrm{h} 2}$

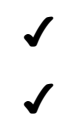




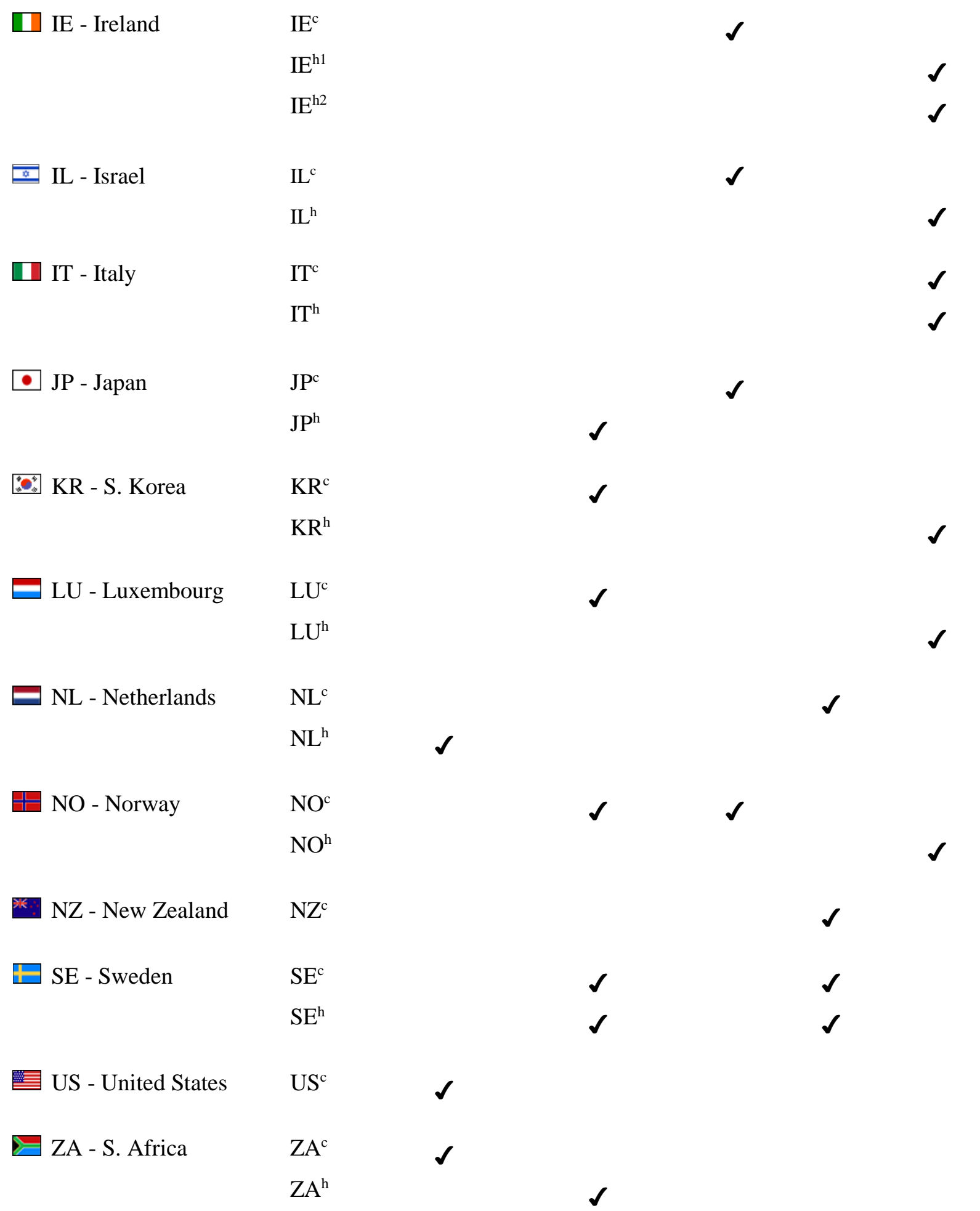

Note: $\mathrm{AU}^{\mathrm{h}}$ is constructed using a weighted average of median prices. $\mathrm{CA}^{\mathrm{h}}$ is constructed using a weighted average of average prices. $\mathrm{IE}^{\mathrm{h} 1}$ and $\mathrm{IE}^{\mathrm{h} 2}$ are constructed using unweighted average prices. $\mathrm{IT}^{\mathrm{c}}$ is constructed using weighted average prices. $\mathrm{IT}^{\mathrm{h}}$ is reported as disaggregated average prices, which we aggregate using a weighted average. $\mathrm{KR}^{\mathrm{h}}$ is undetermined. $\mathrm{LU}^{\mathrm{h}}$ is constructed using weighted average prices. $\mathrm{NO}^{\mathrm{h}}$ is undetermined.

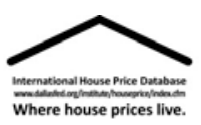

